\title{
Ciclos climáticos e causas naturais das mudanças do clima
}

\author{
Climate Cycles and Natural Causes of Climate Change
}

Marcos José de Oliveira ${ }^{1}$, Celso Dal Ré Carneiro², Francisco Arthur Silva Vecchia ${ }^{3}$, Gustavo Macedo de Mello Baptista4

1-Doutorando em Progr. Pós-Grad. Ciências da Eng. Ambiental, Escola de Engenharia de São Carlos, Universidade de São Paulo, EESC/USP -

marcos.jose@gmail.com

2-Instituto de Geociências, Universidade Estadual de Campinas, IG/Unicamp - cedrec@ige.unicamp.br

3-Escola de Engenharia de São Carlos, Universidade de São Paulo, EESC/USP - fvecchia@sc.usp.br

4-Instituto de Geociências, Universidade de Brasília, IG/UnB - gmbaptista@unb.br

ABSTRACT: The periodic nature of climate changes on the Earth can be explained in terms of a limited number of terrestrial and astronomical factors. In annual/daily scales, the climate varies according to the Earth's revolution and rotation. Medium term climate cycles (decades/centuries/millennia) are related to changes in solar radiation caused by the influences of major planets of the Solar System. Oceanic oscillations (decadal order) are possibly caused by the planetary and lunar influences. Long term climate cycles (tens and hundreds of thousand years) are caused by variations in the parameters of Earth's orbit (eccentricity, obliquity and precession). Impact events of large bodies on the planet and mass extinction arise from supercycles (tens of millions of years) caused by the vertical oscillation of the solar system relative to the galactic plane. Tectonics, volcanism and the evolution of supercontinents exhibit supercycles (hundreds of million years) induced by the Solar System movement around the Milky Way center and by the cosmic rays variation. Astronomical factors permeate virtually all the climate cycles orders, acting directly or indirectly in many bio-geo-oceanic-atmospheric processes. It is concluded that the Earth's climate is characterized by cycles astronomically controlled by the Moon, the Sun, the planets, the Solar System and even the Galaxy.

\section{Manuscrito:}

Recebido: 25/02/2014

Corrigido: 16/03/2016

Aceito: 26/05/2017

Citation: Oliveira M.J., Carneiro C.D.R., Vecchia F.A.S., Baptista G.M.M. 2017. Ciclos climáticos e causas naturais das mudanças do clima. Terræ Didatica, 13(3):149-184. <http://www. ige.unicamp.br/terraedidatica/ $>$.

Keywords: Climate change, climate, Climatology, Geology, natural processes, carbon dioxide, anthropogenic global warming.

\section{Introdução}

\begin{abstract}
A presente histeria sobre aquecimento global-com a previsão apocalíptica de fusão das calotas de gelo polar, inundação de cidades costeiras e desertificação de zonas produtoras de alimentos - não ajuda os cidadãos a compreender as forças reais e complexas que moldam o clima da Terra (Hecht 1993-1994).
\end{abstract}

Tentar entender o clima tem sido prática de sobrevivência desde os primórdios da humanidade. Inegavelmente, compreender o momento ideal do plantio e da colheita fez parte das técnicas da agricultura primitiva que permitiram ao homem a transição do nomadismo para o sedentarismo. Assim, a partir da constatação da óbvia alternância entre o dia e a noite, da observação das fases da Lua, da dedução das estações do ano, foi-se descobrindo a estreita relação entre esses fenômenos (cíclicos e de origem astronômica) com as alterações do clima na Terra (também de caráter periódico). Tais fenômenos naturais tornaram-se também a base de calendários e de unidades de medição do tempo cronológico.
A limitada capacidade de observação humana de enxergar outros diversos ciclos da natureza foi amplificada por meio de técnicas e instrumentos somente com o advento da Ciência Moderna, no século 17. Nesse período relativamente recente de toda a história da civilização, importantes descobertas $^{1}$ foram feitas no campo científico, sendo a primeira delas, com viés climático, realizada em 1843 , sobre a periodicidade de 11 anos das manchas solares. Em homenagem ao descobridor - o astrônomo amador Samuel Heinrich Schwabe [1789-1875] - o fenômeno é hoje denominado de ciclos de Schwabe.

Em 1909, os geógrafos e geólogos Albrecht Penck [1858-1945] e Eduard Brückner [18621927] apresentaram evidências sobre os ciclos das eras glaciais e interglaciais. A elucidação do motivo das glaciações foi apresentada em 1930 pelo engenheiro e matemático Milutin Milankovitch [1879-1958], que provou, matematicamente, que

\footnotetext{
1 Em artigo abordando métodos e origens do estudo dos ciclos climáticos na Terra, Oliveira et al. (2015) resgatam a história de renomados cientistas (Hutton, Agassiz, Penck, Brückner, Milankovitch e Schwabe) que, ao final do século 18 , foram pioneiros em elucidar e criar as bases para a compreensão da natureza periódica do clima.
} 
a quantidade de radiação solar recebida pela Terra variava conforme ciclos orbitais terrestres. Definitivamente reconhecida somente em 1976 como um modelo científico, a teoria orbital como causa das alternâncias entre as eras glaciais e interglaciais é hoje conhecida como ciclos de Milankovitch, os quais, juntamente com os ciclos de Schwabe, evidenciam a influência do Sol no clima da Terra.

Desde então, novos padrões de variações do clima têm sido identificados, como, por exemplo, o El Niño - Oscilação Sul (ENOS), o mais conhecido das várias oscilações decadais do sistema oceânico-atmosférico. Com a disponibilização de séries longas e detalhadas das mudanças paleoclimáticas nas últimas três décadas, novos ciclos climáticos têm sido pesquisados e identificados.

Portanto, é fundamental ampliar a noção dos ciclos climáticos para além dos ciclos diários e anuais. Com esse intento, este artigo difunde resultados de descobertas recentes sobre diversos ciclos climáticos ainda pouco conhecidos. Com base em extensa revisão bibliográfica, contempla-se a explicação dos principais ciclos climáticos: ciclos solares, ciclos das eras glaciais, ciclos de queda de asteroides e cometas, ciclos oceânico-atmosféricos e ciclos bio-geo-oceânico-atmosféricos relacionados ao tectonismo, vulcanismo, raios cósmicos e formação de supercontinentes.

\section{Ciclos Climáticos e Fenômenos Correlatos}

As mudanças climáticas podem ser causadas por fatores naturais ou antrópicos que modificam os componentes do balanço de radiação terrestre. A radiação solar representa o principal fator natural no balanço de radiação terrestre e, consequentemente, consiste em uma contribuição significativa nas mudanças do clima. A quantidade de radiação recebida e reemitida pela Terra depende basicamente de três fatores, os quais seguem ordenados conforme o caminho percorrido pela radiação - desde o corpo emissor (Sol) até corpo receptor (Terra):

1. Emissão da radiação: fator primário determinado por variações solares, como os ciclos solares de Schwabe e outros.

2. Recepção da radiação: fator secundário determinado por variações da posição terrestre em relação ao Sol, conforme observado nos ciclos diários, ciclos anuais e ciclos de Milankovitch.

3. Reflexão, absorção, distribuição do calor e reemissão da radiação: fator terciário determinado por alterações da composição atmosférica (gases de efeito estufa e nuvens), do modelado da superfície terrestre (uso dos solos) e dos oceanos (circulação oceânica).
As causas naturais das mudanças climáticas atuam nesses três grandes fatores. As causas humanas, não atuando nas duas primeiras categorias astronômicas, podem interferir somente no fator terrestre de terceira ordem, alterando as concentrações de gases e partículas na atmosfera e o uso e ocupação dos solos. As causas de mudanças climáticas podem ser classificadas em duas grandes categorias: 1. Causas externas são referentes aos agentes modificadores exteriores ao sistema climático que influenciam nos três fatores acima descritos; 2. Causas internas compreendem os agentes que influenciam no fator terciário, com mudanças nas características da atmosfera, da superfície terrestre e da circulação dos oceanos. A humanidade somente pode interferir nas causas internas.

\subsection{Variações das Emissões Solares}

Como o Sol essencialmente fornece toda a energia que impulsiona sistema climático da Terra, é óbvio que as variações solares têm o potencial de diretamente alterar o clima. As variações solares referem-se às mudanças na quantidade de radiação total emitida pelo Sol e na sua distribuição espectral. A partir do Sol, a Terra recebe continuamente no topo de sua atmosfera um fluxo de energia eletromagnética cujo valor, na média ${ }^{2}$, é de aproximadamente $1.365 \mathrm{~W} \cdot \mathrm{m}^{-2}$ ( ou $\left.81,66 \mathrm{~kJ} \cdot \mathrm{m}^{-2} \cdot \mathrm{min}^{-1}\right)$. Anteriormente à existência de satélites de alta precisão, a radiação solar emitida era considerada constante por muitos cientistas. Tal fato é refletido no termo constante solar. Devido às interferências atmosféricas, fracassaram todas tentativas de detectar, em solo, as variações na constante solar. Foi então que, com o uso de satélites fora da atmosfera, o monitoramento da radiação solar permitiu identificar pequenas variações (Beer et al. 2000, Reboita et al. 2015).

\subsubsection{Ciclos Solares de Schwabe}

A radiação solar medida pelos satélites durante as décadas recentes indica que as variações da emissões do Sol oscilam de forma periódica,

2 Devido à variação da distância entre a Terra e o Sol, a irradiância solar no topo da atmosfera varia cerca de 6,9\% durante 0 ano. Quando a Terra e 0 Sol estão mais próximos (periélio) ou mais distantes (afélio), a constante solar é, respectivamente, de $1.412 \mathrm{~W}^{-2}$ no início de janeiro e $1.321 \mathrm{~W} \cdot \mathrm{m}^{-2}$ no início de julho. Em qualquer dado momento, a quantidade de radiação solar recebida em uma localização na superfície terrestre depende do estado da atmosfera (presença/ausểncia de nuvens), da latitude do local, do horário e do dia do ano (Paulescu et al. 2013). 
fenômeno conhecido como o ciclo solar ou ciclo solar de Schwabe ${ }^{3}$. Cada ciclo solar, que dura aproximadamente 11 anos, é caracterizado por uma variação no surgimento e desaparecimento de manchas solares: os períodos de atividades solares elevadas são conhecidos por máxima solar (maior quantidade de manchas solares), e os períodos de atividades reduzidas são denominados de mínimo solar (menor quantidade de manchas solares). Essa oscilação causou, nos dois últimos ciclos, uma variação de $0,1 \%$ (cerca de 1,3 $\mathrm{W} \cdot \mathrm{m}^{-2}$ ) na amplitude da radiação solar emitida. A Fig. 1 exibe os ciclos denominados ${ }^{4}$ como os ciclos de números 21, 22 e 23 e, na Fig. 2, imagens do Sol ilustram as manchas solares e as fáculas ${ }^{5}$.

Uma vez que inexistem dados de observações diretas para estudar a variabilidade da radiação solar em escalas de tempo maiores do que décadas, estimativas são realizadas com base em correlações comparativas a medições em testemunhos ${ }^{6}$.

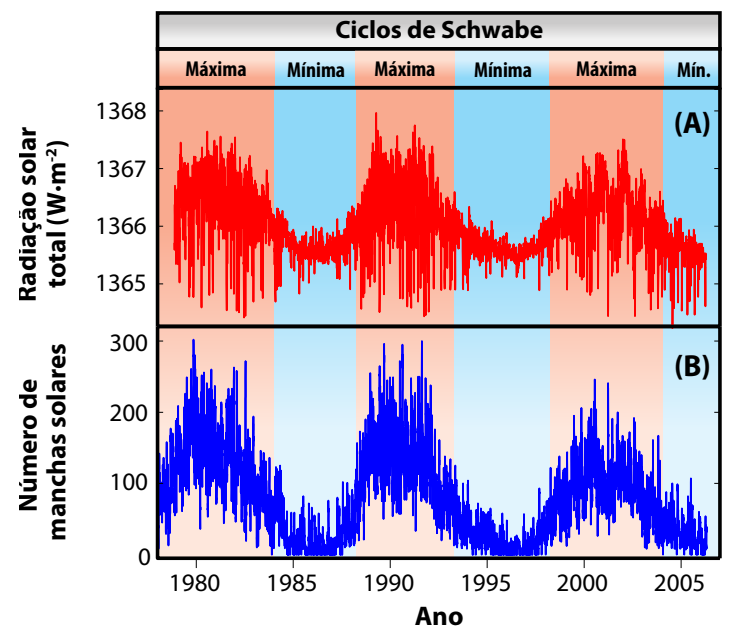

Figura 1. Ciclos de Schwabe - alternância entre períodos de máximas e mínimas solares, conforme exibem as variações (desde 1978) da: (A) radiação solar total e (B) do número de manchas solares. Fonte: modificado de Schöll et al. (2007).
(A)

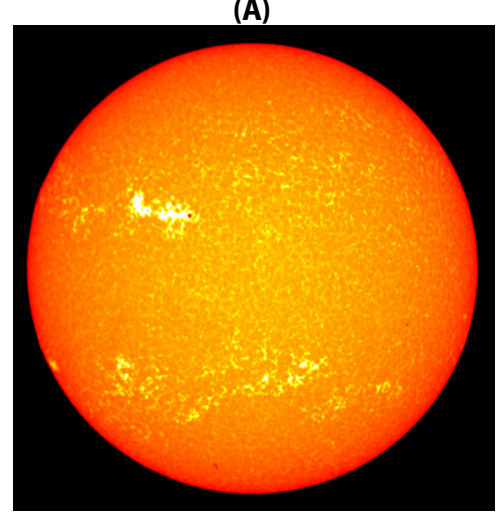

(B)

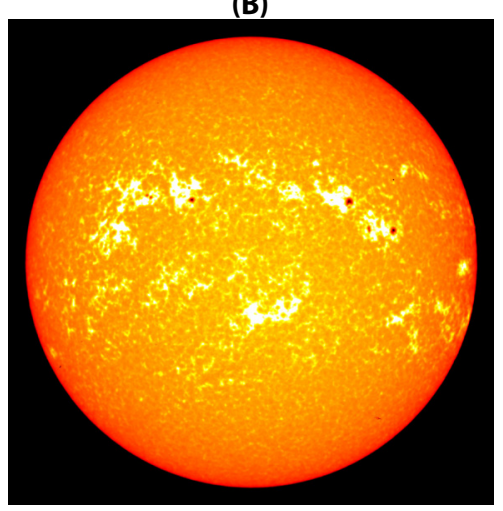

(C)

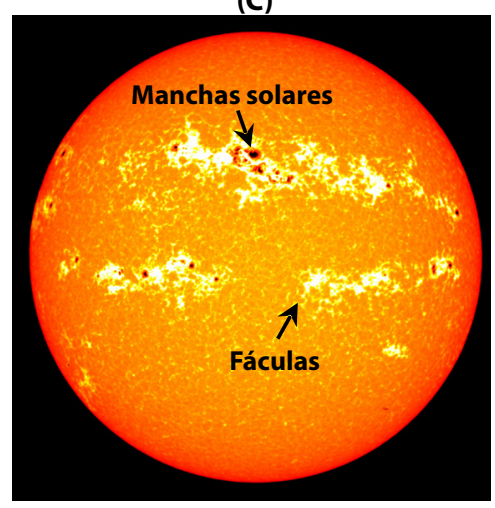

Figura 2. Três vistas do Sol mostrando diferentes níveis de atividade solar: (A) Atividade solar fraca (imagem de 28/ out/1998); (B) Atividade solar moderada (imagem de 27/abr/2002); (C) Atividade solar elevada (imagem de 28/ mar/2001). As cores foram alteradas para melhorar a aparência das fáculas (regiões claras), que são mais quentes do que as manchas solares (regiões escuras). Fonte: elaborado a partir de imagens de NASA (2003).

3 Em Oliveira et al. (2015), detalhada-se a inusitada história de Samuel Heinrich Schwabe [1789-1875], astrônomo amador que, após quase 25 anos observando o Sol todos os dias, descobriu que o número de manchas variava de forma regular. Tal descoberta é considerada uma das mais importantes da Astronomia.

40 ciclo número 1 é tradicionalmente designado para o período de 1755 a 1766.

5 Apesar de visualmente (a olho nu) parecer sempre igual, o Sol não é uma esfera com luminosidade uniforme. A0 contrário, a superfície é pontilhada por núcleos escuros de manchas solares acompanhadas por regiões brilhantes conhecidas como fáculas. As manchas solares são fenômenos temporários na fotosfera solar que aparecem visivelmente como manchas escuras em comparação às regiões vizinhas. Elas são causadas por intensa atividade magnética induzida, provavelmente, pela influência gravitacional e magnética de Júpiter e Saturno, os planetas do Sistema Solar com maiores massas. As manchas solares ocorrem em locais em que o campo magnético do Sol se estende para fora da superfície solar, esfriando um pouco essa região e tornando-a menos brilhante. Essas perturbações no campo magnético solar deixam a área da mancha solar cerca de $1.500^{\circ} \mathrm{C}$ mais fria do que a área circundante, com temperatura superficial de $5.500^{\circ} \mathrm{C}$. Uma vez que manchas solares são mais escuras do que a fotosfera ao redor, seria de se esperar que mais manchas resultassem em menos radiação solar, ou seja, quanto mais manchas escuras, menos luz seria emitida pelo Sol. No entanto, as margens no entorno das manchas solares são regiões mais quentes e brilhantes do que a média. Tais áreas são denominadas de fáculas, que do latim significa "pequena tocha" ou, literalmente, pontos brilhantes. Como regra geral, as fáculas estão localizadas perto das manchas solares, mas também podem existir sem elas. Podendo possuir até $160.000 \mathrm{~km}$ de diâmetro (13 vezes maior que a Terra), as manchas solares podem ser visíveis na Terra sem 0 auxílio de um telescópio. Já as fáculas, a olho nu, são mais difícies de serem discernidas das demais regiões do Sol, pois apresentam um contraste baixo demais para produzir contribuições visivelmente significativas para a intensidade local, sendo esse constrante perceptível somente com 0 uso de instrumentos. Assim, mesmo com a escuridão provocada pelas manchas solares, prevalece a luminosidade das fáculas e, no cômputo geral, o brilho solar aumenta (Kopp \& Lean 2011, Kostyk 2013).

6 Oliveira et al. (2015) descrevem como os diversos tipos de testemunhos (anéis de arvores, sedimentos marinhos, núcleos de gelo, isótopos etc.) permitem reconstruir o clima no passado e seus diferentes componentes e fatores (precipitação, umidade, temperatura atmosférica, temperatura dos oceanos, nível dos oceanos, direção e velocidade dos ventos, variabilidade solar, atividades vulcânicas, circulação atmosférica, concentração de gases na atmosfera, produtividade biológica e nutrientes nos oceanos, distribuição de plantas e animais, vazão de rios, salinidade, pH, volume de gelo, extensão da calota polar, detritos transportados pelo gelo, entre outros). 
Conforme apresentado na Fig. 1-A, os valores da radiação solar foram disponibilizados apenas durante os últimos três ciclos e se baseiam em uma composição de diversos satélites de observação. No entanto, uma alta correlação entre as medições de radiação e outros testemunhos de atividade solar

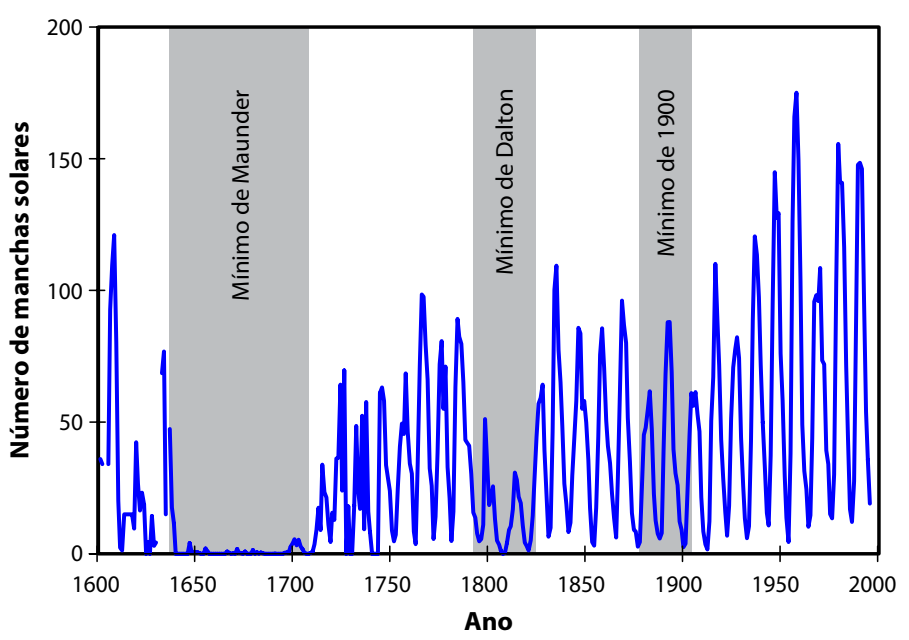

Figura 3. Variação da quantidade de manchas solares desde 1610. Fonte: modificado de Beer et al. (2000).

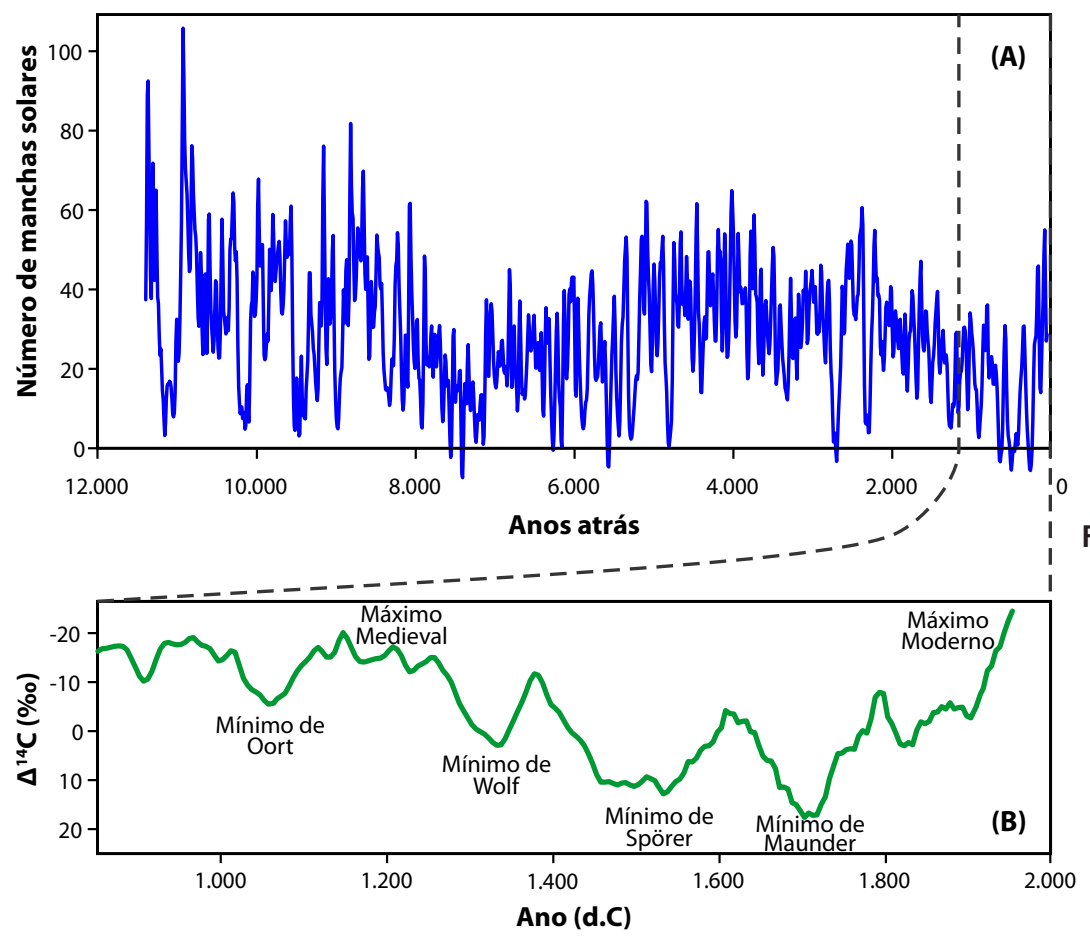

permite estimar razoavelmente a atividade solar no passado. O mais importante método entre esses testemunhos é o registro das observações a olho nu do número de manchas solares (Fig. 1-B), que tem sido registrada ${ }^{7}$ desde aproximadamente 1610 , como apresentado na Fig. 3 .

Reconstruções dendroclimatológicas da atividade solar, com base em datações radiométricas em anéis de crescimento de árvores, foram realizadas para períodos maiores que as quatro décadas de observações diretas do número de manchas solares. A Fig. 4-A exibe reconstruções do número de manchas solares nos últimos 11.000 anos, enquanto que um recorte do período desde o ano 900 d.C., mostrado na Fig. 4-B, exibe os valores da variação da concentração do radiocarbono $\left({ }^{14} \mathrm{C}\right)$.

Observando a reconstrução nos últimos 1.000 anos, os períodos de baixa (alta) produção de ${ }^{14} \mathrm{C}$ correspondem a períodos de alta (baixa) atividade solar. No período de 950 a 1.300, elevadas atividades solares coincidem com o período conhecido na história humana como Período Medieval Quente. Logo após, uma sucessão de períodos excepcionalmente frios na Terra, chamada de Pequena Era

Figura 4. Reconstruções das atividades solares passadas: (A) Variação da quantidade de manchas solares nos últimos 11.000 anos; (B) Concentração de radiocarbono atmosférico nos últimos 1.100 anos. Fonte: elaborado com base em Solanki et al. (2004), gráfico $(A)$; e Reimer et al. (2004), gráfico (B).

70 reconhecimento de manchas solares como um fenômeno solar amplamente reconhecido é, sem dúvida, uma das primeiras realizaç̃es de pesquisas astronômicas com telescópios. As manchas solares foram observadas pela primeira vez por David Fabricius [1564-1617], Galileu Galilei [1564-1642], Christoph Scheiner [15731650] e Thomas Harriot [1560-1621], na primeira década do século 17. Alguns observadores acreditavam que as machas solares eram nuvens que flutuavam na atmosfera do Sol, obscurecendo um pouco de sua luz. Galileu, contudo, definitivamente merece 0 crédito por ter estabelecido que as manchas solares são parte do Sol, que mudam com o tempo, e que 0 Sol gira com um período de cerca de um mês lunar (rotação sinódica de aproximadamente 27 dias) (0skar 2009).

80 radiocarbono $\left({ }^{14} \mathrm{C}\right)$ é produzido por interações nucleares induzidas por raios cósmicos que entram na atmosfera. A intensidade dos raios cósmicos depende da atividade solar através da mudança do campo magnético interplanetário. Uma vez que $0{ }^{14} \mathrm{C}$ atmosférico é assimilado pelas árvores, a variação atmosférica desse isótopo do carbono reflete mudanças na atividade solar e, portanto, pode ser reconstruída por meio de análises de anéis de árvores (Masuda et al. 2009). A concentração do ${ }^{14} \mathrm{C}$ na atmosfera é baixa durante os máximos solares e elevada durante os mínimos solares. 0 eixo vertical da Fig. 4-B está invertido para que 0 mínimo da concentração de ${ }^{14} \mathrm{C}$ corresponda ao máximo do número de manchas solares. 
do Gelo, coincide com períodos que apresentaram número drasticamente reduzido de manchas solares: Mínimo de Oort ${ }^{9}$ [1010-1050], Mínimo de Wolf [1280-1340], Mínimo de Spörer ${ }^{11}$ [1420-1530] e Mínimo de Maunder ${ }^{12}$ [1645-1715]. Dessa forma, o padrão correspondente de manchas solares indica que as atividades solares afetam diretamente o clima da Terra, demonstrando claramente a variabilidade natural do clima e a coincidência com eventos conhecidos na história humana (Masuda et al. 2009).

\subsubsection{Outros Ciclos Solares}

De acordo com Beer et al. (2000), as reconstruções de ${ }^{14} \mathrm{C}$, e por inferência as atividades solares, indicam que, além do ciclo de Schwabe, o Sol possui outros ciclos: ciclo de Hale ${ }^{13}$, revelando que o ciclo solar é um ciclo magnético no qual a polarização magnética das manchas solares se inverte a cada 22 anos; ciclo inferior de Gleissberg ${ }^{14}$, de 88 anos; ciclo superior de Gleissberg, de 120 anos; ciclo de Suess ${ }^{15}$ (ou também ciclo de De Vries), de 208 anos; e ciclos consideravelmente maiores de 500 anos (sem nome atribuído), 1.000 anos (ciclos de Eddy), bem como os ciclos de Hallstatt de 2.300 anos (USGS 2000, Abreu et al. 2010, Kern et al. 2012).

As evidências indicam influência significativa dos efeitos do Sol no clima na Terra, uma vez que os diferentes ciclos solares representaram um forçamento radiativo considerável nas mudanças climáticas nos últimos milênios. Para Zuffo (2015, p. 20$)^{16}$ :

A teoria dos ciclos solares consegue explicar muito melhor o efeito natural do clima que aquela do aquecimento global de origem antropogênica.

No mesmo sentido, trabalho de Scafetta (2010) alega que $60 \%$ do aquecimento global observado desde 1970 é devido a causas naturais decorrentes dos ciclos solares de Schwabe e Hale, além do ciclo lunar de 9,1 anos e da influência dos períodos orbitais de Júpiter e Saturno. Assim, a atividade solar é provavelmente modulada por forças planetárias gravitacionais e eletromagnéticas que atuam sobre o Sol. A influência da radiação solar no clima é, de fato, bastante significativa, responsável, inclusive, pelos ciclos glaciais e interglaciais, conforme será apresentado no item "2.2.2. Ciclos Glaciais de Milankovitch”.

\subsubsection{Movimento Inercial Solar}

A variabilidade da radiação solar está associada ao movimento inercial solar e ao dínamo solar. A posição do Sol não é fixa, está sempre mudando: impulsos de torque provocados pelos planetas impelem o Sol ao redor do centro de massa do Sistema Solar (baricentro). Estudado há mais de 40 anos, o movimento inercial solar é o deslocamento do Sol, em torno do baricentro, provocado pelas posições variáveis dos planetas gigantes (Júpiter, Saturno, Urano e Netuno).

O primeiro estudo, publicado por Jose (1965), indicou que o movimento real do Sol é muito complicado, algo já notado por Newton em Principia:

... uma vez que o centro de gravidade (centro de massa do Sistema Solar) está continuamente em repouso, o Sol, de acordo com as várias posições dos planetas, deve mover-se continuamente para todos os lados, mas nunca vai deslocar-se longe do centro.

O baricentro do Sistema Solar fica localizado entre 0,01 e 2,2 vezes o raio do Sol. O caminho do Sol consiste, na verdade, em um circuito com voltas irregulares, ou seja, cada circunferência não se completa sobre si mesma a cada volta, tal

9 Jan Hendrik Oort [1900-1992], astrofísico holandês que descobriu o mínimo de atividade solar referente ao período de 1010-1050.

10 Johann Rudolf Wolf [1816-1893], astrônomo suíço que descobriu o mínimo de atividade solar referente ao período de 1280-1340.

11 Friederich Wilhelm Gustav Spörer [1822-1895], astrônomo alemão, foi o primeiro a observar um período prolongado de baixa atividade das manchas solares. Seus trabalhos foram citados por E. W. Maunder.

12 Edward Walter Maunder [1851-1928] foi um astrônomo inglês que estudou as manchas solares e sugeriu que a atividade solar estava diretamente ligada ao clima. Ele relacionou o número de manchas solares como uma indicação da atividade solar. Assim, Maunder desvendou que durante 0 período de frio entre $1645-1715$ houve pouca atividade solar, e essa descoberta levou à nomeação do fenômeno em sua homenagem.

13 Homenagem a George Ellery Hale [1868-1938], astrônomo norte-americano que, junto com colaboradores, elucidou as bases físicas do ciclo solar em 1908.

14 Wolfgang Gleißberg [1903-1986] foi um astrônomo, matemático e físico alemão que, além de descobrir o ciclo de quase 90 anos, também desenvolveu métodos de previsão da atividade solar.

15 Hans Eduard Suess [1909-1993] foi um físico-químico e físico nuclear americano, nascido na Áustria, que encontrou uma variação significativa de 208 anos em registros de radiocarbono de anéis de árvores.

16 Sobre os efeitos do Sol no clima, nos regimes de chuva e períodos de secas, em especial sobre recente situação da crise hídrica do ano de 2015 na região do Sistema Cantareira, sugere-se o trabalho de Zuffo (2015) como referência. 
como uma órbita planetária comum. Assim, o Sol se move circularmente ao longo de uma área com lado de 4,3 raios solares (ou 9,0 $10^{12}$ $\mathrm{km}^{2}$ ). Jose (1965) descobriu que, embora este movimento seja complicado (Fig. 5), o Sol retorna à mesma posição a cada 179 anos, fenômeno conhecido como ciclo de Jose. Encontrado em testemunhos da atividade solar nos últimos 8.000 anos, o ciclo de Hallstatt $(\sim 2.400$ anos) tem como causa o movimento solar (Charvátová 2000), especificamente causado por uma grande ressonância estável envolvendo os quatro planetas jovianos - Júpiter, Saturno, Urano e Netuno (Scafetta 2016).

Jose (1965) identificou

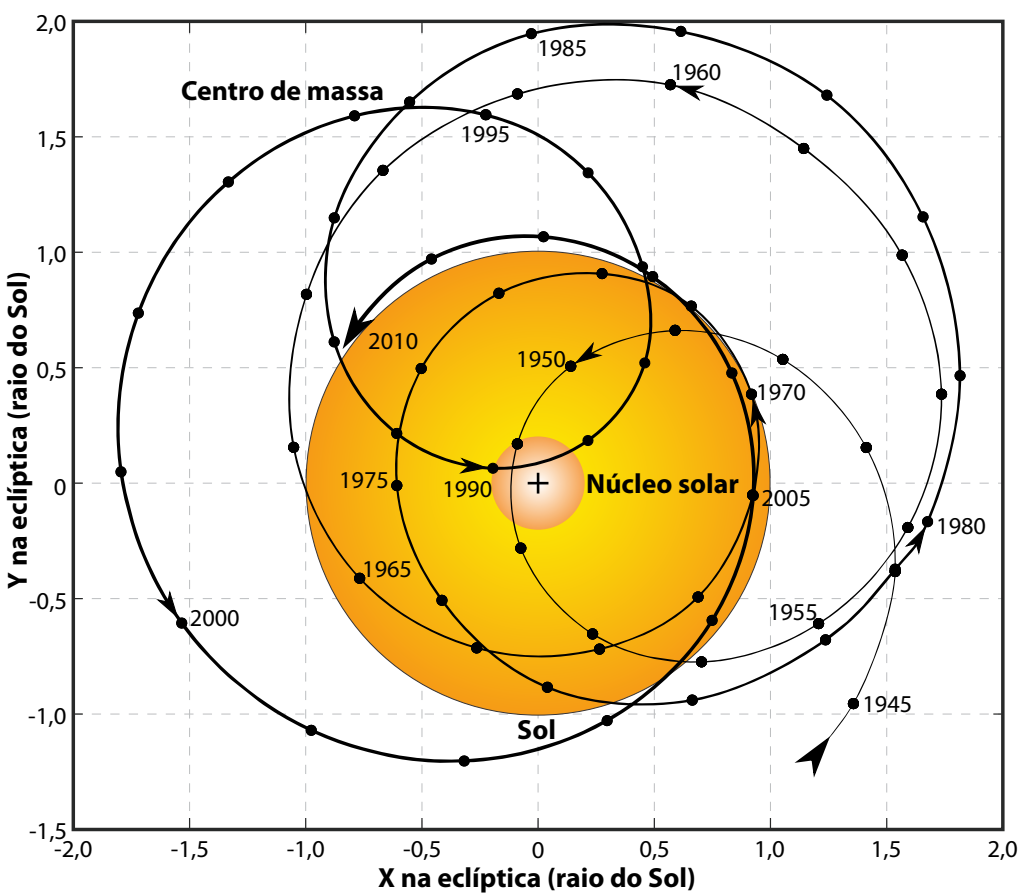

Figura 5. Oscilações do Sol em torno do centro de massa do Sistema Solar, no período de 1945 a 2010. São mostradas as posições celestes anuais do baricentro (pequenos círculos) em relação ao centro do Sol (cruz). Fonte: elaborado com base em Landscheidt (1981) e Scafetta (2010). que certas forças dinâmicas exercidas sobre o Sol pelos movimentos dos planetas são a causa da atividade das manchas solares. Embora 99,9\% da massa do Sistema Solar esteja contida no Sol, $98 \%$ da quantidade de movimento angular está localizada nos planetas (Blizard 1987), ou seja, mesmo que os planetas não possuam muita massa em relação ao Sol, eles possuem bastante energia cinética (relacionada às translações) indutora de torque.

Recentemente, para os diversos ciclos da atividade solar, Abreu et al. (2012) demonstraram que as influências planetárias são de fato a principal causa das mudanças na irradiação solar. Ao estudar as perturbações dos planetas no funcionamento do dínamo solar, eles encontraram excelente concordância entre os ciclos de longo prazo da atividade solar e as periodicidades no torque planetário. Scafetta (2010) finalmente explica a origem dos ciclos e manchas solares: os planetas, em particular Júpiter e Saturno, com seus movimentos em torno do Sol, dão origem a grandes oscilações gravitacionais e magnéticas que fazem vibrar o Sistema Solar. As vibrações têm as mesmas frequências das órbitas planetárias. As vibrações do Sistema Solar podem ser direta ou indiretamente sentidas pelo sistema climático e podem fazer com que oscilem com as mesmas

frequências. Mecanismos físicos mais específicos envolvidos no processo incluem forças de maré gravitacional, fenômenos de transferência de rotação orbital e perturbações magnéticas.

Reunindo aproximadamente $92 \%$ da massa planetária do Sistema Solar, os grandes planetas jovianos - Júpiter e Saturno - possuem amplos campos magnéticos que interagem com o plasma solar e com o campo magnético de interação. As forças gravitacionais e magnéticas agem como forças externas do dínamo solar, do vento solar e do sistema Terra-Lua e podem modular tanto a dinâmica solar e, direta ou indiretamente, por intermédio do Sol, o clima da Terra. Por exemplo, o ciclo solar de 11 anos está bem sincronizado com o alinhamento de Vênus, Terra e Júpiter. O ciclo das manchas solares também apresenta uma bi-modalidade com períodos que oscilam entre 10 e 12 anos, que se situam entre os períodos sinódicos opostos de Júpiter e Saturno e o período de Júpiter, respectivamente. Os resultados de Scafetta (2010) indicam que Júpiter, Saturno, Urano e Netuno modulam a dinâmica solar. Assim, as evidências mostram que o clima pode ser parcialmente impulsionado por forças mecânicas, tais como torques gravitacionais e magnéticos, e não apenas as forças radiativas como comumente suposto. 


\subsection{Variações Orbitais Terrestres}

A variação da radiação solar incidente na atmosfera terrestre ocorre não somente devido às variações das atividades solares, mas também devido às mudanças orbitais da Terra, as quais determinam influências de curto e longo prazo no clima, cuja magnitude é de ordem bastante superior às causadas pelas variações das emissões solares.

\subsubsection{Ciclos Diários e Anuais}

Existem muitos ciclos climáticos, alguns são totalmente compreendidos, outros não são tão imediata e obviamente cíclicos. Uma vez que o clima muda em diversas escalas, as variações menores, mais próximas da percepção humana, ajudam a entender as grandes oscilações do passado geológico. Nesse sentido, em termos de períodos curtos de tempo, as mudanças das condições climáticas e meteorológicas incluem: as flutuações diurnas, os ciclos sinópticos (relacionados às circulações das massas de ar), os ciclos intra-estações, os ciclos sazonais (estações do ano) e os ciclos anuais.

Os ciclos diários são facilmente observados e demonstrados pelo aquecimento e resfriamento produzidos pela alternância dos dias e das noites. Um ciclo diário, que se repete a cada 24 horas, é resultado de uma rotação completa da Terra em torno do próprio eixo. O ciclo diário implica uma das formas mais básicas dos padrões climáticos ${ }^{17}$ : a variação diurna de temperatura com comportamento aproximadamente sinusoidal. Apesar de a rotação terrestre ser o fator determinante nos ciclos diários de temperatura, ressalta-se que estes são influenciados por condições atmosféricas - ditadas pelas massas de ar - e por fatores locacionais como altitude, latitude, umidade, nebulosidade e velocidade dos ventos. Portanto, a aparência sinusoidal do perfil de temperatura do ar pode possuir algumas irregularidades.

A Terra é aquecida durante o dia ao receber radiação solar, mas continuamente perde calor pela radiação terrestre. $\mathrm{O}$ aquecimento e o resfriamento dependem de um desequilíbrio entre a radiação solar recebida e a radiação emitida pela superfície terrestre. Durante o dia, a radiação solar excede a radiação terrestre e, assim, a superfície torna-se mais quente. À noite, a radiação solar cessa, mas a radiação terrestre continua sendo emitida, causando o resfriamento da superfície. O resfriamento continua até pouco depois do nascer do Sol, quando então a radiação solar novamente ultrapassa a radiação terrestre. A temperatura mínima normalmente ocorre depois do nascer do Sol e a temperatura máxima ocorre entre 1 a 3 horas após o pico de radiação solar.

A magnitude da variação da temperatura do ar é expressa em termos de sua amplitude térmica, que é calculada ao subtrair o valor da temperatura máxima pelo valor da temperatura mínima. Em regiões úmidas, a amplitude térmica geralmente é menor, enquanto que em regiões desérticas, devido à baixa umidade do ar e ausência de nuvens, ocorrem as maiores variações diurnas de temperatura, podendo atingir extremos de até $50^{\circ} \mathrm{C}$ de amplitude térmica.

Além da rotação diária, a Terra completa, no período de um ano, uma órbita em torno do Sol. Devido à inclinação do eixo da Terra, a quantidade de luz solar que atinge determinado ponto na superfície varia ao longo do ano. O ciclo anual de temperatura reflete diretamente a variação da radiação solar e indica as mudanças sazonais do clima, como os períodos quentes do verão e frios do inverno. As mudanças na intensidade e duração da insolação recebida dependem da duração do dia e do ângulo de incidência da radiação, ambos determinados pela latitude e dia do ano. Durante o verão no hemisfério sul, a duração do dia é maior e o ângulo de incidência é menor, logo, a radiação incidente é maior do que nos períodos de inverno. Em termos de latitude, ocorre pequena variação na radiação solar no equador e trópicos, resultando em temperaturas médias mensais uniformes ao longo do ano. Em latitudes médias, a radiação solar apresenta uma amplitude pronunciada entre a insolação máxima (verão) e mínima (inverno). Em latitudes polares, a diferença sazonal na radiação solar é extrema, pois os dias e as noites podem durar 24 horas ininterruptas, dependendo da estação do ano.

A título de ilustração, na Fig. 6 estão apresentados cinco ciclos anuais (Fig. 6-A), um ciclo anual (Fig. 6-B), sete ciclos diários (Fig. 6-C) e dois ciclos diários médios (Fig. 6-D) provenientes de dados obtidos, a cada 30 minutos, em estação climatológica localizada em Itirapina/SP (latitude 22 $2^{\circ} 10^{\prime}$ $\mathrm{S}$, longitude $47^{\circ} 50^{\prime} \mathrm{O}$, altitude $753 \mathrm{~m}$ ) referentes ao período de 2001 a 2005. A amplitude térmica diária

17 Além das implicacões climáticas, o ciclo diário repercute diretamente no funcionamento dos seres vivos. Ao provocar variacões na luminosidade, temperatura e marés, a alternẩncia entre 0 dia e a noite influencia os processos biológicos e determina um ritmo biológico com oscilacões endógenas de aproximadamente 24 horas, fenômeno conhecido como ritmo circadiano. 0 termo circadiano vem do latim circa diem (cerca de um dia). Amplamente observados nas plantas, animais, fungos e cianobactérias, os ritmos circadianos são formalmente estudados pela Cronobiologia, campo da Biologia que examina os fenômenos periódicos em organismos vivos e sua adaptação aos ritmos solares e lunares. 

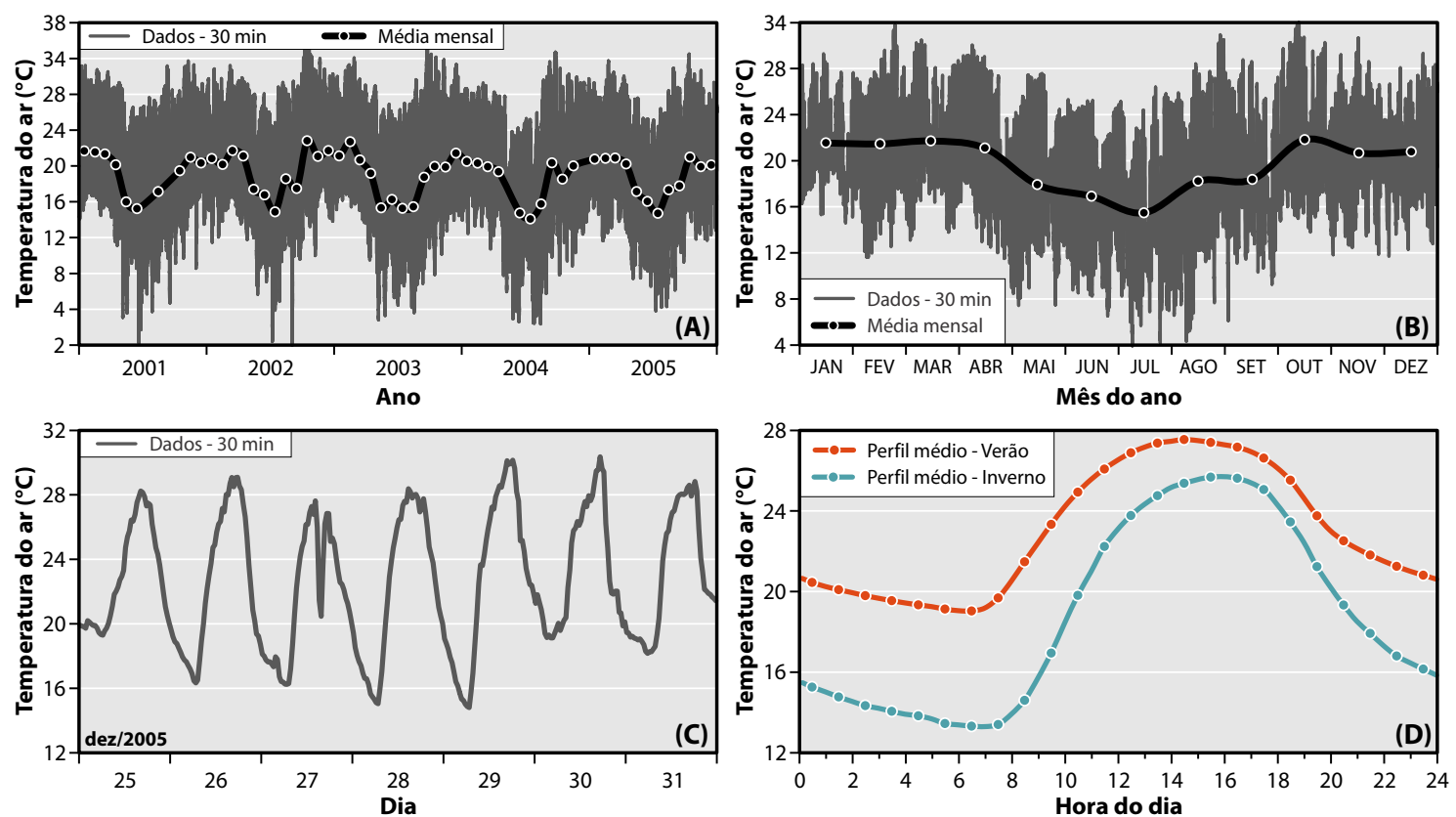

Figura 6. Exemplos de ciclos anuais e diários da temperatura do ar. (A) Cinco ciclos anuais (2001-2005); (B) Um ciclo anual (2005); (C) Sete ciclos diários (25-31 dez/2005); (D) Dois ciclos diários médios provenientes de dados obtidos a cada 30 minutos. Fonte: elaboração própria utilizando dados obtidos na estação climatológica do Centro de Recursos Hídricos e Estudos Ambientais, Escola de Engenharia de São Carlos, Universidade de São Paulo (CRHEA/EESC/USP), Itirapina/SP.

no período foi de $12,0^{\circ} \mathrm{C}$ em média, mas eventualmente atingiu mais de $20,0^{\circ} \mathrm{C}$. A diferença sazonal entre verão/inverno fica evidenciada na Fig. 6-D. No verão, a temperatura diária média do ar foi de $23,0^{\circ} \mathrm{C}$ e, no inverno, foi de $21,0^{\circ} \mathrm{C}$. A temperatura máxima registrada no período foi de $37,4^{\circ} \mathrm{C}$ e a temperatura mínima foi de $1,8^{\circ} \mathrm{C}$. No solstício de verão, 21 de dezembro é o dia com maior duração de luz solar, com $13 \mathrm{~h} 24 \mathrm{~min}$; no solstício de inverno, 21 de junho é o dia com menor duração de luz solar, com 10h36min. Essa condição, juntamente com o ângulo de incidência dos raios solares, determina os perfis médios de temperatura do ar nos períodos de verão e inverno exibidos na Fig. 6-D.

\subsubsection{Variações da Duração do Dia e do Ano}

A Terra gira uma vez por dia, mas o conhecido período de 24 horas desse dia nem sempre foi cons- tante. Em escala geológica, a velocidade de rotação da Terra já foi muito mais rápida do que é hoje: quando a Terra se formou, um dia tinha em torno de 6 horas de duração; há 300 milhões anos atrás, um ano durava cerca de 450 dias e um dia durava aproximadamente 21 horas. Como resultado da redução da velocidade de rotação da Terra ${ }^{18}$, a duração do dia aumentou. A desaceleração da rotação terrestre foi gradual, porém ocorreu mais rapidamente quando a água líquida começou a se formar há cerca de 3,5 bilhões de anos atrás. De acordo com o modelo de Arbab (2009), a duração do dia aumenta a uma taxa atual de 0,002 segundos/século. Segundo Stephenson \& Morrison (1995), ao longo dos últimos 3.500 anos, a duração do dia aumentou em 84 milisegundos (0,0017 s/séc.).

Em escalas de tempo sazonais, a variação na duração do dia pode ser interpretada em termos de troca de momento angular entre a Terra sólida e as camadas fluidas superficiais (atmosfera e oceanos) e

\footnotetext{
18 Segundo van Andel (1994), a velocidade de rotação da Terra desacelerou gradualmente como resultado de interações gravitacionais com a Lua, fenômeno conhecido como aceleração de marés que envolve a fricção das marés e provoca variações na distância entre a Lua e a Terra. Assim, há 400 milhões de anos atrás, o mês lunar tinha 30 dias, ao invés dos atuais 28 dias de duração. Arbab (2009) propôs outra hipótese baseada na variação da constante gravitacional. Foi assumido que, conforme a expansão do universo está acelerando no momento presente e a fim de evitar um colapso no futuro, uma forma de contornar essa situacão é ter a força da gravidade variando um pouco com o tempo. No caso de um universo plano, a expansão acelerada do universo é equilibrada com 0 aumento da força da atração gravitacional ao longo do tempo. Assim, 0 autor pressupôs que 0 aumento da gravidade e a expansão do universo são as causas da desaceleração da rotação terrestre. Em sentido inverso, Christianto et al. (2009) defendem a visão predominantemente aceita de que a gravidade diminuiu com 0 tempo. Considerando 0 fato de que os raios dos planetas são inversamente proporcionais às suas gravidades, inicialmente, com a gravidade elevada, a Terra possuía uma crosta pequena e uniforme, sem oceanos, assim como outros planetas rochosos, e com o tempo foi se expandindo conforme a redução da gravidade. Desse modo, Christianto et al. (2009) levantam a hipótese de que o raio atual é 2 vezes o raio da Terra primitiva. No princípio, a forca gravitacional era 4 vezes mais forte e a Terra girava 4 vezes mais rápido e por este motivo, 0 dia tinha apenas 6 horas. Percebe-se até então, pelas duas hipóteses, que a "constante" gravitacional na verdade pode ser variável. A gravidade aumenta em um caso e diminui em outro. Apresentando uma terceira hipótese, Machado (1967) afirma que a gravidade tem variado com certa periodicidade durante o tempo geológico, implicando fases alternadas de expansão e contração da Terra. As variações cíclicas da gravidade e do raio terrestre podem estar relacionadas com a revolução do Sistema Solar ao redor do centro imaginário da Via Láctea, cujo ciclo perdura por 225-250 milhões de anos.
} 
internas (núcleo fundido). No caso da atmosfera, as variações na quantidade de movimento angular são dominadas pelo efeito dos ventos, seguidas pelos efeitos de grandeza menor oriundos de mudanças na pressão. As contribuições dos oceanos possuem influências ainda menores do que as da pressão. A força dos ventos contra as montanhas altera a duração do dia em mais ou menos um milésimo de segundo, durante um período de um ano (Dickey et al. 2011).

A duração de um dia na Terra também varia ao longo de períodos mais longos, como interanual (dois a 10 anos), decadal (aproximadamente 10 anos) ou várias décadas. Um modo mais dominante que flutua a cada 65 a 80 anos alterou a duração do dia em aproximadamente 4 milissegundos no início do século 20. Essas flutuações longas são devidas ao fluxo de ferro líquido no núcleo externo da Terra, onde o campo magnético terrestre se origina. Ao interagir com o manto da Terra, esse fluido afeta a rotação da Terra (Dickey et al. 2011).

As variações recentes na duração do dia podem estar associadas a variações da temperatura média do ar na Terra, podendo provocar flutuações de até $0,2^{\circ} \mathrm{C}$ na temperatura superficial global. Apesar de essas variações recentes na duração do dia serem da ordem de milissegundos, a relação não está diretamente relacionada à menor ou maior quantidade de radiação recebida em intervalos de tempo tão curtos. A hipótese para essa correlação é a possibilidade de os movimentos do núcleo da Terra perturbarem o campo magnético e, assim, modificarem o fluxo a quantidade de partículas carregadas (raios cósmicos), estas supostamente responsáveis pela formação de nuvens. Pela mudança na nebulosidade, é possível afetar o quanto de energia do Sol é refletido de volta ao espaço e o quanto é absorvido. Outra possibilidade é um efeito indireto sobre o clima causado pela influência solar, afetando simultaneamente o núcleo terrestre e o clima (NASA 2011).

\subsubsection{Ciclos Glaciais de Milankovitch}

O matemático sérvio Milutin Milankovitch $^{19}$ passou 30 anos pesquisando mudanças em características orbitais ${ }^{20}$ da Terra e sua influência sobre a quantidade de radiação solar recebida na superfície terrestre. Três características da órbita terrestre mudam lentamente ao longo de dezenas de milhares de anos, conforme ilustrado na Fig. 7:

- Excentricidade orbital;

- Inclinação axial (ou obliquidade) $)^{21}$ e

- Precessão dos equinócios (ou orientação do eixo de rotação).
(B)

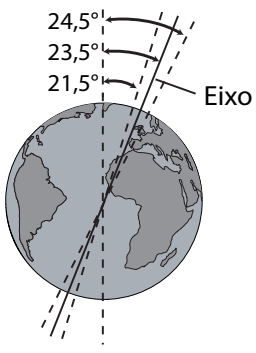

(C)

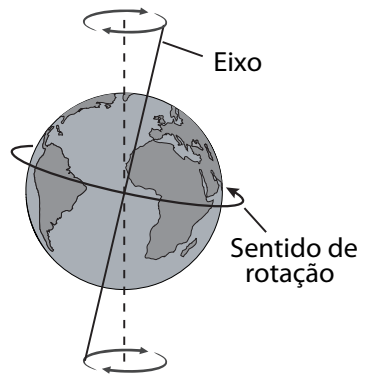

Figura 7. Variações orbitais terrestres: (A) Excentricidade orbital; (B) Inclinação do eixo terrestre; (C) Precessão dos equinócios. Fonte: modificado de Harper (2007).

Os parâmetros orbitais apresentam diferentes ciclos de mudança que afetam a quantidade de insolação recebida pela Terra. As causas das variações orbitais terrestres estão relacionadas à influência dos movimentos dos corpos do Sistema Solar. Ou seja, os parâmetros orbitais de Terra oscilam de acordo com a variação dos campos gravitacionais e magnéticos gerados pelo Sol, pela Lua e pelos outros planetas, especialmente Júpiter e Saturno ${ }^{22}$ (Scafetta 2010).

A Terra gira sobre um eixo que forma atualmente $^{23}$ um ângulo de $23,5^{\circ}$ em relação ao plano de rotação. Esse não é um ângulo constante, pois varia de $21,5^{\circ}$ a $24,5^{\circ}$ ao longo de um período de 41.000 anos (Fig. 7-B). Quando o ângulo é menor, ocorrem diferenças menores de temperatura entre o verão e o inverno do que quando o ângulo é maior; com um ângulo maior, os invernos são

19 Oliveira et al. (2015) apresentam a história de Milutin Milankovitch [1879-1958] e sua teoria proposta em 1930, que somente foi reconhecida e comprovada quase duas décadas após a sua morte.

20 Para mais detalhes sobre os parâmetros orbitais de Milankovitch, consultar Reboita et al. (2015).

210 termo clima surgiu da palavra grega klima, que se referia antigamente a uma suposta inclinação da Terra, aproximando à atual concepção de latitude. A origem histórica da palavra klima remete aos estudos realizados pelas civilizações sumérias datadas no ano de 400 a.C. (Critchfield 1966).

22 A importância relativa dos três ciclos orbitais não foi constante ao longo dos milhões de anos. No passado, durante o Pleistoceno (iniciado há 2,6 milhões de anos atrás), 0 ciclo de 41 mil anos da obliquidade dominou a primeira parte dessa época, resultando em períodos glaciais e interglaciais de quase a mesma duração. Nos últimos 800 mil anos, 0 ciclo de 100 mil anos da excentricidade orbital tem predominado, e a duração dos períodos glaciais passou a ser de 5 a 10 vezes maiores do que os períodos interglaciais. As mudanças estão relacionadas a forças celestes: o comportamento orbital terrestre é afetado por forças gravitacionais do Sol, da Lua e dos planetas, em especial as perturbações induzidas por Júpiter e Saturno (van Andel 1994, Scafetta 2010).

23 A inclinação está em fase de redução do seu ângulo no ciclo, e atingirá o valor mínimo em torno do ano 10.000 d.C. 
mais frios e os verões mais quentes, devido aos diferentes tempos de exposição à insolação. A excentricidade orbital muda conforme ciclos de 100.000 anos $^{24}$, variando entre mais circular (como agora) e mais elíptica e, em seguida, voltando a ser circular (Fig. 7-A). Quando é mais circular, então a distância entre a Terra e Sol varia pouco entre as estações; e quando a órbita é elíptica, há uma diferença significativa da distância Terra-Sol no verão e no inverno. $\mathrm{O}$ efeito da excentricidade no clima da Terra depende também da última característica orbital: a precessão dos equinócios. A Terra oscila sobre seu eixo em um movimento análogo ao de um pião, fenômeno conhecido precessão dos equinócios. Durante um período de $26.000 \operatorname{anos}^{25}$, o eixo de rotação oscila e forma um círculo (Fig. 7-C). A oscilação determina a estação do ano durante a qual a Terra estará mais próxima do Sol (Harper 2007).

$\mathrm{O}$ efeito das três características orbitais fica claro quando todos os extremos se combinam: se a órbita é a mais excêntrica possível, se a oscilação coloca a Terra muito longe do Sol durante o inverno e se o ângulo do eixo é o máximo de $24,5^{\circ}$, então os invernos serão muito frios e verões serão muito quentes. As variações orbitais alteram, além do total da quantidade de luz solar que atinge a superfície da Terra, também a distribuição da radiação no globo. A compreensão das variações orbitais induziu Milankovitch a relacionar a influência destas com os efeitos no clima terrestre de longo prazo, tornando-se a teoria mais plausível e aceita para a ocorrência das glaciações.

Milankovitch estudou dados astronômicos desde 600.000 anos atrás até 1.800 d.C. e calculou a quantidade de insolação em diferentes latitudes para cada ano. Em seguida, ele previu que as mudanças cíclicas induziriam as eras glaciais, quando o montante de radiação solar fosse o menor durante os meses de verão, reduzindo o derretimento da neve nas altas latitudes. Assim, a neve que caiu durante o inverno não derreteria durante o verão e, ano após ano, ao longo de milhares de anos, o gelo acumulado formaria geleiras que avançariam em direção ao equador que, por fim, produziriam uma idade do gelo (Harper 2007).

Cálculos aperfeiçoados e comparados com resultados paleoclimáticos recentes permitiram confirmar a ocorrência intercalada de eras glaciais $^{26}$ (frias) e interglaciais (quentes), fenômenos periódicos denominados de ciclos de Milankovitch, conforme ilustrado na Fig. 8.

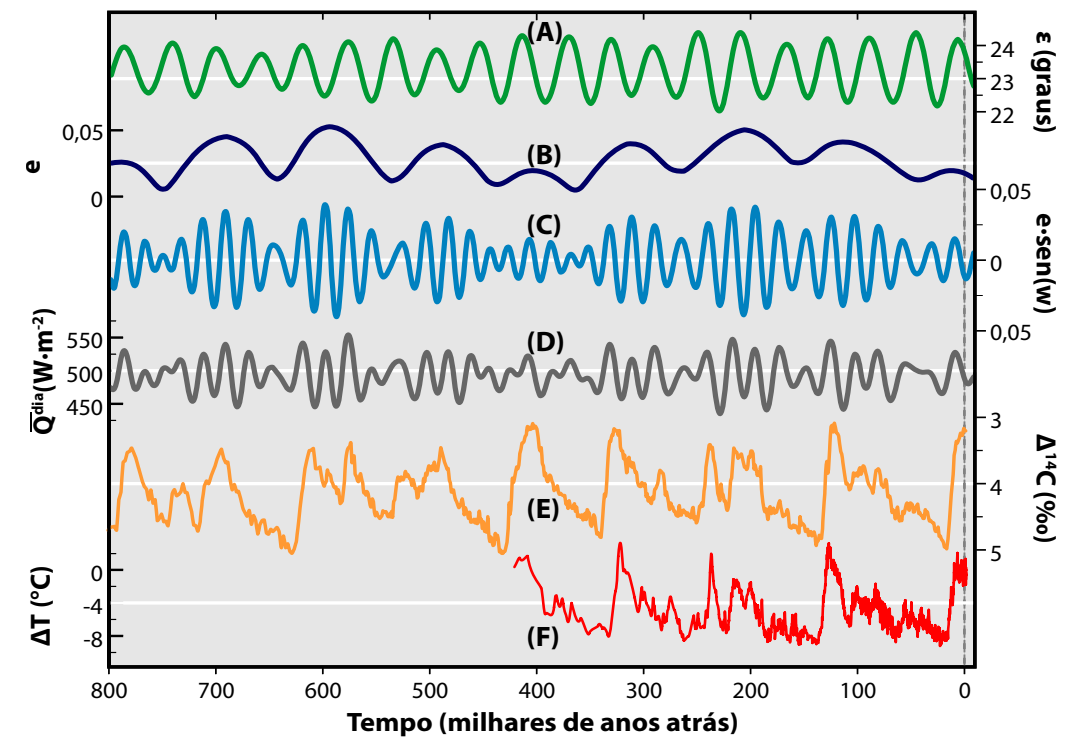

Figura 8. Parâmetros orbitais e ciclos de Milankovitch nos últimos 800 mil anos. (A) Obliquidade ( $\varepsilon$ ) ou inclinação axial; (B) Excentricidade (e); (C) Longitude do periélio $(w)$ e índice de precessão [e·sen $(w)$ ], que, juntamente com obliquidade, controla o ciclo sazonal da insolação; (D) Radiação média de insolação no topo da atmosfera ( $\bar{Q}^{\text {dia }}$ ), no dia do solstício de verão na latitude $65^{\circ} \mathrm{N}$. Foraminíferos bentônicos de sedimentos oceânicos e testemunhos de gelo em Vostok (Antártida) mostram duas reconstruções diferentes para $(\mathbf{E})$ o nível do mar e (F) a variação da temperatura global no passado. A linha vertical cinza corresponde ao ano 2.000 d.C. Fonte: modificado de Fiedler (2009).

\footnotetext{
24 Além do atual ciclo de 100 mil anos, a Terra possuiu no passado um ciclo de 400 mil anos na excentricidade. Registros durante o Ótimo Climático do Mioceno (16,9 a 13,5 milhões de anos atrás) revelam que as oscilações de alta frequência da excentricidade (100 mil anos) estavam sobrepostas com oscilações com períodos de 400 mil anos. Tais ciclos de baixa frequência indicam uma ligação entre forçamentos da excentricidade e mudanças no reservatório de carbono nos oceanos. 0 ciclo da excentricidade longa é considerado como um componente do "batimento cardíaco" do sistema climático da Terra. Ao longo do Ótimo Climático do Mioceno, ocorreram cerca de nove ciclos de 400 mil anos. No final do Mioceno, a expansão dos mantos de gelo, em especial o desenvolvimento de camadas de gelo permanentes na Antártida, suprimiu o ciclo de 400 mil anos no reservatório de carbono dos oceanos, melhorou a circulação do 0 ceano Pacífico profundo e, finalmente, favoreceu a variabilidade do clima conforme os ciclos de 100 mil anos (Holbourn et al. 2007, Ma et al. 2011, Pälike et al. 2006).

250 período de um ciclo completo dos equinócios, de cerca de 26.000 anos, é também conhecido como Ano Platônico ou Grande Ano. A precessão era desconhecida para Platão, mas ele definiu 0 Grande Ano como o retorno dos corpos celestes (planetas) e a rotação diurna das estrelas fixas para suas posições originais.

26 Durante 0 último período glacial, ocorreram quasi-periodicamente algumas flutuações climáticas abruptas denominadas de eventos de Dansgaard-Oeschger (D-0), com um tempo de recorrência de 1.470 anos. Os processos causadores e 0 período desses eventos ainda não estão claros, porém, os eventos podem ser causados por uma amplificação dos fenômenos solares, ou por uma causa interna do sistema de terra, como os modos quasi-estacionários do sistema atmosfera-oceano. No final de uma sequência de eventos de D-0 durante um período prolongado de frio, ocorrem os eventos de Heinrich, a cada 10 mil anos. A ciclicidade de 1.470 anos também é encontrada durante o Holoceno, onde os eventos são chamados de eventos de Bond.
} 
Análises de perfurações no gelo a mais de 3 $\mathrm{km}$ de profundidade na Estação Vostok - uma base de pesquisas localizada no centro da Antártida, a região mais fria da Terra - produziram um registro de condições ambientais do passado que remontam até 420 mil anos e que abrangem quatro períodos glaciais anteriores (Fig. 9). É claramente visível que existe um padrão de correlação entre o dióxido de carbono $\left(\mathrm{CO}_{2}\right)$ e a temperatura por quatro ciclos glacial-interglacial ${ }^{27}$.

Sabe-se que a solubilidade do $\mathrm{CO}_{2}$ nos oceanos varia de modo inversamente proporcional à temperatura, ou seja, há evidências de que o aumento (ou redução) de temperatura do ar cause a redução (ou ou aumento) das concentrações de $\mathrm{CO}_{2}$ nos oceanos, e não o contrário. Consequentemente, o $\mathrm{CO}_{2}$ atmosférico acompanha a temperatura, isto é, a concentração desse gás na atmosfera é diretamente proporcional à temperatura: no equilíbrio químico do gás carbônico, quanto maior a temperatura terrestre, menos gás será solubilizado nos oceanos na forma de ácido carbônico $\left(\mathrm{H}_{2} \mathrm{CO}_{3}\right)$ e, assim, maior é a concentração do $\mathrm{CO}_{2}$ na atmosfera (Florides \& Christodoulides 2009).

\subsection{Variações da Atmosfera e Superfície Terrestre}

Além das variações solares e orbitais terrestres, as variações na composição da atmosfera e do uso e ocupação dos solos representam o terceiro fator de alteração do balanço de radiação terrestre, cuja consequência implica mudanças climáticas em diferentes escalas têmporo-espaciais. As causas dessas variações podem ser devido às ações humanas ou devido a eventos naturais, principalmente por atividades vulcânicas e colisão de meteoritos e cometas.

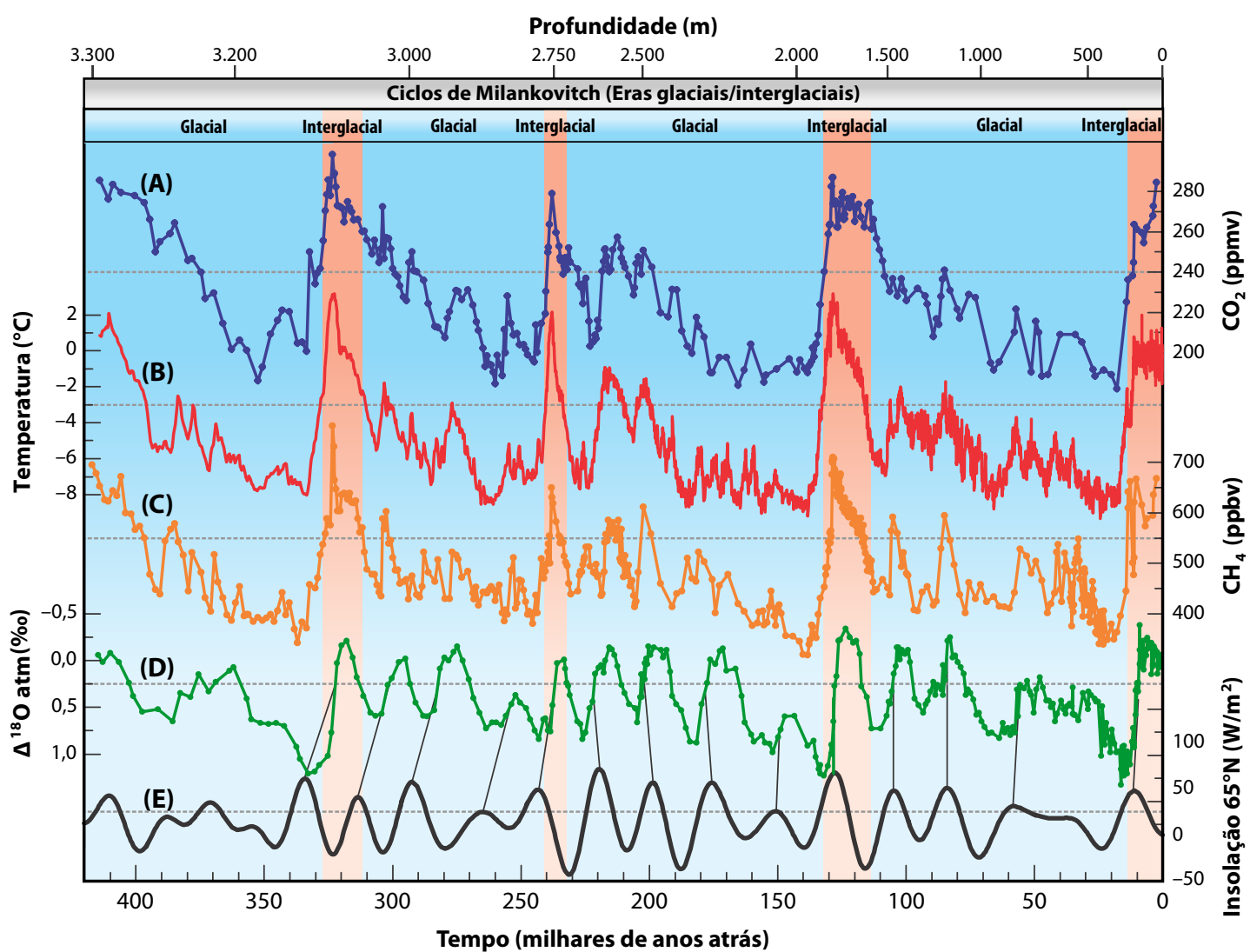

Figura 9. Ciclos de Milankovitch registrados nos testemunhos de gelo. Séries de Vostok (curvas coloridas), insolação (curva preta) e períodos glaciais e interglaciais (preenchimentos verticais azuis e vermelhos, respectibamente). Séries com relação ao tempo (escala com indicação de profundidades correspondentes no eixo superior): (A) Dióxido de carbono $\left(\mathrm{CO}_{2}\right)$; (B) Temperatura isotópica da atmosfera; (C) Metano $\left(\mathrm{CH}_{4}\right)$; (D) Composição isotópica de oxigênio $\left(\Delta^{18} \mathrm{O}_{\mathrm{atm}}\right)$; (E) Insolação, em meados de junho, na latitude 65N. Fonte: modificado de Petit et al. (1999).

27 Florides \& Christodoulides (2009) explicam que 0 aumento de concentração de $\mathrm{CO}_{2}$ ocorre com atraso de 400 a 1.000 anos após a mudança de temperatura, portanto, indicando que a relação entre temperatura e $\mathrm{CO}_{2}$ parece ser exatamente 0 contrário do que se presume ser do modelo convencional de estudos do clima. Um gatilho inicial de mudança na temperatura (como pequenas mudanças na órbita da Terra, por exemplo) resulta em uma liberação de $\mathrm{CO}_{2}$ dos reservatórios naturais (como 0 oceano) para a atmosfera, com uma defasagem de alguns séculos. 


\subsubsection{Aerossóis}

No contexto do clima, a principal causa humana de modificação da atmosfera é atribuído às emissões de gases de efeito estufa. Além dessa causa, a influência de aerossóis troposféricos pode estar associada à poluição industrial e à queima de combustíveis fósseis e biomassa vegetal.

Partículas sólidas de sulfato resultam da oxidação de dióxido de enxofre $\left(\mathrm{SO}_{2}\right)$ emitido quando combustíveis fósseis são queimados. Processos industriais, a queima de biomassa vegetal natural ou induzida pelo homem e a erosão dos solos também contribuem com a formação, na troposfera, de gotículas e materiais particulados, ambos denominados aerossóis. Os aerossóis representam dois efeitos no sistema climático:

- O efeito direto da maioria dos aerossóis é refletir a radiação solar para o espaço e, consequentemente, conferir um esfriamento na área afetada; enquanto que alguns particulados, como a fuligem, são escuros e possuem o efeito contrário, causando um efeito de aquecimento local. A magnitude de resfriamento ou aquecimento depende da natureza dos aerossóis e da sua distribuição na atmosfera (Mcguffie \& Henderson-Sellers 2005).

- O efeito indireto dos aerossóis é mais difícil de avaliar que os efeitos diretos, mas não por isso são menos importantes. Os aerossóis agem como núcleos de condensação adicionais, favorecendo a geração de gotículas que formam as nuvens. Com o aumento de nuvens, ocorre o incremento da refletividade delas e, consequentemente, menos radiação solar entra no sistema, resfriando o planeta (devido ao forçamento negativo gerado no balanço de radiação). O efeito das mudanças nas nuvens pode ter repercussões complexas, uma vez que as nuvens também afetam a quantidade de radiação reemitida pela superfície terrestre (Mcguffie \& Henderson-Sellers 2005).

\subsubsection{Atividade Vulcânica}

A atividade vulcânica projeta grandes quantidades de partículas e gases na atmosfera, influenciando o mecanismo dos aerossóis descrito anteriormente e, portanto, afetando também o clima. A principal contribuição dos vulcões é decorrente de partículas estratosféricas de ácido sulfúrico $\left(\mathrm{H}_{2} \mathrm{SO}_{4}\right)$, que rapidamente se condensam e formam aerossóis de sulfato.

Erupções vulcânicas podem produzir anomalias significativas na temperatura, da ordem de décimos de graus centígrados. Grandes erupções vulcânicas - como os recentes casos do Monte Tambora (1815), Krakatoa (1883), El Chichón (1982) e Monte Pinatubo (1991), Fig. 10 - não são tão frequentes, porém causam efeitos climáticos expressivos. Exemplos: as últimas cinco maiores erupções vulcânicas dos últimos 100 anos podem ter provocado a queda de 0,1 a $0,4{ }^{\circ} \mathrm{C}$ da temperatura média global; a erupção do Monte Pinatubo resultou no resfriamento de $0,5^{\circ} \mathrm{C}$; em consequência da erupção do Monte Tambora, maior erupção vulcânica recente, não houve verão no Hemisfério Norte e o resfriamento foi tão intenso que o ano de 1816 ficou conhecido como o Ano Sem Verão. Claramente, verifica-se um efeito notável dessas erupções no clima terrestre global. O vulcanismo entre 1250-1500 e 1550-1700, em conjunção com os efeitos climáticos do Mínimo de Spörer e de

Figura 10. Impacto de erupções vulcânicas na temperatura, no período de 1700-2000.

(A) Erupções e variações correspondentes da profundidade ótica (medida da quantidade de radiação solar que é bloqueada através de uma coluna da atmosfera. Quanto maior o valor, menor a passagem de radiação); (B) Variações da temperatura média global (desconsiderando forçamentos solares positivos, que compensam o efeito negativo do vulcanismo). Fonte: modificado de

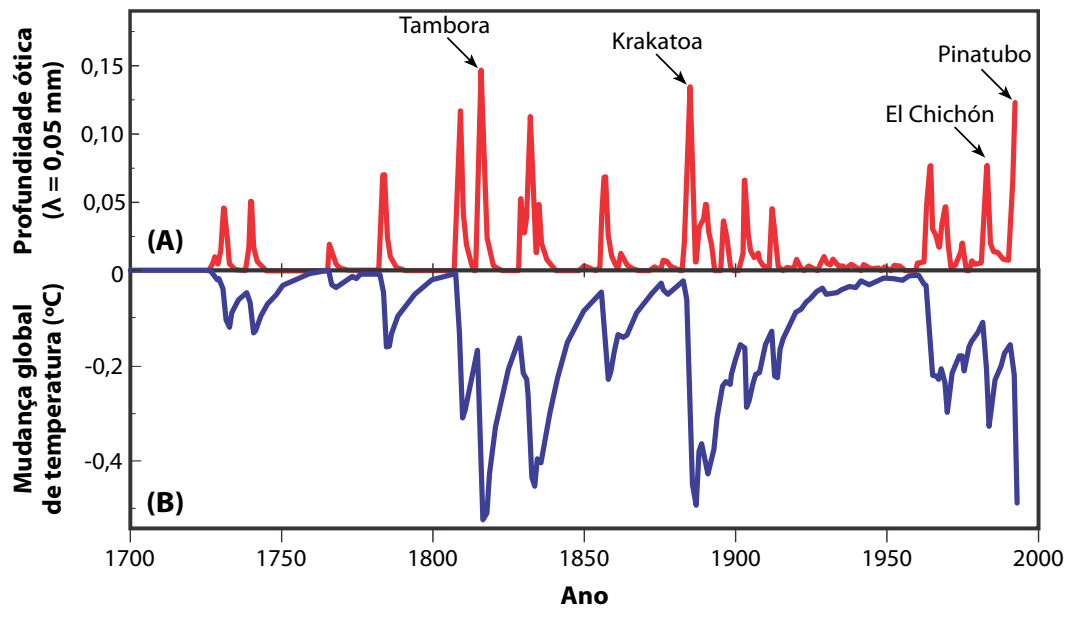
Bertrand et al. (1999). 
Maunder, tem sido cogitado como a possível causa da Pequena Era do Gelo (Mcgregor \& Nieuwolt 1998, Mcguffie \& Henderson-Sellers 2005).

Com menor frequência de ocorrência, erupções vulcânicas de elevada magnitude causaram, no passado, impactos drásticos e duradouros no clima terrestre. O caso do supervulcão Toba, localizado ao norte da Ilha de Sumatra na Indonésia, ilustra a grandeza desse tipo de fenômeno natural e o impacto climático decorrente. O evento de Toba, ocorrido há 73.000 anos atrás, representou a maior erupção vulcânica dos últimos 2 milhões de anos. Um volume de 2.500 a $3.000 \mathrm{~km}^{3}$ de magma foi projetado - comparado ao volume de 100 a $200 \mathrm{~km}^{3}$ da erupção de 1815 de Tambora - e 1\% da superfície terrestre ficou coberta com $10 \mathrm{~cm}$ de cinzas vulcânicas. $\mathrm{O}$ sulfato vulcânico produzido nesta mega-erupção causou a queda de $10^{\circ} \mathrm{C}$ no verão em altas latitudes, além de um inverno vulcânico de 6 anos, seguido por um período de resfriamento que durou 1.800 anos (Rampino \& Self 1993, Mason et al. 2004, Williams et al. 2009).

A atividade vulcânica varia ao longo de uma ampla gama de escalas temporais, desde ciclos com menos de um ano de período em sistemas vulcânicos únicos até intervalos que se estendem a escalas do tectonismo de placas. As conexões entre vulcanismo, o ciclo do carbono e o clima estão bem estabelecidas nas escalas de longo período (conforme será apresentado no item "2.5. Superciclos: Tectonismo, Vulcanismo e Raios Cósmicos"). Em escalas intermediárias (milhares de anos), relevantes para variações durante eras glaciais/interglaciais, Kutterolf et al. (2013) indicam que o vulcanismo está associado aos ciclos orbitais de Milankovitch, em especial com o período da obliquidade de 41 mil anos. Os autores sugerem que o clima da era glacial induz atividades vulcânicas por meio de mudanças de pressão na crosta associadas com as redistribuições de massas de gelo.

\subsubsection{Colisões de Asteroides ou Cometas}

Uma causa externa de mudanças climáticas que influencia no fator da atmosfera deve-se à colisão de asteroides ou $\operatorname{cometas}^{28}$ na superfície terrestre. Com alto poder de gerar mudanças severas, colisões de grandes corpos são eventos de baixa frequencia, porém causaram as maiores catástrofes naturais da Terra. Os impactos de enormes colisões têm sido propostos como possíveis causas de grandes mudanças climáticas e também com efeitos devastadores à vida terrestre, implicando raros eventos de extinção em massa ${ }^{29}$. Muitos dos distúrbios causados pelos impactos de asteroides, como o aumento da concentração dos aerossóis troposféricos e estratosféricos, são similares aos distúrbios internos do sistema climático, tanto artificial (atividades antrópicas) quanto natural (vulcanismos) (Mcguffie \& Henderson-Sellers 2005).

A Terra é continuamente bombardeada por detritos espaciais cujos tamanhos variam desde poeira microscópica até meteoritos; diariamente, mais de 100 meteoritos pesando cerca de $0,5 \mathrm{~kg}$ atingem o planeta. Bólidos maiores de 50 metros de diâmetro atingem a superfície, em média, a cada 1.000 ou 2.000 anos. O famoso caso da cratera de Barringer (Fig. 11), ou também

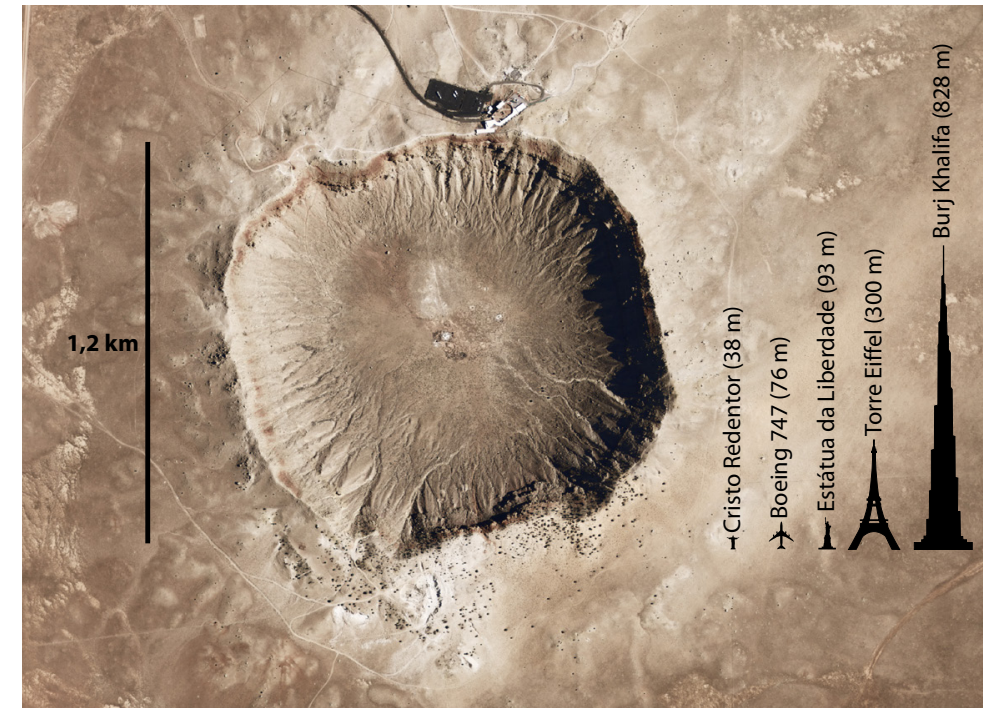

Figura 11. Fotografia aérea da cratera de Barringer (Cratera do Meteoro), a maior cratera de impacto dos Estados Unidos, localizada no Arizona. À direita, objetos em escala, para fins de comparação: Cristo Redentor; Boeing 747 (um dos maiores aviões do mundo); Estátua da Liberdade; Torre Eifel; e Burj Khalifa (o maior prédio do mundo). Fonte: elaborado com base em imagem de NASA (2009).

28 A principal diferença entre um asteroide e um cometa é a composição. Os asteroides são feitos de metais e material rochoso, enquanto que os cometas são compostos de gelo, poeira e material rochoso. Quando os cometas se aproximam do calor do Sol, o gelo e outros materiais na superfície aquecem até evaporar. Tal vapor é visto como a "cauda" do cometa.

29 Diante da ameaça constante da queda de um grande corpo celeste, diversos livros e filmes sugerem que a humanidade teria a necessidade de desenvolver mecanismos para monitorar e proteger-se contra as catástrofes provocadas pelos impactos. Esse cenário foi abordado nos filmes Armagedom (do Inglês: Armageddon) e Impacto Profundo (do Inglês: Deep Impact), ambos de 1998. 
conhecida como a Cratera do Meteoro, é a maior cratera de impacto (ou astroblema ${ }^{30}$ ) dos Estados Unidos e o local do impacto de meteorito mais bem preservado do mundo. Liberando energia equivalente a uma bomba de hidrogênio (10 megatons TNT), o impacto de um meteorito, com $50 \mathrm{~m}$ de diâmetro, viajando a $12 \mathrm{~km} / \mathrm{s}$, deixou há 50 mil anos atrás um buraco de $1 \mathrm{~km}$ de diâmetro e $200 \mathrm{~m}$ de altitude em uma região localizada no deserto do Arizona, EUA (NASA 2009).

Outro caso famoso é o evento de Tunguska, o maior episódio de impacto próximo à superfície Terra na história registrada. Ocorrida em 30 de junho de 1908, a queda do meteorito resultou na sua ruptura catastrófica acima do solo em uma região despovoada da Sibéria, na Rússia. O objeto, com tamanho estimado entre 60 e 190 metros de diâmetro, não chegou a atingir o solo e, logo, não criou uma cratera de impacto. Entretanto, gerou uma grande explosão em cerca de $10 \mathrm{~km}$ de altitude - na ordem de 3 a 30 megatons TNT, equivalentes a 1.000 bombas de Hiroshima que derrubou cerca de 80 milhões de árvores em uma área de $2.000 \mathrm{~km}^{2}$ (Kvasnytsya et al. 2013).

Mais recentemente, o evento de Chelyabinsk ocorreu sobre uma região relativamente povoada da Rússia durante o amanhecer do dia 15 de fevereiro de 2013 . Viajando a $20 \mathrm{~km} / \mathrm{s}$, o meteorito de $20 \mathrm{~m}$ explodiu entre 24 e $30 \mathrm{~km}$ de altitude e liberou 0,5 megatons TNT de energia. A onda de choque danificou milhares de janelas e centenas de pessoas foram hospitalizadas. Nos momentos mais intensos da explosão, a bola de fogo brilhou 30 vezes mais do que o Sol, causando queimaduras de pele e de retina. As explosões aéreas de Chelyabinsk foram as maiores desde Tunguska em 1908. Mas, ao contrário de outros acontecimentos históricos, a queda foi gravada por tecnologia moderna, incluindo satélites que fotografaram o meteoro a partir do espaço, bem como diversas câmeras de segurança e de vídeo pessoais que registraram imagens impressionantes do percurso da rocha cortando o céu e gerando um rastro de fumaça e fogo (Brown et al. 2013, Borovička et al. 2013, Sample 2013).

Efeitos abruptos e duradouros no clima são causados por grandes asteroides com diâmetro a partir de $1 \mathrm{~km}$, os quais têm um período médio de recorrência em torno de 100.000 anos. Impactos de objetos com $10 \mathrm{~km}$ ocorrem aproximadamente a cada 50 milhões de anos. A última ocorrência dessa magnitude sucedeu há 65 milhões de anos atrás com o evento $K-P g$

\footnotetext{
30 Do grego astron + blema = "cicatriz de estrela", termo poeticamente cunhado, em 1961, pelo geólogo e oceanógrafo norte-americano Robert Sinclair Dietz [1914-1995].
}

(antigamente conhecido como evento $K-T^{31}$ ), que provocou uma extinção em massa e marcou o fim do período Cretáceo (K) e o início do Paleogeno $(\mathrm{Pg})$.

Causando o evento mais devastador na história da vida na Terra, o impacto há 65 milhões de anos atrás de um grande asteroide ou cometa, com aproximadamente $10 \mathrm{~km}$ de diâmetro, criou um astroblema de 180 a $200 \mathrm{~km}$ de diâmetro, hoje denominada cratera de Chicxulub, soterrada ao sul da Península de Yucatán no México. Uma interpretação do fenômeno atribui ao evento a extinção de mais da metade das espécies do planeta, inclusive pondo fim à era dos dinossauros. A energia do seu impacto foi de 1 bilhão de vezes maior do que o da bomba lançada em Hiroshima. Além dos efeitos colaterais imediatos ao impacto do corpo celeste na superfície terrestre - incêndios globais, terremotos, tsunamis de mais de 100 metros que poderiam provocar inundações em regiões $20 \mathrm{~km}$ adentro dos continentes - efeitos ambientais catastróficos se sucederam, com o sistema climático drasticamente alterado devido à escuridão prolongada causada pela poeira e cinzas liberadas no impacto e ao inverno de impacto causado pelos aerossóis de sulfato. Um cenário de escurecimento completo, em que a poeira levantada pelo impacto impedia a luz solar de chegar à superfície, pode ter durado vários meses após o impacto. A intensidade de luz pode ter sido tão baixa que a fotossíntese cessou em grande parte da Terra e a visão pode ter sido impossível. O resfriamento global pode ter durado de anos a décadas, com a redução de $10^{\circ} \mathrm{C}$ na temperatura da superfície terrestre (Toon et al. 1997, Schulte et al. 2010, Agência Fapesp 2010).

A maior extinção em massa de todos os tempos aconteceu há 254 milhões de anos atrás, no fim do período Permiano. O evento P-Tr (Permiano-Triássico), conhecido também como "A Grande Mortandade" pela NASA (2002), foi considerado "a mãe de todas as extinções em massa" pelo paleontólogo Douglas H. Erwin (Erwin 1993), paleobiologista especialista em Paleozoico e estudioso das causas desse evento. Entre outras possíveis explicações, a ideia de um impacto como a causa da extinção do Permiano foi levantada diversas vezes, mas somente recentemente foi encontrada uma cratera capaz de confirmar a teoria. Novas evidências de Tohver et al. (2012) sugerem que a cratera responsável pelo impacto fica entre os municípios de Araguainha e Ponte Branca, na fronteira dos estados de Mato

310 evento é mais conhecido como evento Cretáceo-Terciário (K-T), mas o termo Terciário não é mais recomendando como uma unidade formal pela Comissão Internacional sobre Estratigrafia. 
Grosso e Goiás, Brasil. A cratera, chamada de domo de Araguainha, foi descrita por Crósta (1982, 1987, 2002); sua idade é muito próxima do limite Permiano-Triássico (Crósta 2012). Possui atualmente cerca de 40 quilômetros de diâmetro, mas inicialmente teria $24 \mathrm{~km}$ de largura e 2,4 $\mathrm{km}$ de profundidade. Embora a cratera seja relativamente pequena, quatro vezes menor que a de Chicxulub, ainda assim, é o maior astroblema da América do Sul e uma das 20 maiores do mundo. A energia do impacto iniciou uma cadeia de eventos, incluindo tsunamis e milhares de terremotos de magnitude de até 9,9 na escala Ritcher-significativamente mais poderosos do que o maior registrado por sismógrafos modernos - em um raio de mil quilômetros em torno da cratera. Os efeitos desencadeados, como a provável emissão de grandes quantidades de metano, resultaram em uma imensa extinção em massa em que $90 \%$ de todas as espécies marinhas e $70 \%$ das espécies terrestres desapareceram (Pivetta 2013, UWA 2013).

Em toda a história geológica da Terra, os dois maiores impactos confirmados de meteoros ocorreram no éon Proterozoico (de 2.500 a 542 milhões de anos atrás), quando surgiram as primeiras formas de vida unicelulares avançadas e multicelulares e, portanto, não se menciona a ocorrência de uma extinção em massa para esse período. Localizada na África do Sul, a cratera de Vredefort - hoje já bastante erodida - é o maior astroblema da Terra, com mais de $300 \mathrm{~km}$ de diâmetro. $\mathrm{O}$ asteroide que atingiu Vredefort, há 2.023 milhões de anos atrás, tinha aproximadamente de 5 a $10 \mathrm{~km}$ de diâmetro. Representando a segunda maior cratera de impacto conhecida do planeta, a bacia de Sudbury é uma grande estrutura geológica localizada em Ontário, Canadá. Ela foi formada, há 1.849 milhões de anos atrás, pelo impacto de um meteorito de 10 a $15 \mathrm{~km}$ de diâmetro, que gerou uma cratera de $250 \mathrm{~km}$ de diâmetro (French 1998).

Atualmente estão sendo pesquisados dois grandes astroblemas, ainda não confirmados. $\mathrm{O}$ primeiro astroblema em estudo está situado perto da região de Maniitsoq da Groenlândia Ocidental, cujo asteroide de $30 \mathrm{~km}$ caiu há três bilhões de anos atrás e criou uma cratera de $600 \mathrm{~km}$ de largura e $25 \mathrm{~km}$ de profundidade. Se confirmada a sua existência, ela seria a maior cratera de impacto conhecida na Terra (Coghlan 2012, Garde et al. 2012). O segundo astroblema, situado na Antártida oriental, é a cratera da Terra de Wilkes. Sob um manto de gelo de $2 \mathrm{~km}$ de espessura, há indícios da existência de uma cratera de aproximadamente
$450 \mathrm{~km}$ de diâmetro, que foi gerada pelo impacto de um corpo de $45 \mathrm{~km}$ de diâmetro há 250 milhões de anos trás (von Frese et al. 2009, von Frese et al. 2013). Essa época é compatível com o evento P-Tr, portanto, torna-se um forte candidato do impacto responsável pela mega-extinção.

O evento mais catastrófico de toda a história terrestre, considerada a hipótese consensualmente aceita para a causa da formação da Lua, praticamente destruiu a Terra, porém, ocorreu antes da existência de qualquer vida. A hipótese do Impacto Gigante explica que a Lua foi formada há aproximadamente 4,5 bilhões de anos atrás, a partir dos restos que sobraram de uma colisão entre a Terra e um corpo do tamanho de Marte (cujo diâmetro é metade da Terra), chamado de Theia ${ }^{32}$ (Halliday 2000).

A partir dos casos apresentados, infere-se que, quando maior o corpo, maior é intervalo existente entre eventos de magnitude similar. Essa relação diretamente proporcional entre o tamanho do meteorito e o tempo de recorrência está ilustrada na Fig. 12.

A distribuição espacial das estruturas de impacto conhecidas é bastante desigual, sendo que a maioria está localizada na América do Norte, norte da Europa e na Austrália (Fig. 13). Devido à falta de estudos, a América do Sul é a região onde menos se tem a confirmação de crateras abertas por impactos de corpos celestes, totalizando somente 7 astroblemas contra 58 na América do Norte, 35 na Europa, 27 na Ásia, 24 na Austrália e 17 na África. O domo de Araguainha é a maior cratera do Brasil e a $16^{\mathrm{a}}$ maior do mundo (Agência Fapesp 2004).

\subsubsection{Extinç̧ões em Massa}

Além dos efeitos abruptos e impetuosos no clima terrestre como repercussão direta das colisões cósmicas, nota-se uma estreita relação entre a ocorrência de grandes episódios de impacto com eventos de extinções em massa na Terra (Tiwari \& Rao 2003). Confirmada por Schulte et al. (2010), a teoria do impacto para a extinção em massa do evento K-Pg foi delineada por Alvarez et al. (1980). Intuitivamente, quanto maior o astroblema, maiores são a energia do impacto e o grau de extinção de espécies, conforme fica ilustrada na Fig. 14 essa relação diretamente proporcional.

32 Na mitologia grega, Theia é uma deusa e mãe de Selene, a deusa da Lua. 


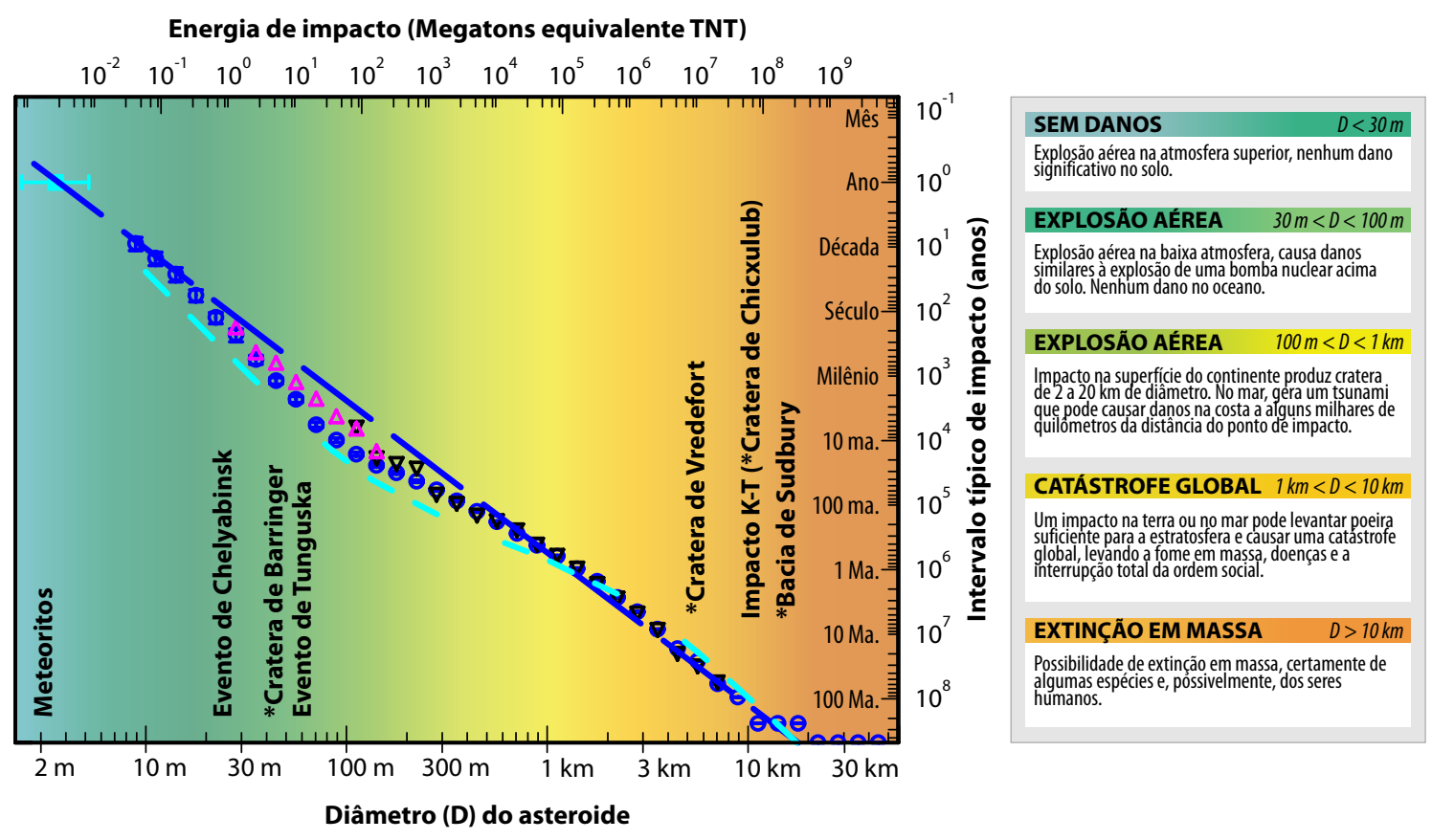

Figura 12. Diagrama da frequência e energia do impacto de objetos com a Terra em função do tamanho do objeto. À direita, resumo dos efeitos esperados para cada classe de impacto. *O local correspondente das indicações dos eventos e crateras na figura representa o diâmetro aproximado dos respectivos asteroides envolvidos; os diâmetros das crateras foram apresentados no texto. Legenda: ma. = milhares de anos; Ma. = milhões de anos. Fonte: modificado de Pierazzo \& Artemieva (2012).

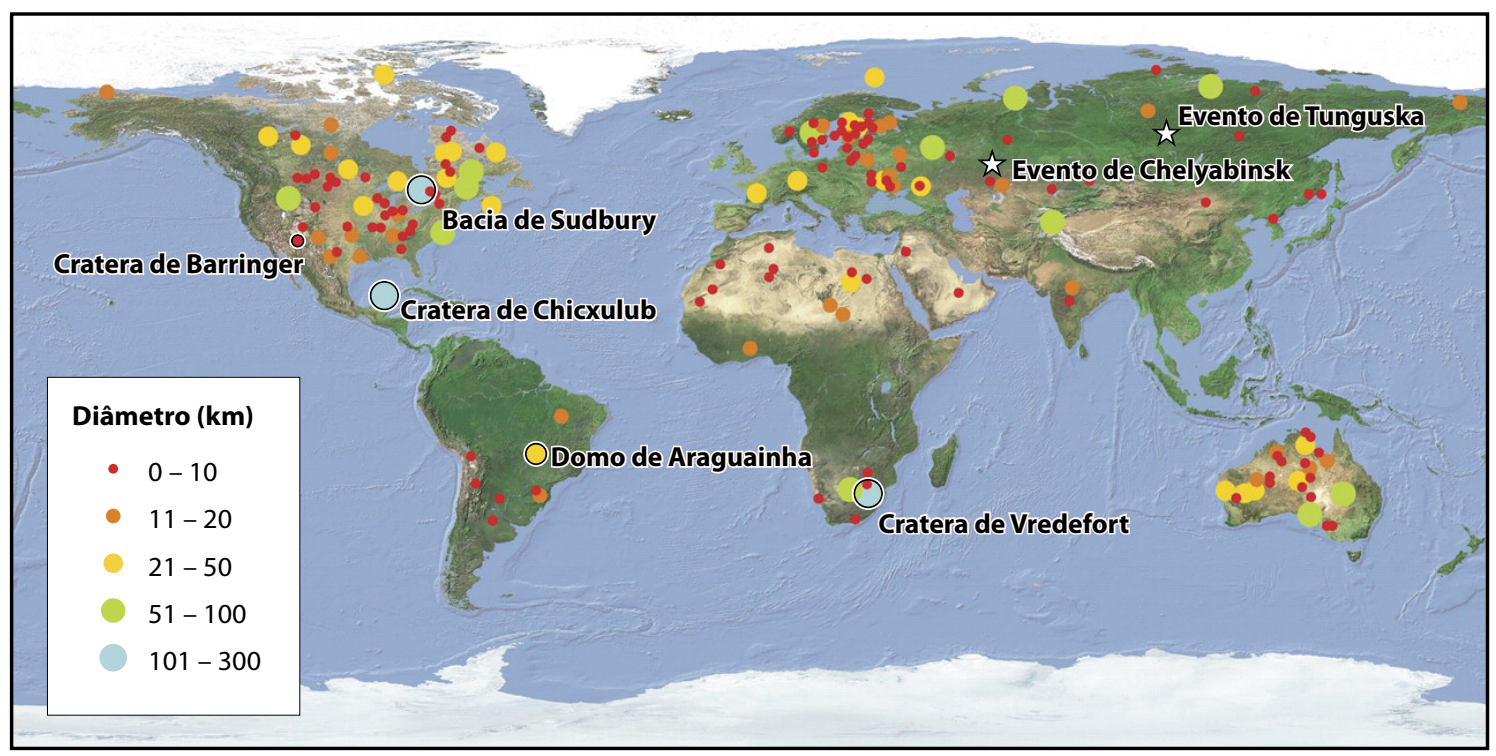

Figura 13. Distribuição das cerca de 180 estruturas de impacto confirmadas na Terra. Os eventos indicados por estrela $\left(^{*}\right)$ não possuem cratera (os asteroides explodiram na atmosfera antes de atingir o solo). Fonte: modificado de Reimold \& Jourdan (2012), os quais utilizaram dados (atualizados até 2011) obtidos a partir do Earth Impact Database.

No diagrama apresentado na Fig. 12, fica implícita a pressuposição de uma periodicidade média de colisões de asteroides e cometas na Terra de acordo com os seus tamanhos, ideia originária de Raup \& Sepkoski (1984). Analisando a distribuição temporal das maiores extinções nos últimos 250 milhões de anos, os autores identificaram 10 eventos que apresentam uma periodicidade de aproximadamente 26 milhões de anos (Fig. 15), possivelmente relacionada com forças astronômicas do Sol, do Sistema Solar ou da Galáxia.

Uma possível explicação da periocidade das extinções em massa seria a passagem do nosso Sistema Solar através dos braços espirais da Via 


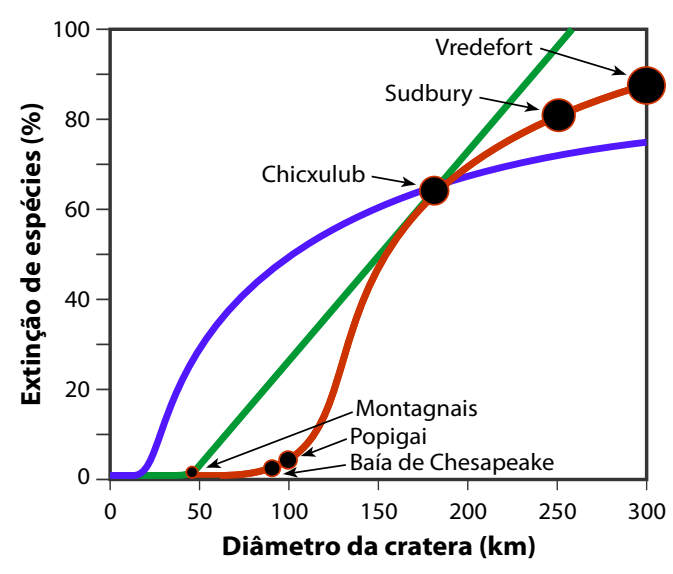

Figura 14. "Curvas da morte" indicando a relação entre a porcentagem da extinção em massa e tamanho do diâmetro da cratera deixada pelo impacto de um asteroide ou meteorito. As curvas verde, azul e vermelha foram obtidas respectivamente por Jansa et al. (1990), Rampino et al. (1997) e Prothero (2006). Pelas curvas azul e verde, previu-se que impactos muito menores poderiam causar extinções significativas. No entanto, a curva vermelha, mais atual, sugere que apenas os impactos maiores têm o potencial de causar extinções em massa. Fonte: modificado de Prothero (2006).

Láctea. Essa visão recebeu forte contribuição com a hipótese de Shiva $a^{33}$ de Rampino \& Haggerty (1996), a qual evolui para uma "teoria unificada de crises de impacto e extinções em massa" (Rampino et al. 1997) e, finalmente, para a "teoria galáctica de extinções em massa" de Rampino (1998). Em linhas gerais, a explicação astronômica periódica para tais

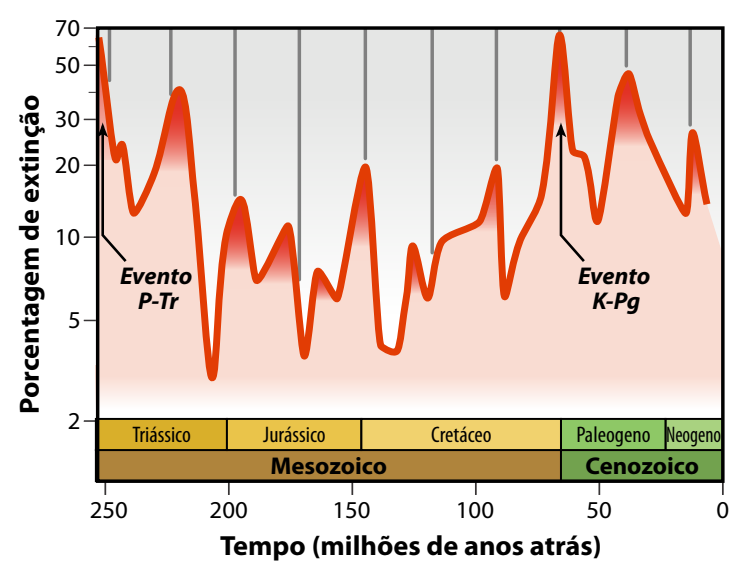

Figura 15. Registro das extinções nos últimos 250 milhões de anos e indicação de ciclos de aproximadamente 26 milhões de anos (linhas verticais). Fonte: modificado de Raup \& Sepkoski (1984).

pulsos de impactos pode estar associada aos movimentos do Sistema Solar através da Via Láctea: além de girar em torno do centro da Galáxia, o Sistema Solar também oscila para cima e para baixo através do plano galáctico com um meio-ciclo de aproximadamente 30 milhões de anos (Fig. 16).

O ciclo galáctico conduz a Terra e o Sistema Solar a encontros quasi-periódicos com nuvens interestelares e a variações periódicas na força da "maré galáctica", cuja máxima ocorre em tempos de travessia do plano galáctico. O efeito de "carrossel galáctico"34, ocasionado pela poderosa força gravitacional exercida pela massa de nuvens de gás e poeira

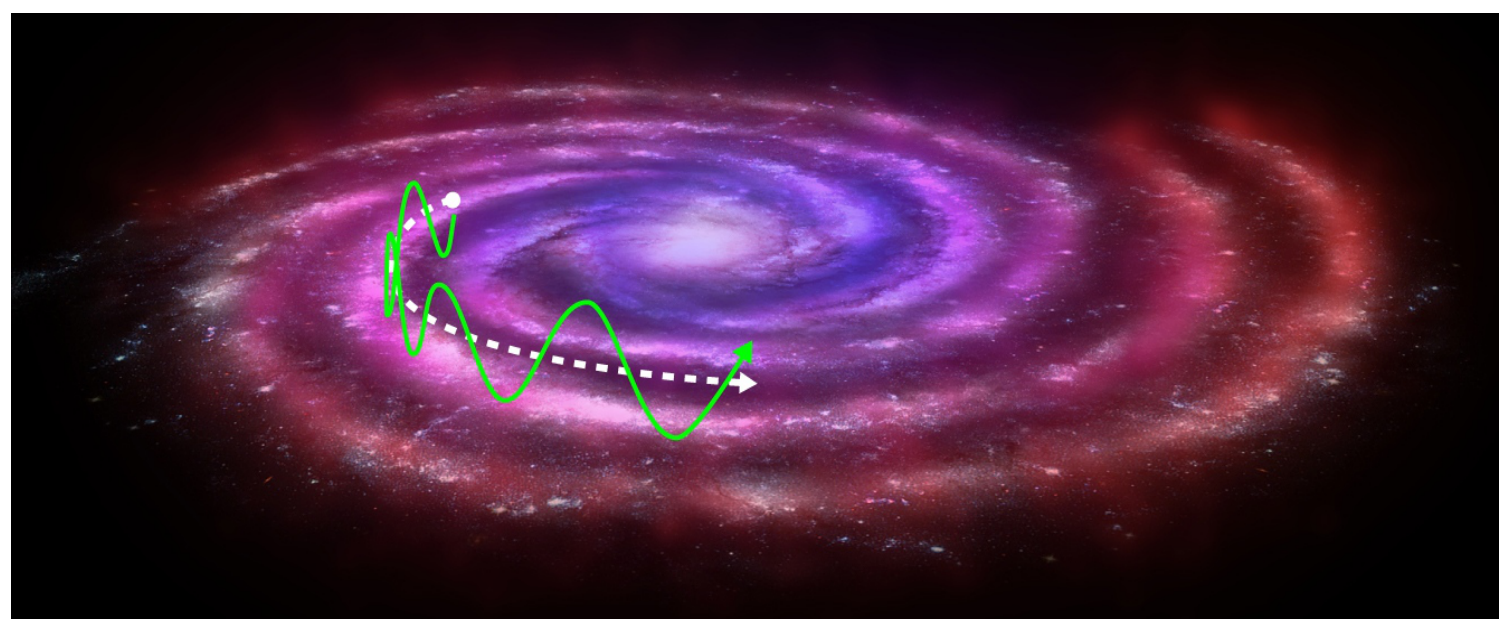

Figura 16: Representação esquemática do Sistema Solar circundando o centro da Via Láctea (sentido da linha tracejada branca), tendo como trajeto um movimento repetitivo de sobe e desce ("carrossel") através do plano galático (curva verde). Fonte: Gibney (2014).

33 Shiva é uma divindade hindu da destruição e renovação, sendo uma das mais antigas divindades adoradas. Rampino e Haggerty (1996) a descrevem como uma 'dançarina cósmica': "ela segura em uma das mãos a chama da destruição e, na outra mão, o damaru, um tambor que regula o ritmo da dança, que simboliza a criaçãa. Ela se move dentro de um anel de fogo - 0 ciclo cósmico - mantido por uma interação de destruição e criação, batucando um ritmo tão regular como qualquer relógio de colisões de cometas".

34 Para fins de melhor visualização didática do movimento do Sistema Solar ao redor do centro da Via Láctea, sugere-se dois vídeos de DjSadhu (2012, 2013) disponíveis nas URLs: https://youtu.be/C4V-oolTrws e https://youtu.be/0jHsq36 NTU 
da Galáxia, pode implicar perturbações gravitacionais nos cometas da nuvem de Oort, produzindo chuvas periódicas de meteoros no Sistema Solar interior. Contudo, considerando que tais modelos não poderiam explicar uma força gravitacional forte o suficiente para causar o efeito, Randal \& Reece (2014) especulam que, na verdade, uma camada mais densa de matéria escura, localizada no centro do plano galáctico, seria capaz de provocar as chuvas periódicas de meteoros (Gibney 2014).

Segundo Matese et al. (1994) e Rampino \& Haggerty (1996), a melhor estimativa do próximo evento de grande impacto é ocorrer dentro dos próximos 600 mil anos. Todavia, considerando o desvio padrão do modelo de Matese et al. (1994) dos picos nos fluxos de cometas oriundos da nuvem de Oort, o valor com o intervalo de confiança para o próximo evento de impacto é de 0,6 \pm 1,7 milhões de anos, ou seja,já iniciou há 1,1 milhões de anos atrás e se estende até os próximos 2,4 milhões de anos. Assim, conforme afirmam os autores, pode-se dizer que hoje estamos no auge de uma contínua chuva de meteoros.

Para Stothers (1985), os episódios de impacto de crateras, no entanto, não são precisamente periódicos, pois o mecanismo galáctico deve ser em parte estocástico. A componente irregular pode ser atribuída à aleatoriedade na distribuição local espacial das nuvens interestelares (e outros objetos galácticos perturbados) e a componente periódica provavelmente surge da oscilação vertical harmônica do Sistema Solar através do plano galáctico. Assim, o modelo galáctico sobre o catastrofismo terrestre ainda é viável e pode ser testado de várias maneiras, seja por teorias ou observações.

Existem também modelos astrofísicos periódicos alternativos para a hipótese de Shiva, um deles envolvendo uma estrela binária companheira do Sol, chamada de Nemesis ${ }^{35}$, ou Estrela X, ou ainda Estrela da Morte (Whitmire \& Jackson 1984, Davis et al. 1984); ou um décimo planeta, o Planeta $X$, orbitando além de Netuno (Whitmire \& Matese 1985), ambos supostamente capazes de perturbar a rota de cometas a cada 28 milhões de anos. Todavia, segundo Rampino \& Haggerty (1996), essas explicações são pouco prováveis ${ }^{36}$. Existe também uma hipótese semelhante de que os cometas entram no Sistema Solar a partir de uma região da nuvem de Oort devido a perturbações causadas, provavelmente, por um objeto com a massa de até 4 vezes a de Júpiter. Este planeta gigante gasoso hipotético foi apelidado de Tyche ${ }^{37}$ (Matese \& Whitmire 2011).

Nos registros fósseis terrestres, a periodicidade de eventos de extinções em massa, juntamente com os processos geo-bioclimáticos relacionados, ocorrem em períodos quasi-regulares que variam entre 27 e 33 milhões de anos, conforme estatisticamente constatado por Tiwari \& Rao (2003) e Melott \& Bambach (2010). Assim, a repetição de eventos de extinção nos mesmos pontos em diferentes cruzamentos com os braços espirais da Galáxia sugere uma causa galáctica comum para a extinção em massa (Gillman \& Erenler 2008).

Por mais de 30 anos, os cientistas têm discutido sobre a hipótese da periodicidade de impactos de bólidos e eventos de extinção biológica. Em publicações recentes, persistem alegações divergentes: de um lado, Rampino \& Caldeira (2015) alegam que a hipótese dos impactos continua viável; de outro lado, para Erlykin et al. (2017), as causas astronômicas podem ser largamente descartadas e, para Bond \& Grasby (2017), o vulcanismo em grande escala seria o principal motor de extinções em massa. Apesar de algumas hipóteses e observações sobre as causas das mega-extinções, o tema permanece, entretanto, uma questão ainda controversa e em constante debate no âmbito científico.

\subsubsection{Guerras Nucleares}

A propósito, ainda que não seja uma causa natural de mudanças climáticas, encaixa-se neste ponto do texto a consideração sobre a ocorrência de guerras nucleares - uma potencial causa humana de mudanças climáticas - devido ao fato de seus efeitos serem bastante parecidos com os do inverno vulcânico e do inverno de impacto.

35 Nêmesis, na mitologia grega, é a deusa que personifica a retribuição, destino, equilíbrio e vingança divina.

36 Em 2012, o brasileiro Rodney Gomes, astrônomo do Observatório Nacional do Brasil, apresentou em encontro da Sociedade Americana de Astronomia resultados (Gomes \& Soares 2012) que retomaram a busca de evidências sobre o Planeta X. Depois de calcular as órbitas de objetos do cinturão de Kuiper, o pesquisador notou que alguns desses objetos pareciam ser deslocados das órbitas esperadas. Segundo ele, a causa dessas órbitas irregulares seria provavelmente a presença de um companheiro solar de massa-planetária, com cerca de quatro vezes o tamanho da Terra - quase 0 tamanho de Netuno (Terra 2012, Lovett 2012). Recentemente, com base em efeitos gravitacionais observados em 6 objetos, confirmou-se a existência do Planeta $X$, agora denominado como "Planeta Nove", em virtude da reclassificacão de Plutão como um planeta anão. Possuindo cerca de dez vezes a massa da Terra, o nono planeta do Sistema Solar possui uma trajetória elíptica que leva de 10.000 a 20.000 para dar uma volta ao redor do Sol (Hand 2016, Ribeiro 2016, Witze 2016). Como mais uma evidência da existência do nono planeta, a influência gravitacional dele foi recentemente proposta como possível causa da inclinação incomum e até então inexplicável de seis graus do nosso Sol (Dvorsky, 2016).

37 Tyche era a deusa grega da fortuna e da prosperidade. Como nome da "irmã benevolente" de Nemesis, Tyche foi escolhido para evitar confusão com uma suposta estrela companheira do Sol, Nemesis, hipótese cuja gravidade provocaria fluxos de cometas no Sistema Solar e conduziria a extinções em massa na Terra. 
A possibilidade de ocorrência de uma guerra nuclear mundial durante a Guerra Fria ${ }^{38}$ favoreceu o surgimento do termo inverno nuclear, proposto por Turco et al. (1983). As explosões das bombas nucleares produziriam efeitos semelhantes de resfriamento global, por causa das fuligens e aerossóis lançados na atmosfera. Para várias simulações feitas pelos autores, os efeitos da poeira e a fumaça geradas nas explosões poderiam reduzir os níveis médios de intensidade de luz a uma pequena percentagem durante semanas, além de provocar quedas a curto prazo da temperatura, na ordem de $-15^{\circ} \mathrm{C} \mathrm{a}-25^{\circ} \mathrm{C}$. Enquanto isso, os modelos climáticos modernos confirmam que as previsões da década de 1980 sobre os efeitos do inverno nuclear foram, no mínimo, subestimadas (Toon et al. 2008).

Um fato distinto dos conflitos nucleares é a presença de mecanismos e efeitos específicos das causas naturais de mudanças da composição da atmosfera, tal como a radioatividade, que não está presente nas atividades vulcânicas nem quando os cometas ou asteroides atingem a Terra. A vulnerabilidade humana frente à ameaça de uma guerra nuclear seria muito maior em relação a efeitos indiretos - incluindo danos nas atividades agrícolas, transporte, energia, medicina, política e de infraestrutura social - especialmente devido aos efeitos adversos na produtividade e disponibilidade de alimentos, do que em relação aos efeitos diretos da guerra nuclear em si.

A compreensão sobre as consequências climáticas e os efeitos indiretos do colapso da sociedade, que seria tão grave que o inverno nuclear resultante produziria fome para milhões de pessoas, pode ter sido fator importante no fim da corrida armamentista entre os Estados Unidos e a União Soviética (URSS). Os presidentes das nações envolvidas, Ronald Reagan (EUA) e Mikhail Gorbachev (URSS), reconheceram o dano ambiental potencial relativo ao uso de armas nucleares e assinaram tratados para redução da quantidade de ogivas nucleares, que teve seu pico em 1986 e está em um declínio que continua até hoje. Entretanto, apesar da redução significativa nos arsenais nucleares americanos e russos, cada país ainda mantém armas suficientes para produzir um inverno nuclear (Robock et al. 2007, Toon et al. 2008).

\subsection{Variações dos Oceanos e Magnetismo}

Além das três principais causas naturais de mudanças climáticas - variações solares, variações orbitais e variações na composição da atmosfera causadas por atividades vulcânicas e impactos de asteroides ou cometas - existem outras causas naturais que afetam o clima em diferentes escalas têmporo-espaciais. Destacam-se as oscilações oceânicas, a circulação termo-halina, o magnetismo terrestre e os superciclos (tectonismo, vulcanismo e raios cósmicos).

\subsubsection{Oscilações Oceânicas}

Somente nos últimos anos os cientistas estão começando a reconhecer a influência dos ciclos oceânico-atmosféricos no clima ${ }^{39}$. Compo \& Sardeshmukh (2009) alegam que o recente aquecimento da Terra ocorreu em grande parte em resposta a um aquecimento dos oceanos no mundo todo, e não como uma resposta direta à crescente emissão antropogênica de gases de efeito estufa. A importância dos oceanos na variabilidade climática é facilmente reconhecida pelos seguintes dados: os oceanos cobrem cerca de $71 \%$ da superfície terrestre; os oceanos possuem 1.000 vezes mais massa $\left(1,3 \cdot 10^{21} \mathrm{~kg}\right)$ do que toda a atmosfera $\left(5 \cdot 10^{18} \mathrm{~kg}\right)$; a capacidade térmica dos oceanos é 1.000 vezes maior do que a da atmosfera; e, por fim, os oceanos absorveram, desde 1960, 20 vezes mais calor do que a atmosfera (Bindoff et al. 2007). Resumindo, os oceanos são os maiores reservatórios de calor na Terra. Entre os oceanos e a atmosfera, a troca de calor impulsiona os ventos e a circulação atmosférica em todo o mundo. Os ventos, por sua vez, geram as correntes oceânicas superficiais e a circulação termo-halina. Assim, a imensa quantidade de calor dos oceanos e a estreita relação com atmosfera corrobora o efeito extremamente importante dos oceanos sobre o clima global.

Representando a oscilação oceânica-atmosférica mais conhecida, o El Niño - Oscilação Sul (ENOS) é a flutuação climática mais forte na Terra em escalas de tempo interanuais, representando impactos globais, embora seja originário no Oceano Pacífico tropical. As componentes oceânicas do ENOS, El Niño ${ }^{40}$ e a La Niña $a^{41}$, representam

38 Retratado no filme 0 Dia Seguinte (do Inglês: The Day After), de 1983.

39 Flutuações periódicas de 35 anos nas interações oceano-atmosfera no Atlântico Norte ou originadas nas marés, relacionadas ao período de periastro lunar, são prováveis causas de características observadas em estudos de anéis de árvores e em certos sedimentos laminados. Objeto de investigação nos Países Baixos ainda no início do século 17, 0 ciclo de 35 anos ganhou notoriedade com os estudos de mudanças nos níveis do mar Cáspio conduzidos pelo Professor alemão Eduard Brückner, motivo pelo qual a periodicidade é ora conhecida como Ciclos de Brückner (Oliveira et al. 2015).

400 nome derivado do Espanhol, El Niño ("o menino"), refere-se ao menino Jesus, já que o fenômeno é geralmente observado durante a época do Natal no Oceano Pacífico, ao longo da costa oeste da América do Sul. Os pescadores nessa regiäo observaram que, normalmente no fim do ano, a baixa quantidade de peixes estava associada à ocorrência de temperaturas do mar mais altas do que o normal. 0 extenso aquecimento dos oceanos e a redução dos ventos alísios de leste limitam a ressurgência de águas frias profundas, ricas em nutrientes, impactando negativamente na pesca local.

41 La Niña ("a menina", do Espanhol) representa a fase fria, oposta ao El Niño, no âmbito do fenômeno ENOS. 
as variações quasi-periódicas (de 2 a 7 anos) da temperatura das águas superficiais do Pacífico tropical oriental. A componente atmosférica, Oscilação Sul, reflete as flutuações mensais ou sazonais na diferença de pressão de ar no Pacífico ocidental. As duas variações estão acopladas: a fase oceânica quente (El Niño) acompanha a alta pressão superficial do ar, enquanto a fase fria (La Niña) acompanha a baixa pressão superficial do ar.

Estudo de Mclean et al. (2009) relata que o ENOS pode ser um dos principais condutores de anomalias de temperatura, não só nos trópicos, mas representando também uma influência dominante e consistente na escala global. Os autores afirmam que o forçamento do clima associado ao ENOS contribui majoritariamente para a variabilidade $\mathrm{e}$ tendências recentes e, talvez, contribua inclusive na temperatura global, fato nem sempre considerado nos modelos climáticos globais atuais. Molion (2006) aponta que as temperaturas médias globais, obtidas por meio de satélites desde 1979, aumentaram quando da ocorrência de eventos El Niño e diminuíram quando da ocorrência de eventos $\mathrm{La}$ Niña. O autor afirma que o sistema Terra-atmosfera pode sofrer, naturalmente, uma variação de temperatura de cerca de $1,5^{\circ} \mathrm{C}$ entre fases fria e quente do ENOS (Fig. 17).

O Oceano Pacífico - o maior oceano da Terra, cobrindo quase $1 / 3$ da superfície global (31\%) - possui, além do ENOS, a Oscilação Decadal do Pacífico (ODP) ${ }^{42}$, um padrão periódico de mudança da temperatura superficial que afeta o hemisfério norte na região de latitude $20^{\circ} \mathrm{N}$. Com ciclos multidecadais, a ODP atravessa uma fase quente e uma fria geralmente a cada 50-70 anos (Fig. 18). Uma amplificação do ENOS combinada com forçamentos atmosféricos estocásticos é a hipótese predominante sobre a causa da ODP (Newman et al. 2003).

Com quasi-ciclo de 50 a 90 anos (Fig. 19), a Oscilação Multidecadal do

42 A ODP foi nomeada por Steven R. Hare, que a percebeu enquanto pesquisava, em 1997, as relacões entre os ciclos de producão do salmão no Alasca e o clima do Pać́fico (Mantua et al. 1997).

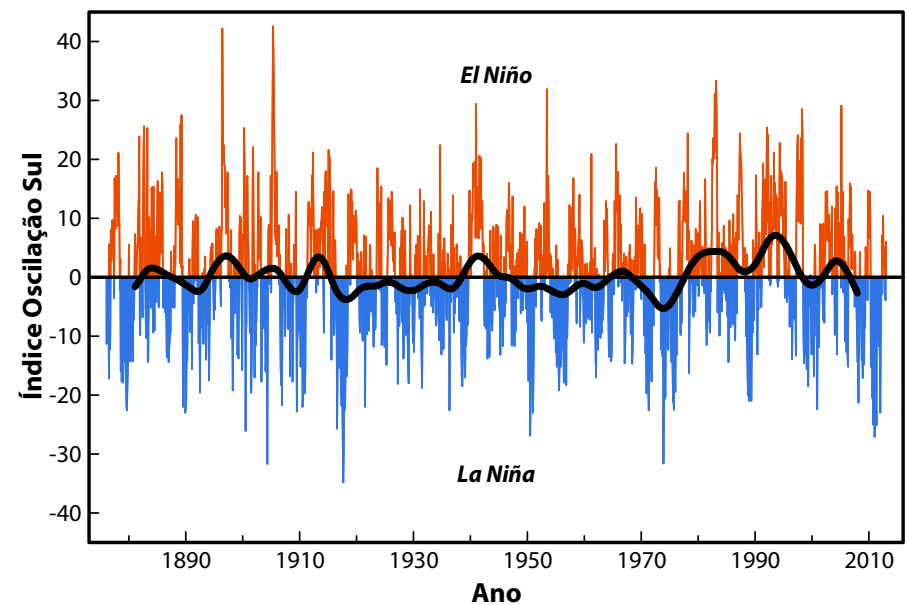

Figura 17. Índice Oscilação Sul. Valores anuais (de 1876 a 2013) indicando períodos de El Niño (vermelho) e La Niña (azul). Curva preta: média móvel de 12 meses. Fonte: modificado de Giorgio (2013a).

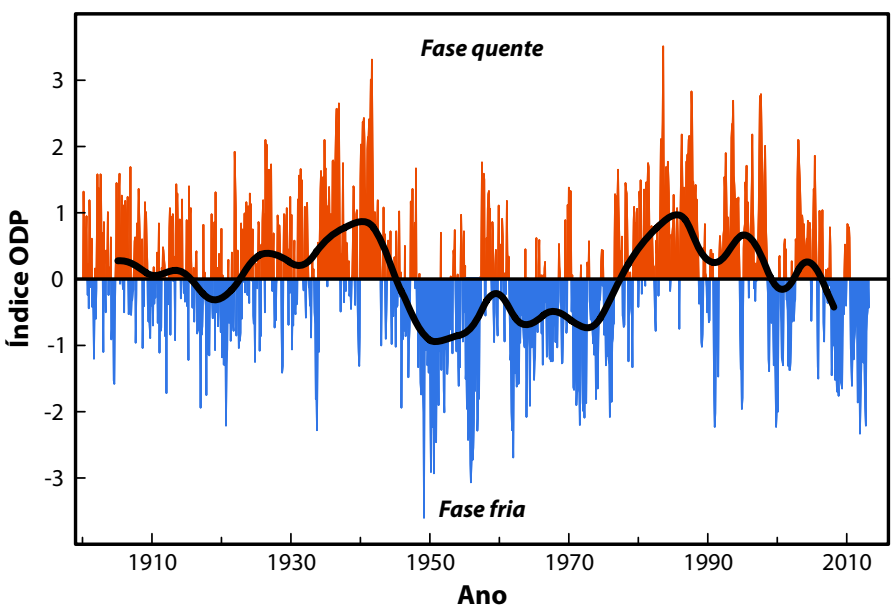

Figura 18. Índice Oscilação Decadal do Pacífico. Valores anuais (de 1900 a 2013) indicando as fases quente (vermelho) e fria (azul). Curva preta: média móvel de 12 meses. Fonte: modificado de Giorgio (2013b).

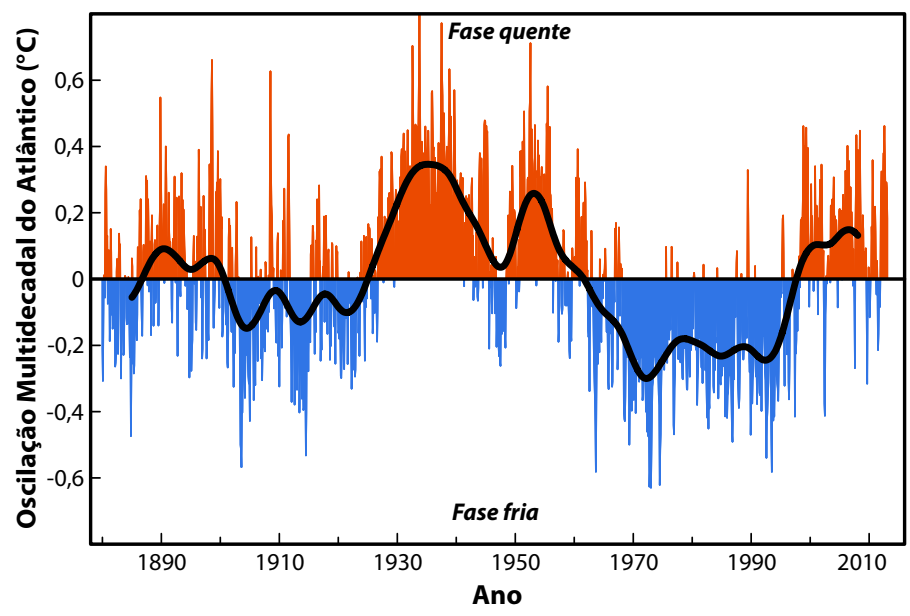

Figura 19. Oscilação Multidecadal do Atlântico. Valores anuais (de 1880 a 2013) indicando as fases quente (vermelho) e fria (azul). Curva preta: média móvel de 12 meses. Fonte: modificado de Giorgio (2013c).

ISSN 1679-2300 
Atlântico (OMA) é um modo ${ }^{43}$ de variabilidade natural no Oceano Atlântico Norte que representa uma influência dominante na temperatura do ar e precipitação sobre grande parte do hemisfério norte, em particular, na América do Norte e Europa. A OMA é acompanhada pela Oscilação do Atlântico Norte $(O A N)$, um modo de variabilidade multidecadal da pressão ao nível do mar. Exibindo padrões de temperatura da superfície do mar semelhante à OMA, a Oscilação Interdecadal do Pacífico (OIP), com um ciclo variando entre 15 e 30 anos, afeta tanto o norte quanto o sul do Pacífico.

A Oscilação Madden-Julian (OMJ), também conhecida como a oscilação ou onda de 30-60 dias, é o maior elemento da variabilidade intrasazonal que afeta toda a troposfera tropical, porém com maior evidência nos Oceanos Índico e Pacífico ocidental. Basicamente, a OMJ consiste na propagação de uma onda atmosférica na direção zonal (sentido leste) ao longo do globo terrestre e em torno do equador. Com padrões de larga escala e acoplamento entre circulação atmosférica e convecção profunda, a OMJ envolve variações no vento, temperatura da superfície do mar, nebulosidade e, principalmente, na precipitação (Zhang 2005).

Além dos já mencionados, cabe citar que existem outros modos de variabilidade climática:

- Oscilação Quasi-Bienal (OQB): oscilação nos campos do vento zonal e temperatura da estratosfera tropical, com período de 27 a 28 meses.

- Padrão Pacífico/América do Norte: teleconexão que relaciona um padrão de circulação atmosférica sobre o Oceano Pacífico Norte com um padrão de circulação atmosférica no continente norte-americano.

- Modo Anular do Norte (MAN) e o Modo Anular do Sul (MAS) - novas denominações, respectivamente, da Oscilação do Ártico $(\mathrm{OA})$ e da Oscilação da Antártida $(\mathrm{O} A A)$ : estão associados a padrões de pressão atmosférica nas latitudes polares e médias. Nessas regiões, um cinturão de ventos (ou sistemas de baixa pressão) se move para o norte ou para o sul, conforme o modo de variabilidade.

- Modo Equatorial do Atlântico (MEA) ou "El Niño do Atlântico": padrão climático que ocorre na direção zonal (leste-oeste), em escalas de tempo interanuais, no Oceano Atlântico equatorial. Esse modo quasi-periódico resulta na alternância entre aquecimento/resfriamento da superfície do mar, acompanhado por mudanças na circulação atmosférica.

- Dipolo do Atlântico Tropical (DAT): refere-se a um padrão norte-sul da temperatura de superfície do mar com predominância em escalas de tempo de décadas, com um período em torno de 12 anos.

- Dipolo do Oceano Índico (DOI), também conhecido como o "El Niño Indiano": oscilação irregular das temperaturas da superfície do mar no Oceano Índico Ocidental acompanhada por anomalias nos ventos e na precipitação. A componente atmosférica do modo DOI é denominada Oscilação do Oceano Índico Equatorial (OOIE).

Cada oscilação possui forças diferentes de acoplamento entre atmosfera e oceano, assim como elas diferem na intensidade de mudança dos padrões climáticos e no nível de influência das características climáticas locais, regionais e até mesmo globais. Os mecanismos causadores das oscilações ainda permanecem incertos e desconhecidos. Embora as oscilações climáticas sejam induzidas por dinâmicas oceânicas internas ainda pouco compreendidas, os principais modos de variabilidade climática, como o ENOS, a ODP e a OMA, podem ser induzidos, segundo Scafetta (2010, 2012), por forçamentos periódicos extraterrestres complexos que agem sobre o clima por meio de mecanismos de amplificação e de retroalimentação.

Os planetas do Sistema Solar influenciam o clima da Terra por meio da modulação dos parâmetros orbitais do sistema Terra-Lua e da Terra. Tais parâmetros podem modular o momento angular da Terra por meio de marés gravitacionais e forças magnéticas. Assim, as oscilações orbitais são amplificadas pelo sistema climático devido à sincronização dos osciladores naturais. Essa interpretação de Scafetta (2010) é apoiada nos registros de temperatura que contêm um ciclo nítido de 9,1 anos relacionado a ciclos de marés lunares de longo prazo. Analogamente, outras oscilações atmosférico-oceânicas seriam provavelmente impulsionadas por oscilações astronômicas.

43 A variabilidade natural do sistema climático, particularmente em escalas de tempo sazonais até decadais, ocorre predominantemente com padrões espaciais e temporais preferenciais, por meio das características dinâmicas da circulação atmosférica e das interações com as superfícies terrestres e oceânicas. Tais padrões, frequentemente chamados de modos, regimes, teleconexões ou dipolos, são comumente utilizados na descriç̃o das diferentes oscilaç̃es atmosféricas-ocenânicas sazonais, multianuais e multidecadais. Um modo de variabilidade climática é, em outras palavras, um padrão de clima com características identificáveis, efeitos regionais ou globais específicos e com comportamento geralmente oscilatório, que remete ao uso do termo modo oscilatório. Um modo pode ser também entendido como uma tendência de o sistema climático variar de uma maneira particular, geralmente uma oscilação entre dois estados preferenciais (fases ou dipolos), ao invés de uma mudança permanente. 


\subsubsection{Influência da Lua}

Além das marés oceânicas, percebidas pelas repetitivas alterações no nível das águas dos oceanos, a combinação de forças gravitacionais exercidas pela Lua e pelo Sol (este com menor influência) no campo gravitacional da Terra também ocasiona, em escala global na atmosfera, oscilações periódicas conhecidas como marés atmosféricas.

A Lua pode alterar o clima ao parcialmente modular as correntes do oceano (modificando a intensidade do processo de ressurgência dentro dos oceanos) e também pode alterar os padrões de pressão do ar por meio de forças gravitacionais. Scafetta (2010) sugere uma possível influência da Lua sobre o clima na Terra ao apresentar que diversos registros de temperatura mostraram um ciclo de aproximadamente 9,1 anos, periodicidade que é quase a metade do ciclo de $\operatorname{Saros}^{44}$ (18,1 anos) ou do ciclo nodal lunar ${ }^{45}$ (18,6 anos), também conhecido como Oscilação Lunissolar ou ciclo Draconiano ${ }^{46}$.

Conduzidas pelos ciclos de Saros e Draconiano, as marés atmosféricas lunares de longo prazo podem indiretamente propiciar condições para a ocorrência de eventos de El Niño/La Niña que aquecem/resfriam a Terra. As condições favoráveis para o surgimento desses dois eventos ocorrem pela ação das marés lunares na transição dos padrões da pressão atmosférica e da dinâmica dos ventos alíseos no Oceano Pacífico. Assim, mudanças na frequência relativa dos eventos El Niño/La Niña podem ser responsáveis por grande parte das mudanças observadas na temperatura média terrestre durante o século 20 (Wilson 2013).

McKinnell \& Crawford (2007) notaram que existe uma forte relação entre períodos de baixa declinação lunar com ocorrência de alguns fortes eventos de El Niño em 1940/41, 1957/58 e 1997/98. Em 2007, os autores já alertavam que a ocorrência de um El Niño intenso em 2015 despertaria a atenção para esta, até então, "coincidência”. De fato, o ano de 2015 apresentara um dos maiores eventos de El Niño já registrados. Cerveny \& Shaffer (2001) e Molion (2017) reportaram uma correlação estatística entre uma modulação lunar nodal e o ENOS, confirmando que grandes eventos de El Niño ocorreram em anos de declinação lunar mínima. É amplamente aceito que o ciclo nodal altera as misturas das marés, a circulação oceânica e o transporte de calor de grande escala no Oceano Pacífico Norte. Com as marés enfraquecidas, a redução da advecção de água fria favorece condições mais quentes da superfície do mar, característica típica do El Niño (Yasuda \& Osafune 2006).

Keeling \& Whorf (1997) propuseram que marés extremas podem produzir mudanças cíclicas na temperatura superficial dos oceanos. As alterações, com período de aproximadamente 90 anos, refletem leves graus de desalinhamento nas ocasiões de maior aproximação da Terra com a Lua e o Sol, momentos de extremas forças de maré. A dissipação da energia das marés extremas aumenta a mistura vertical da água do mar, favorecendo o arrefecimento episódico na superfície oceânica.

Causadas por ressonâncias nos movimentos periódicos da Terra e da Lua, as variações quasi-periódicas na força das marés oceânicas globais também podem estar associadas, na escala de tempo milenar, a um ciclo de marés com período bastante definido de 1.800 anos. Este ciclo pode ser reconhecido como a principal condicionante de mudanças mais proeminentes e extensas no clima durante o Holoceno: a Pequena Idade do Gelo, por exemplo. pode ser interpretada como apenas um episódio de resfriamento em uma série de tais ciclos. Assim, a previsão de "aquecimento global pronunciado" nas próximas décadas seria reinterpretada como a continuação de um aquecimento natural gradual que vem ocorrendo desde o fim da pequena Idade do Gelo (Keeling \& Whorf 2000).

44 Um ciclo de Saros corresponde a um período de 6.585,3 dias (ou 18 anos e 11 dias), que pode ser usado para prever os eclipses do Sol e da Lua.

450 ciclo nodal é a variação da declinação do plano da órbita da Lua com relação ao equador terrestre, que varia de $18,4^{\circ}$ a $28,6^{\circ}$ de latitude a cada 18,6 anos (período da precessão dos nodos orbitais da Lua). A Lua passa cerca de 10 anos fora dos trópicos e 8,6 anos dentro dos trópicos. Quando está fora dos trópicos, seu percurso em 28 dias é mais "meridional" (norte-sul), acelerando as correntes marinhas que transportam mais calor para fora dos trópicos, aquecendo 0 Oceano Atlântico Norte. Quando está dentro dos trópicos, o mesmo percurso de 28 dias é mais "zonal", distribuindo o calor na direção leste-0este e exportando menos calor para fora dos trópicos, logo, acumulando o calor na região equatorial. Nessa situação, existe grande chance de disparar um evento El Niño iniciando no Pacífico Leste: a força gravitacional da Lua, juntamente com os ventos alísios, seria responsável por empurrar e empilhar, inicialmente, as águas no Oceano Pacífico Ocidental, criando as condições oceânicas propícias ("gatilho") que antecedem um evento El Niño forte. Dessa forma, a Lua pode interferir no clima global/regional indiretamente por meio de sua ação gravitacional ao modificar, em primeiro lugar, a velocidade das correntes marinhas e 0 transporte de calor meridional nos oceanos e, na sequência, mudar a configuração da temperatura da superfície do mar, particularmente nos setores norte dos 0ceanos Atlântico e Pacífico, que têm suas bacias fechadas. (Molion 2015, Siqueira \& Molion 2015, Molion 2017).

46 A órbita da Lua se encontra em um plano com uma inclinação de cerca de cinco graus em relação ao plano da eclíptica. 0 ciclo Draconiano (ou Dracônico) está relacionado com os caminhos da Lua e do Sol. Os dois pontos onde o caminho da Lua cruza o caminho aparente do Sol, na eclíptica, são chamados de nodos orbitais da Lua. A eclíptica deve seu nome ao fato de que um eclipse do Sol ou da Lua só pode acontecer quando a Lua está nesses nodos, ficando o Sol, a Terra e a Lua alinhados. 0 termo Dracônico/Draconiano refere-se um dragão mitológico que supostamente vivia nos nodos e regularmente "comia" o Sol ou a Lua durante um eclipse. A força gravitacional da Lua sobre a Terra causa uma pequena oscilação periódica do eixo de rotação terrestre, com o mesmo ciclo de 18,6 anos, fenômeno conhecido na Astronomia como nutação, do latim nutatione (balanço). 


\subsubsection{Circulação Termo-halina}

A circulação termo-halina é um componente-chave do sistema climático. Conduzido pelos diferentes gradientes de densidade criados pelo calor da superfície e pelos fluxos de água doce, o mecanismo das correntes oceânicas transporta grandes quantidades de calor e sal a partir do equador em direção aos polos. Uma mudança na força da circulação termo-halina pode levar a grandes mudanças climáticas regionais e globais. Um hipotético colapso no transporte de calor poderia provocar um deslocamento para o sul da Zona de Convergência Intertropical, além de desencadear um evento de El Niño (Laurian et al. 2010).

De acordo com Wood et al. (2003), uma interrupção da circulação pode ser grave, implicando o resfriamento do Hemisfério Norte, sendo que em algumas regiões a magnitude poderia ser maior do que as mudanças esperadas pelo aquecimento global nos próximos 50 anos. Estudo de Bryden et al. (2005) relata que a circulação diminuiu substancialmente na metade do século passado, em cerca de $30 \%$. Tal fato poderia implicar a redução de $4^{\circ} \mathrm{C}$ da temperatura média na Europa, provocando uma pequena era do gelo ${ }^{47}$.

Trabalho de Willis (2010) indica que a circulação termo-halina não tem mais sofrido desaceleração significativa nos últimos 15 anos; ao contrário, é sugerido que a circulação pode mesmo ter acelerado cerca de $20 \%$ no passado recente. Segundo NASA (2010), as mudanças verificadas são, provavelmente, parte de um ciclo natural, coincidindo com um padrão natural decadal de aquecimento e resfriamento do Atlântico.

\subsubsection{Magnetismo Terrestre e Inversões Magnéticas}

O magnetismo terrestre e sua influência no clima é um tema de pesquisas recentes. A correlação entre geomagnetismo e o clima pode estar associado ao campo magnético terrestre, cujas variações estão ligadas a correntes externas na ionosfera e magnetosfera induzidas pelos ventos solares e pela radiação eletromagnética. Portanto, a evolução da tendência magnética possui alta correlação com a evolução da radiação solar. As variações entre a temperatura média e variações no campo geomagnético são tentadoras. Todavia, essa correlação aparente não é por si só suficiente para demonstrar uma conexão de causa e efeito (Courtillot et al. 2007).

Os deslocamentos dos polos magnéticos nos últimos 105 anos demonstraram forte correlação com variações na temperatura, sugerindo uma conexão potencial entre esses dois fenômenos. $\mathrm{O}$ movimento dos polos magnéticos afeta o formato do campo geomagnético e, consequentemente, altera os padrões de proteção da Terra contra raios cósmicos galácticos e solares. Assim, os deslocamentos afetam a distribuição e dispersão de raios cósmicos em áreas mais sensíveis da atmosfera (Kerton 2009).

Inversões magnéticas, em escalas de tempo geológico, podem estar associadas às glaciações. Porém, não é sugerido que todas as inversões magnéticas estejam relacionadas a mudanças no clima. Forças astronômicas, como o impacto de asteroides na Terra, podem ser supostamente os precursores das inversões, as quais dependem de um súbito resfriamento no clima causado pelo impacto (Worm 1997). Existem hipóteses polêmicas de que o resfriamento global provocaria o aumento do volume do gelo nas calotas polares, que seria responsável pela redução do momento de inércia terrestre e, assim, causaria o aumento da velocidade rotacional, que, por sua vez, induziria ao cisalhamento do núcleo terrestre. Assim, o efeito induzido pela glaciação eventualmente deflagraria o rompimento da geração do campo magnético, todavia, tais mecanismos ainda não estão bem compreendidos e aceitos como hipótese válida (Schneider et al. 1992).

\subsection{Superciclos: Tectonismo, Vulcanismo e Raios Cósmicos}

$\mathrm{Na}$ escala temporal na ordem de dezenas a centenas de milhões de anos, existem superciclos de processos tectônicos e vulcânicos - impulsionados por mecanismos internos (processos do manto) ou externos (raios cósmicos) - que repercutem de maneira extraordinária no clima terrestre.

47 A interrupção fictícia da Corrente do Golfo inspirou o filme 0 dia depois de amanhã (do Inglês: The Day After Tomorrow) em 2004. Mas segundo Schiermeier (2005), as mudanças drásticas do clima retratadas no filme - em que Nova York é engolida por uma idade do gelo instantaneamente - são mera fantasia. Não está claro se existe uma relação do aquecimento global com a tendência de enfraquecimento da circulação termohalina. Possíveis distúrbios - tais como redemoinhos do oceano e flutuações naturais na força do sistema de circulação - devem ser considerados. Apesar das possíveis repercussões climáticas significativas, a chance de ocorrência de um colapso iminente do sistema de circulação é pequena. Schiermeier (2006) aponta que os resultados de Bryden et al. (2005) surpreenderam os cientistas da área, uma vez que tais resultados poderiam ser causados por variação natural ou "ruídos", ou seja, simples coincidência. Mesmo se os resultados estivessem corretos, o enfraquecimento da circulação termohalina não teria os efeitos drásticos de resfriamento que foram previstos para a Europa. Por fim, Schiermeier (2006) cita a seguinte frase de Wallace S. Broecker, um dos primeiros cientistas a notar efeito do transporte global do clima: "A noção de que um colapso da circulação termohalina pode desencadear uma pequena era do gelo é um mito". 


\subsubsection{Modos Climáticos do Fanerozoico}

Longe de ser estático, o clima na Terra, na escala geológica nos últimos 542 milhões de anos (éon Fanerozoico), variou consideravelmente: passou de fases extremamente frias de glaciações a períodos áridos de aquecimento global. Sumarizando tais variações, Frakes et al. (1992) identificaram períodos de tempo com padrões similares nas condições climáticas e propuseram os Modos Climáticos do Fanerozoico, dividindo os períodos da história climática entre Modos Quentes e Modos Frios. O Modo Frio é atribuído a épocas de resfriamento global em que predominava a ocorrência de grandes extensões de gelo; enquanto que o Modo Quente é atribuído a épocas em que o clima se apresentava quente, indicado pela abundância de dados geoquímicos de distribuições de fauna e pela presença de pouco ou nenhum gelo polar.

Informações paleoclimáticas da temperatura média terrestre e do nível médio do mar revelam que, ao longo dos últimos 600 milhões de anos, a história do clima não apresentou uma tendência simples de resfriamento e aquecimento, mas sim foi caracterizada pela alternância de períodos quentes e frios, conforme pode ser constatado na Fig. 20. Os Modos Quentes duraram entre $50 \mathrm{a}$ 100 milhões de anos; e os Modos Frios cerca de 40 a 80 milhões de anos. Análises de fatores que afetam o clima sugerem que processos tectônicos, particularmente aqueles relacionados às atividades vulcânicas, governam o início das fases quentes e frias do clima terrestre (Frakes et al. 1992).

\subsubsection{Modos Geladeira-Estufa}

Em modelo análogo, Fischer (1981) constatou que, nos últimos 700 milhões de anos, a Terra passou por três grandes episódios de glaciações, fases em que as calotas cobriam, além das regiões polares, regiões subtropicais. O autor definiu esses estados climáticos da Terra como Modo de Geladeira (Icehouse) e Modo de Estufa (Greenhouse). Nos períodos de resfriamento global, geleiras avançaram diversas vezes e cobriram extensas áreas continentais, caracterizando fenômenos globais conhecidos como glaciações. Como pode ser visto na Fig. 20, há relação direta entre as condições climáticas globais (em termos de temperatura média) e as variações eustáticas do nível dos oceanos. Nos Modos de Geladeira, parte da água disponível na superfície da Terra fica retida nos continentes sob a forma de gelo ou neve, causando queda global do nível do mar. Com a elevação da temperatura no planeta, as geleiras derretem e recuam, ocasionando o aumento no volume de água e a subida do nível dos oceanos (Assine \& Vesely 2008). As causas das mudanças no nível do mar e das temperaturas dos oceanos estão possivelmente associadas a fenômenos de movimentos de placas e vulcanismo (Fig. 21).

Como indicador de atividade vulcânica, a taxa de formação de corpos de granito serve como uma estimativa para o vulcanismo global. O comportamento do vulcanismo é mostrado na parte inferior da Fig. 21, juntamente com curvas eustáticas de Vail et al. (1977) que mostram as flutuações do nível do mar em relação aos continentes. Nos dois ciclos de aproximadamente 300 milhões de anos cada, as três grandes glaciações (indicadas como "mantos de gelo") ocorreram dentro de três fases de vales das curvas (Modos de Geladeira), enquanto os períodos sem glaciações correspondem às fases de crista (Modos de Estufa).

As razões das aparentes coincidências de diferentes ciclos de 300 milhões de anos não estão firmemente estabelecidas. Embora haja muita incerteza a respeito da maneira pela qual as placas litosféricas são conduzidas, a convecção

Figura 20. Variações estimadas do nível eustático do mar e da temperatura global durante o Fanerozoico, ilustrando os Modos Quentes e Frios. Fonte: modificado de Frakes et al. (1992). 
térmica do manto é geralmente considerada como a principal causa. Pela hipótese baseada nesse mecanismo interno, o tectonismo associado ao vulcanismo supostamente conduz o nível dos oceanos, a concentração de dióxido de carbono e finalmente o clima, por meio de mecanismos internos de retroalimentação. Em outra vertente formula-se a hipótese da influência externa de ciclos relacionados à rotação do Sistema Solar ao redor da Galáxia (Fischer 1982). Ambos os modelos concorrentes, que invocam
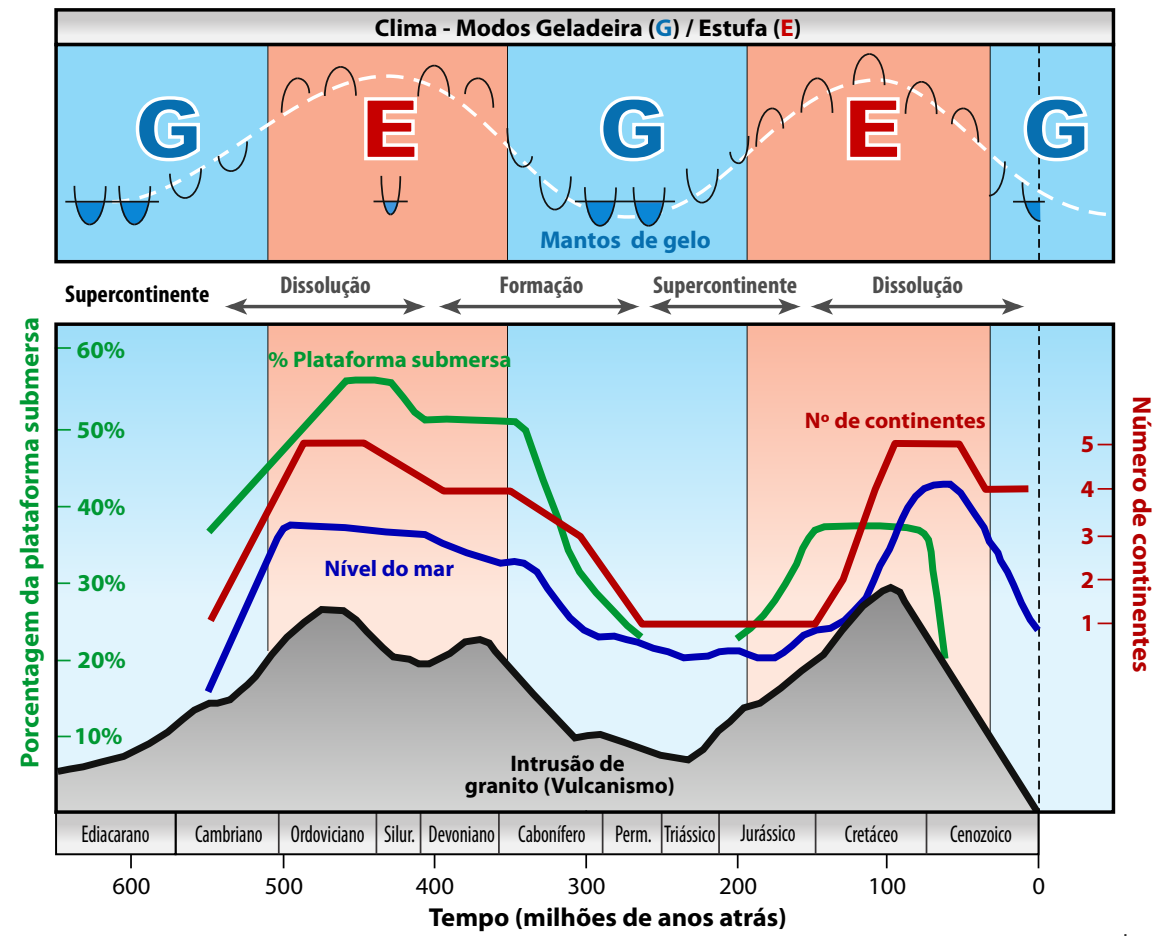

Figura 21. Alternância entre Modos de Geladeira (G) e Modos de Estufa (E) ao longo do Fanerozoico. Curva de variação do nível do mar segundo Vail et al. (1977); períodos de estufa/geladeira e porcentagem da plataforma submersa segundo Fischer (1981); intrusão de granitos, segundo Engel \& Engel (1964). Fonte: modificado de Nance et al. (2014).

alternadamente fatores endógenos e celestes, são revisados por Schlager (2005).

O ciclo de geladeira/estufa deixa dados importantes inexplicáveis. Existem oscilações com períodos de 130 a 150 milhões que podem estar relacionadas ao fluxo de raios cósmicos, os quais modulam o clima via cobertura de nuvens. Price et al. (2013) relatam que diversos estudos colocam em dúvida a ligação entre o dióxido de carbono e o clima, sugerindo que o fluxo de raios cósmicos galácticos seja a principal causa das mudanças climáticas durante o Fanerozoico. Com base em Schlager (2005), a Fig. 22 sintetiza os modelos propostos.

\subsubsection{Movimentação Tectônica}

Movimentações tectônicas, que ocorrem em escalas de tempo de milhões de anos, podem causar mudanças nos padrões da circulação atmosférica e da circulação oceânica (ver Faustinoni \& Carneiro 2015). As correntes oceânicas dependem da geometria dos oceanos e este é controlado pela tectônica de placas. Assim, o movimento das placas e continentes tem efeito profundo sobre a distribuição de massas de terra, serras e da conectividade dos oceanos. Como consequência, as placas tectônicas representam uma influência fundamental no clima global.

O movimento das placas tectônicas resulta na formação e separação de continentes e, em escalas geológicas, provoca a formação ocasional de um supercontinente contendo todos ou quase todos os continentes. Tais configurações constituem os ciclos de supercontinentes que, para completar um único ciclo, envolvem cerca de 300 a 500 milhões de anos (Hasui 2012).

No último 1 bilhão de anos, cinco grandes supercontinentes foram formados (Fig. 23): Kenorland (Superia e Sclavia) [2,6 bilhões de anos atrás (Ga.)], Columbia (ou Nuna ou Hudsonland) [1,8 a 1,6 Ga.], Rodínia [1.000 a 750 milhões anos atrás (Ma)], Pannotia e Gondwana (650-550 Ma) e Pangeia (450-250 Ma) (Condie 1998, Nance et al. 2014). A progressiva separação dos continentes que compunham Pangeia e Gondwana resultou na configuração atual. Ao longo da história da Terra, o constante movimento dos continentes e da formação episódica de supercontinentes tem influenciado tanto o clima global quanto os climas individuais dos continentes.

A presença de continentes e suas respectivas topografias afetam os climas de diversas maneiras: as temperaturas nas altitudes elevadas são menores do que nas altitudes baixas; cadeias de montanhas, ao desviar os ventos, forçam o ar a subir em regiões mais frias da atmosfera, provocando chuvas apenas 


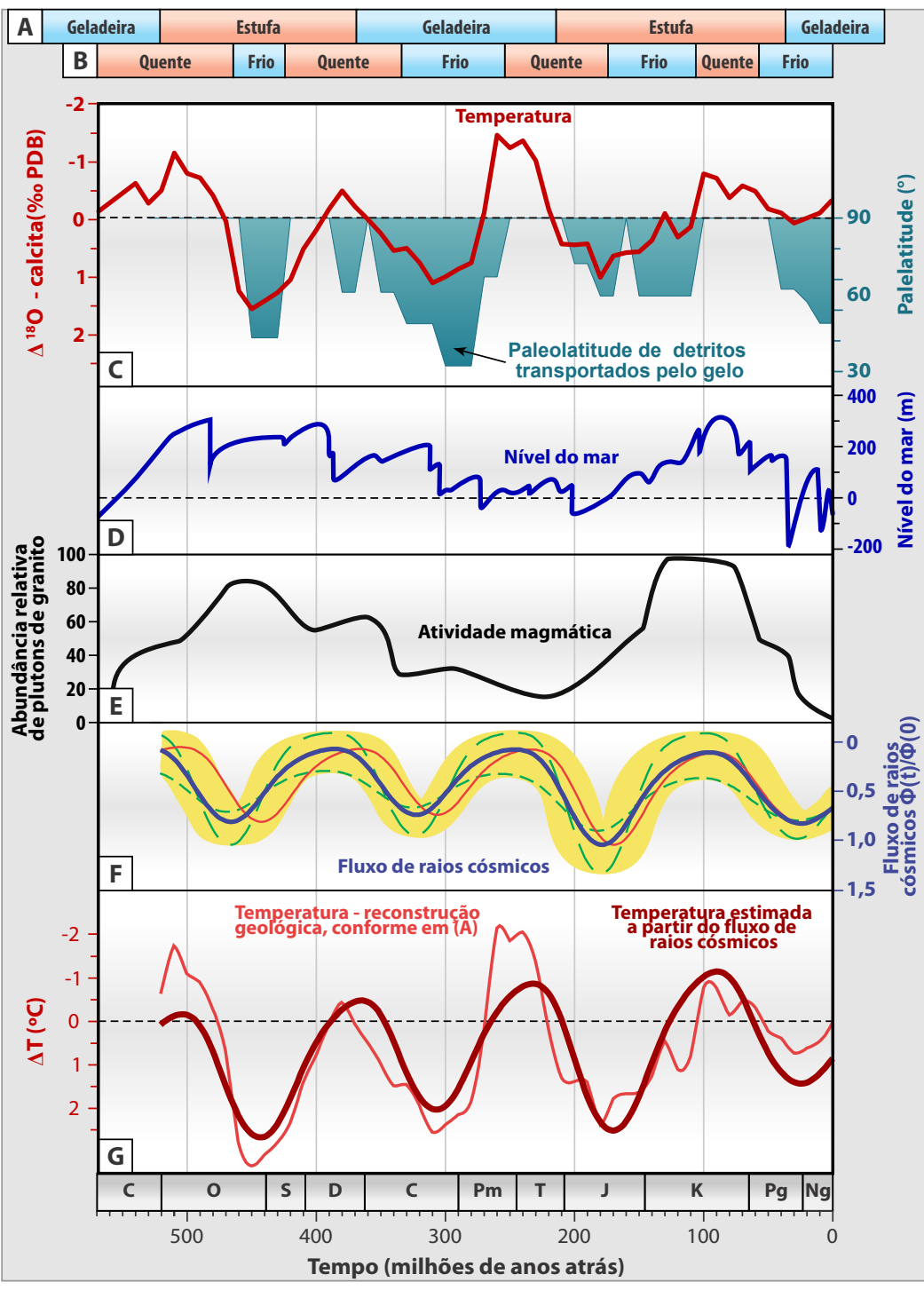

Figura 22. Oscilações durante o Fanerozoico. (A) Modos geladeira/estufa de Fischer (1981); (B) Modos quente/frio de Frakes et al. (1992); (C) Temperatura superficial do mar em baixa latitudes e registros de paleolatitude de detritos transportados pelo gelo, segundo Veizer et al. (2000); (D) Nível do mar segundo Vail et al. (1977); (E) Atividade magmática (vulcanismo) segundo Engel \& Engel (1964); (F) Fluxo de raios cósmicos, segundo Shaviv \& Veizer (2003); (G) Variação geológica da temperatura reconstruída e estimada, segundo Shaviv \& Veizer (2003). Fonte: modificado a partir de Shaviv \& Veizer (2003) e Schlager (2005). de um lado das montanhas (chuvas orográficas); os centros das grandes massas continentais geralmente têm elevações relativamente altas e, consequentemente, são regiões secas e frescas condição conhecida como continentalidade (Rogers \& Santosh 2004).

A subdivisão dos continentes geralmente induz à formação de novos oceanos ao longo de orogenias (formação de montanhas) mais velhas, levando a um processo cíclico de fechamento e reabertura dos oceanos ao longo de praticamente as mesmas zonas, além de consequente formação e dissolução de supercontinentes. A abertura e fechamento de bacias oceânicas (Fig. 24) constituem os ciclos de Wilson ${ }^{48}$ (Ryan \& Dewey 1997, Hasui 2012).

Os supercontinentes são epirogeneticamente elevados e, assim, correspondem a períodos de baixa do nível do mar. Com a fragmentação do supercontinente, os fragmentos continentais resultantes esfriam e desaparecem conforme eles se separam, logo, o nível do mar se eleva. Com a formação de novos oceanos, que não acomodam tanta água do mar quanto os oceanos mais velhos, o nível do mar

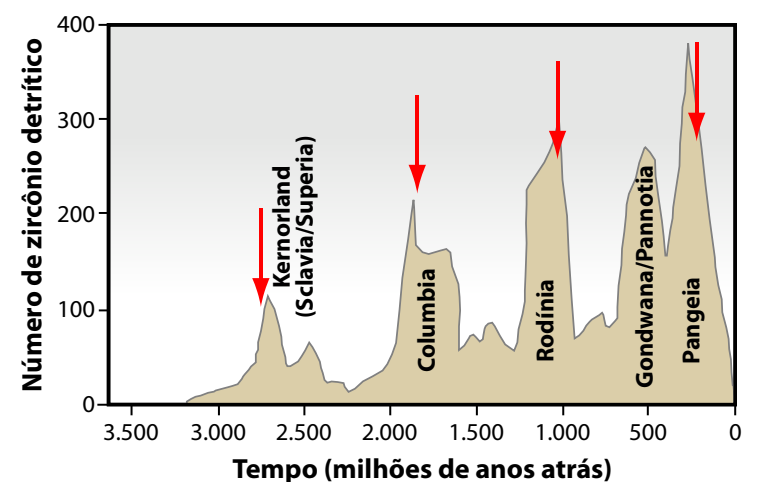
aumenta. Porém, conforme os oceanos ficam mais velhos e mais frios, eles tornam-se mais profundos, fazendo com que o nível do mar diminua até os oceanos começarem a fechar (Nance et al. 2014).

Figura 23. Ciclos dos supercontinentes. Os picos orogênicos (setas vermelhas) indicam as épocas de cristalização da crosta, marcando a formação dos supercontinentes. Fonte: modificado de Nance et al. (2014).

48 John Tuzo Wilson [1908-1993] foi um geofísico e geólogo canadense célebre por suas contribuições pioneiras para a teoria da Tectônica de Placas. 


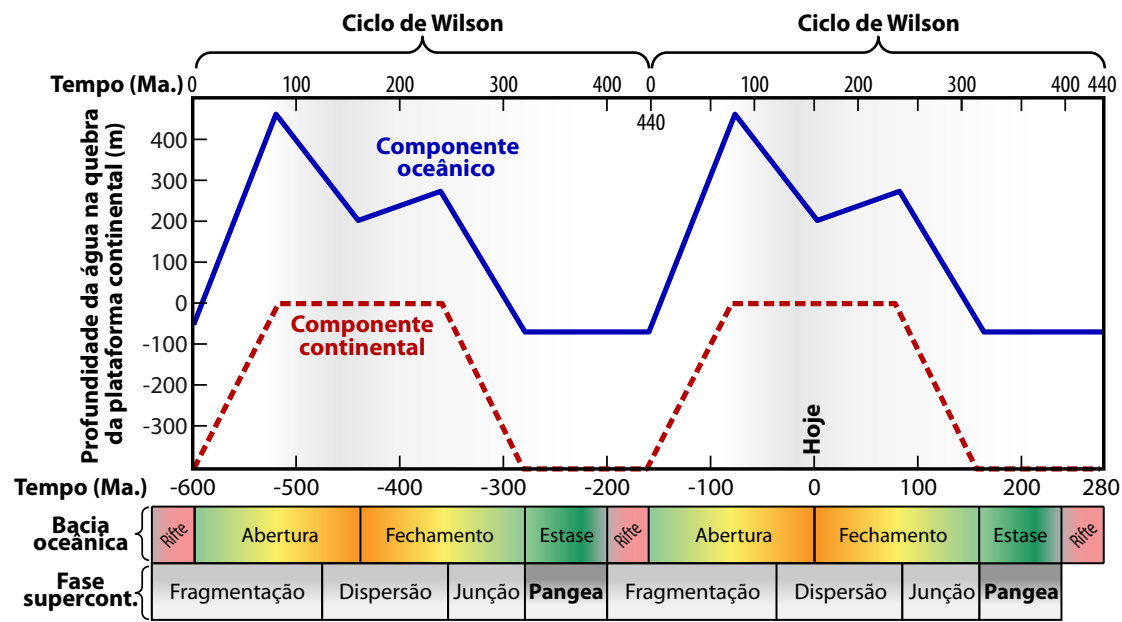

Figura 24. Ciclos de Wilson (bacias oceânicas) e os efeitos das fases dos ciclos dos supercontinentes no nível do mar. Legenda: Ma. = milhões de anos. Fonte: modificado de Miall (2010).

É geralmente aceito que os ciclos dos supercontinentes estão intimamente ligados a processos do manto, incluindo a convecção do manto, ressurgências do manto (superplumas) e plumas mantélicas. Um mecanismo potencial para a condução do ciclo de supercontinentes são as influências opostas do efeito de isolamento dos supercontinentes no fluxo de calor do manto e o efeito de resfriamento da idade sobre o dinamismo da litosfera oceânica. O primeiro conduz à eventual dissolução dos supercontinentes conforme o calor acumula-se abaixo deles, enquanto o segundo resulta na formação dos supercontinentes devido ao fechamento dos oceanos. A formação de um supercontinente cria uma manta térmica convectiva que inibe a liberação de calor interno da Terra. As mudanças na rotação do núcleo da Terra e nos padrões convectivos no manto podem ser tanto a causa quanto a consequência desses acontecimentos de superfície, que também parecem estar ligados a mudanças no campo magnético da Terra. Debaixo de um supercontinente, o desenvolvimento de uma manta térmica leva ao superaquecimento e elevação da crosta em escala continental, podendo ser a causa do eventual rompimento do supercontinente, seguido pelo estabelecimento de um novo padrão de convecção do manto (Miall 2010, Condie 2011, Nance \& Murphy 2013).
Embora a convecção térmica no manto da Terra tenha se tornado um mecanismo popular, como outra provável explicação para os ciclos dos supercontinentes, cabe resgatar os resultados do importante trabalho de Steiner (1967), que comparou qualitativamente a gravidade variável na Terra com diversos fenômenos geológicos, incluindo dados de orogênese, paleoclimáticos, biológicos, entre outros. Machado (1967) propõe que, conforme o Sistema Solar realiza sua órbita ao redor do centro da Via Láctea, a "constante" gravitacional na verdade sofre alterações, provocando a contração e expansão da Terra e do Sol. No caso do Sol, a mudança em seu raio resulta em variações da radiação emitida. No caso da Terra, a expansão/ contração pode produzir a regressão dos oceanos e a fratura da crosta (com aparente migração dos continentes). Desse modo, o modelo galáctico proposto por Steiner (1967) oferece uma solução promissora para o problema da energia envolvida na geotectônica de placas ao apresentar uma visão que reconcilia hipóteses geotectônicas aparentemente contraditórias e, além disso, provavelmente fornece a chave para as evidências sobre os ciclos dos supercontinentes.

\subsubsection{Raios Cósmicos}

A influência de raios cósmicos ${ }^{49}$ no clima terrestre tem sido verificada por vertente de estudos que relacionam a Climatologia com a Astronomia. A Cosmoclimatologia, termo cunhado por Svensmark (2007), sugere que a intensidade incidente de raios cósmicos na atmosfera terrestre correlaciona-se estreitamente com variações de cobertura global de

49 Constatados em 1912 pelo físico austríaco-norte-americano Victor Francis Hess [1883-1964] - ganhador do Prêmio Nobel de Física em 1936 pela descoberta -, os raios cósmicos são partículas carregadas com alta energia originárias do espaco, que viajam quase à velocidade de luz e atingem a Terra a partir de todas as direções. A maioria dos raios cósmicos são núcleos de átomos, mas também incluem elétrons de alta energia, pósitrons e outras partículas subatômicas. 0 termo "raios cósmicos" geralmente se refere a raios cósmicos galácticos, que se originam em fontes fora do Sistema Solar distribuídas por toda a Via Láctea. No entanto, esse termo também inclui núcleos e elétrons acelerados em associação com eventos energéticos no Sol (chamados de partículas energéticas solares). Durante algum tempo, acreditou-se que a radiação era de natureza eletromagnética (motivo do nome de "raios" cósmicos), e alguns livros didáticos ainda incluem incorretamente os raios cósmicos como parte do espectro eletromagnético. Entretanto, durante a década de 1930, verificou-se que os raios cósmicos devem ser eletricamente carregados, pois eles são afetados pelo campo magnético da Terra. A maior parte dos raios cósmicos galácticos é gerada a partir de explosões de supernovas, que ocorrem aproximadamente uma vez a cada 50 anos em nossa galáxia (Mewaldt 1996). 
nuvens. As nuvens refletem/absorvem a entrada e a saída de radiação e, portanto, desempenham um papel importante no balanço de radiação da Terra. Em escalas longas do tempo, esses megaciclos cósmicos apresentam uma correlação entre as variações
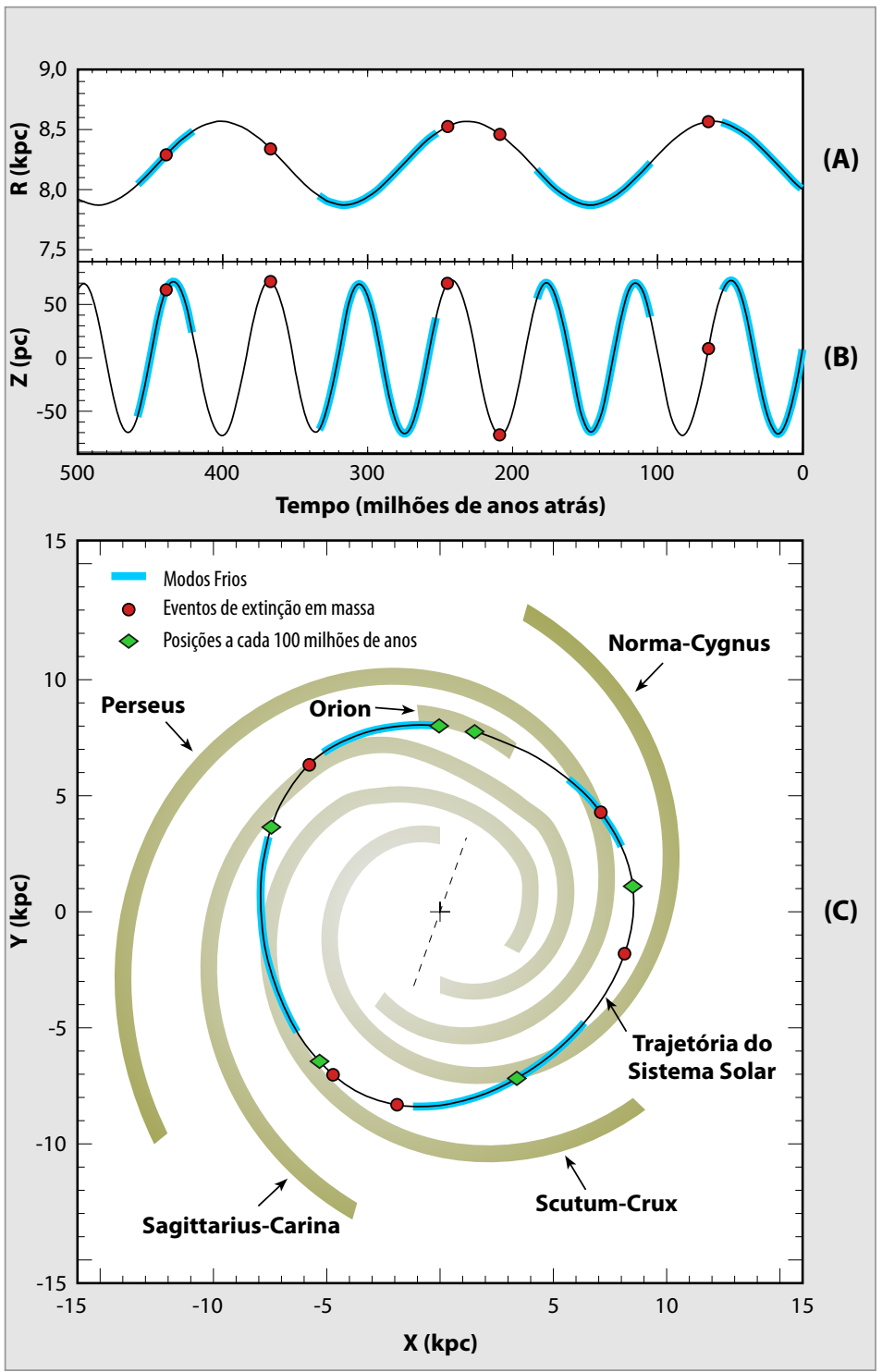

Figura 25. Posições e oscilações do Sistema Solar na Galáxia, ao longo dos últimos 500 milhões de anos. (A) Oscilação radial, sendo $R$ a distância entre o Sol e o centro da Galáxia; (B) Oscilação vertical, sendo Z a distância do Sol até o plano galáctico; (C) Representação esquemática da estrutura espiral da Via Láctea (vista por cima do plano) e da trajetória do Sistema Solar. Linhas grossas azuis: modos frios de Frakes et al. (1992); Círculos vermelhos: eventos de extinções em massa; Losangos verdes: posições a cada 100 milhões de anos. Legenda: pc $=$ parsec (unidade de distância usada na astronomia para representar distâncias estelares). Fonte: modificado de Gies \& Helsel (2005).
(A)

na fonte de raios cósmicos causadas pela passagem do Sistema Solar através dos braços espirais da Via Láctea ${ }^{50}$, e as variações no clima da Terra no último 1 bilhão de anos. Durante algumas passagens pelos braços espirais (Fig. 25), a Terra pode ter encontrado nuvens interestelares com densidade suficiente para alterar a química da atmosfera superior e desencadear eras glaciais de durações relativamente longas (Gies \& Helsel 2005).

A Fig. 26 ilustra uma possível correlação que permite inferir que os Modos Quente/Frio (ou Geladeira/Estufa) durante o Fanerozoico podem estar associados à influência dos raios cósmicos. Scafetta (2010) assinala que as oscilações do campo magnético do Sistema Solar induzido pelo movimento dos planetas (em especial de Júpiter e Saturno) podem influenciar o plasma solar e o vento solar. O vento solar modula a ionosfera terrestre, que influencia o circuito elétrico atmosférico global. O último afeta a formação de nuvens e, portanto, o clima global. Os efeitos observados em diferentes escalas e os mecanismos físico-químicos envolvidos na relação da formação de nuvens com os raios cósmicos podem ser consultados na revisão detalhada realizada por Kirkby (2007).

Shaviv et al. (2014) indicam que o movimento galáctico deixou marcas nos registros do clima terrestre nos últimos 488 milhões de anos atrás. Eles sugerem como possibilidades de explicação: a posição do sistema solar poderia influenciar a frequência de impactos de grandes corpos na Terra; a colisão com nuvens de poeira interestelar; a radiação recebida de raios cósmicos; a presença de um disco galáctico

50 Para completar um ciclo orbital ao redor do centro da Via Láctea, o Sistema Solar gasta cerca de 225 a 250 milhões anos terrestres, período conhecido como ano galáctico ou ano cósmico. Durante o movimento de revolução na galáxia, o Sistema Solar também realiza movimentos oscilatórios perpendiculares ao plano equatorial da galáxia. 0 comprimento desse período é cerca de 64 milhões de anos. 


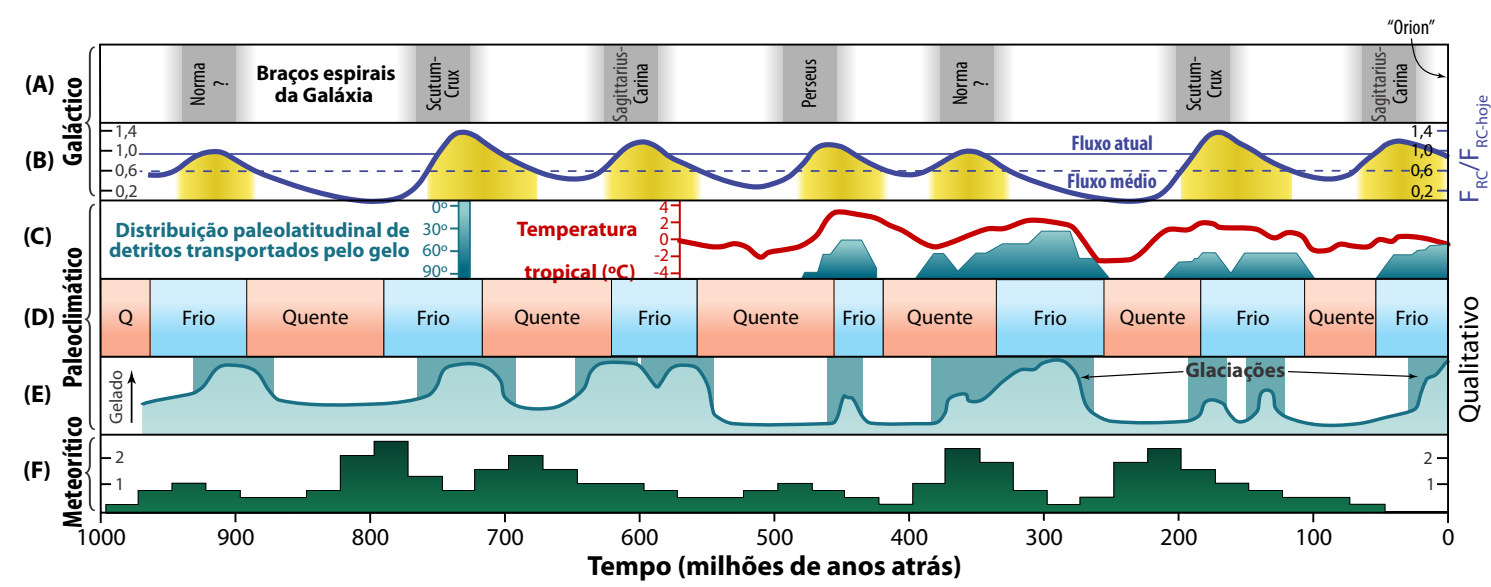

Figura 26. Raios cósmicos e Eras glaciais na Terra. (A) descreve as passagens pelos braços espirais da Galáxia; (B) representa o Fluxo de Raios Cósmicos $\left(F_{R C}\right)$ atingindo o Sistema Solar; Em (C), a curva denota a temperatura na superfície oceânica tropical relativamente aos dias atuais, e as áreas preenchidas expressam a distribuição paleolatitudinal de detritos transportados pelo gelo; (D) e (E) descrevem qualitativamente as épocas pelas quais a Terra experienciou Eras do Gelo; (F) Histograma de épocas de exposição a meteoros de Fe/Ni - as épocas de maior exposição a meteoros se agrupam em torno de períodos com um fluxo menor de raios cósmicos. Fonte: modificado de Shaviv \& Veizer (2003).

denso poderia conter um componente de matéria escura; assim como processos terrestres, tais como a convecção do manto, que poderiam produzir periodicamente plumas das quais resultam em grandes erupções vulcânicas e províncias ígneas.

Segundo a extensa e detalhada obra de Benkö (1985), os fenômenos terrestres de longo período podem, cada vez mais frequentemente, ser atribuídos a fenômenos cósmicos periódicos. Em adição às considerações teóricas, a crescente quantidade de evidências tem tornado bastante plausíveis as surpreendentes coincidências ou expressivas similaridades de períodos existentes entre as diferentes ordens de ciclos. Segundo essa linha, a ciclicidade dos processos tectônicos pode ser remontada a processos cósmicos, levando em consideração que estes efeitos são "filtrados" pelo Sistema Solar ou pelo Sol. Essa é uma teoria de ressonância astronômica que cada vez mais cientistas estão focando para o aperfeiçoamento e estabelecimento de possíveis relações entre ciclos cósmicos e geológicos que, por fim, repercutem, determinam e modificam o clima na Terra. Assim, diversas mudanças físicas significativas podem ser atribuídas principalmente às mudanças do campo gravitacional galáctico, explicando a ciclicidade existente nos fenômenos geológico-tectônico-climáticos de longo período.

\section{Considerações Finais}

Sob uma perspectiva geral, duas questões fundamentais sobre mudanças climáticas dizem respeito a (1) como forças astronômicas forçam as alterações do clima na Terra, e (2) como podem ser explicadas as evidências de variações cíclicas no clima. $\mathrm{O}$ controle astronômico ${ }^{51}$ das flutuações evidencia-se pela manifestação, ao longo do Fanerozoico, nos ambientes climáticos, tectônicos, paleogeográficos e bióticos da Terra. As variações climáticas percebidas nas escalas multi-temporais, de horas a bilhões de $\operatorname{anos}^{52}$, confirmam os elementos para uma nova abordagem. Integradas, as forças astronômicas galácticas, solares, planetárias, orbitais e lunares determinam, definitivamente, o caráter periódico do clima na Terra. A Tabela 1 resume todos os ciclos, seus períodos e mecanismos relacionados, que foram explicados ao longo deste artigo.

A ênfase principal dada aos diversos ciclos climáticos naturais permite entender que os mecanismos causais das mudanças climáticas na Terra envolvem, além de fatores puramente terrestres, fatores envolvendo o Sol, a Lua, a dinâmica dos planetas do Sistema Solar e até mesmo os ritmos da Galáxia. A Terra, a Lua, o Sol e os planetas estão girando e pulsando; suas influências sobre o clima

51 As influências extraterrestres que forçam o clima da Terra são sustentadas por diversas evidências empíricas, destacando-se: o papel do Sol na regulação da dinâmica climática na Terra (Versteegh 2005, Mackey 2009, Zuffo 2015); a complexa interação Terra-Sol-Lua (Berger et al. 2002, Treloar 2002, Davis \& Brewer 2011. Scafetta 2014); as origens astronômicas das oscilacões oceânicas (Mazzarella \& Scafetta 2011); e os superciclos bio-geo-oceânico-atmosféricos relacionados ao movimentos do Sistema Solar na Via Láctea (Tiwari \& Rao 2003, Steiner 1967).

52 Conforme descrito por Benkö (1985), Chumakov (2002, 2005), Bartlein (2007) e Rodríguez-Tovar (2014). 
Tabela 1 - Síntese dos ciclos do clima e relacionados, seus períodos, mecanismos e causas.

\begin{tabular}{|c|c|c|c|c|c|}
\hline \multirow{2}{*}{\multicolumn{3}{|c|}{ Ciclo }} & \multicolumn{2}{|c|}{ Período } & \multirow{2}{*}{ Mecanismo/causa } \\
\hline & & & Tempo & (anos) & \\
\hline \multirow{5}{*}{$\frac{0}{U}$} & \multicolumn{2}{|l|}{ Ciclo diário } & $1 \mathrm{~d}$. & $2,7 \cdot 10^{-3}$ & Movimento de rotação terrestre \\
\hline & \multicolumn{2}{|l|}{ Ciclo sinóptico } & 3 a $7 \mathrm{~d}$. & $1,4 \cdot 10^{-2}$ & Movimentação de massas de ar \\
\hline & \multicolumn{2}{|c|}{ Oscilação Madden-Julian (OMJ) } & 30 a $60 \mathrm{~d}$. & $1,2 \cdot 10^{-1}$ & Onda atmosférica \\
\hline & \multicolumn{2}{|l|}{ Ciclo intra-estações } & $180 \mathrm{~d}$. & $1,6 \cdot 10^{-1}$ & Inclinação do eixo terrestre \\
\hline & \multicolumn{2}{|l|}{ Ciclo anual } & $365 \mathrm{~d}$. & $1,0 \cdot 10^{0}$ & Movimento de translação terrestre \\
\hline & \multicolumn{2}{|c|}{ Oscilação Quase-Bienal (OQB) } & 2 a 2,5 a. & $2,3 \cdot 10^{0}$ & Oscilação atmosférica \\
\hline & \multicolumn{2}{|c|}{ Oscilação "El Niño - Oscilação Sul (ENOS)" } & 2 a 7 a. & $5,0 \cdot 10^{0}$ & Influência lunar/planetária \\
\hline & \multicolumn{2}{|c|}{ Ciclo de Schwabe } & 11 a. & $1,1 \cdot 10^{1}$ & Influência planetas (Júpiter e Saturno) \\
\hline & \multicolumn{2}{|l|}{ Ciclo de Saros } & 18,1 a. & $1,8 \cdot 10^{1}$ & Parâmetro orbital lunar \\
\hline & \multicolumn{2}{|c|}{ Ciclo nodal lunar (ou Ciclo Draconiano) } & 18,6 a. & $1,9 \cdot 10^{1}$ & Parâmetro orbital lunar \\
\hline & \multicolumn{2}{|l|}{ Ciclo de Hale } & 22 a. & $2,2 \cdot 10^{1}$ & Influência planetas (Júpiter e Saturno) \\
\hline & \multicolumn{2}{|l|}{ Ciclo de Brückner } & 35 a. & $3,5 \cdot 10^{1}$ & Influência lunar/planetária \\
\hline & \multicolumn{2}{|c|}{ Oscilação Interdecadal do Pacífico (OIP) } & 15 a 30 a. & $2,3 \cdot 10^{1}$ & Influência lunar/planetária \\
\hline 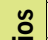 & \multicolumn{2}{|c|}{ Oscilação do Atlântico Norte (OAN) } & 25 a 35 a. & $3,0 \cdot 10^{1}$ & Influência lunar/planetária \\
\hline 言 & \multicolumn{2}{|c|}{ Oscilação Decadal do Pacífico (ODP) } & 50 a 70 a. & $7,0 \cdot 10^{1}$ & Influência lunar/planetária \\
\hline$\underline{E}$ & \multicolumn{2}{|l|}{ Osci } & 50 a 90 a. & $7,0 \cdot 10^{1}$ & Influência lunar/planetária \\
\hline 은 & \multicolumn{2}{|c|}{ Ciclo inferior de Gleissberg } & 88 a. & $8,8 \cdot 10^{1}$ & Influência planetas (Júpiter e Saturno) \\
\hline$\because$ & \multirow{2}{*}{\multicolumn{2}{|c|}{\begin{tabular}{|l} 
Ciclo superior de Gleissberg \\
Ciclo de Jose
\end{tabular}}} & 120 a. & $1,2 \cdot 10^{2}$ & Influência planetas (Júpiter e Saturno) \\
\hline & & & 179 a. & $1,8 \cdot 10^{2}$ & Influência planetas (Júpiter e Saturno) \\
\hline & \multicolumn{2}{|c|}{ Ciclo de Suess (ou Ciclo de De Vries) } & 208 a. & $2,1 \cdot 10^{2}$ & Influência planetas (Júpiter e Saturno) \\
\hline & \multicolumn{2}{|l|}{ Ciclo de 500 anos } & 500 a. & $5,0 \cdot 10^{2}$ & Influência planetas (Júpiter e Saturno) \\
\hline & \multicolumn{2}{|l|}{ Ciclo de Eddy } & $1.000 \mathrm{a}$. & $1,0 \cdot 10^{3}$ & Influência planetas (Júpiter e Saturno) \\
\hline & Eventos de Dansgaard-C & schger & $1.500 \mathrm{a}$. & $1,5 \cdot 10^{3}$ & Influência solar, proc. atmosf./oceanos \\
\hline & Eventos de Bond & & 1.500 a. & $1,5 \cdot 10^{3}$ & Influência solar, proc. atmosf./oceanos \\
\hline & Ciclo de Hallstatt & & 2.300 a. & $2,3 \cdot 10^{3}$ & Influência planetas (Júpiter e Saturno) \\
\hline & Eventos de Heinrich & & $10 \mathrm{ma}$. & $1,0 \cdot 10^{4}$ & Influência solar, proc. atmosf./oceanos \\
\hline & Ciclo de Milankovitch - & Interglacial & $10 \mathrm{ma}$. & $1,0 \cdot 10^{4}$ & Combinação de parâmetros orbitais terrestres \\
\hline 总 & Interglacial/Glacial & Glacial & 100 ma. & $1,0 \cdot 10^{5}$ & Combinação de parâmetros orbitais terrestres \\
\hline 흐 & C. de Milankovitch - Pre & essão equinócios & $20 \mathrm{ma}$ & $2,0 \cdot 10^{4}$ & Parâmetro orbital terrestre \\
\hline 은 & C. de Milankovitch - Inc & hação axial & $40 \mathrm{ma}$. & $4,0 \cdot 10^{4}$ & Parâmetro orbital terrestre \\
\hline $\bar{U}$ & C. de Milankovitch - Exc & ntricidade orbital & $100 \mathrm{ma}$. & $1,0 \cdot 10^{5}$ & Parâmetro orbital terrestre \\
\hline & C. de Milankovitch - Exc & ntricidade orbital longa & 400 ma. & $4,0 \cdot 10^{5}$ & Parâmetro orbital terrestre \\
\hline & Impactos de grandes as & roides/meteoritos & $30 \mathrm{Ma}$. & $3,0 \cdot 10^{7}$ & $\begin{array}{l}\text { Oscilação vertical do Sistema Solar através do } \\
\text { plano galáctico }\end{array}$ \\
\hline $\begin{array}{l}\overline{\frac{U}{U}} \\
\frac{\mathrm{J}}{ \pm} \\
\text { ज }\end{array}$ & $\begin{array}{l}\text { Modo de Estufa/Modo d } \\
\text { Modo Quente/Modo Frio } \\
\text { Ciclo tectonismo/vulcan } \\
\text { Ciclo de supercontinent } \\
\text { Ciclo de Wilson }\end{array}$ & $\begin{array}{l}\text { Geladeira } \\
\text { mo }\end{array}$ & $\begin{array}{l}250 \mathrm{a} \\
500 \mathrm{Ma} .\end{array}$ & $\begin{array}{l}2,5 \cdot 10^{8} \\
\text { a } 5 \cdot 10^{8}\end{array}$ & $\begin{array}{l}\text { Movimento de translação do Sistema Solar } \\
\text { em torno do centro da Galáxia }\end{array}$ \\
\hline
\end{tabular}

Legenda: C. = Ciclo; d. = dia(s); a. = ano(s); ma. = milhares anos; Ma. = milhões de anos.

na Terra agem ciclicamente, de acordo com intervalos definidos pela mecânica celeste.

Dentro de um enorme intervalo temporal que varia em mais de dez ordens de grandeza, compreendendo desde ciclos diários $\left(10^{-3}\right.$ anos) até ciclos tectônicos/galácticos ( $10^{8}$ anos), as variações cíclicas do clima apresentadas foram consideradas individualmente com o intuito de facilitar a compreensão de cada tipo de ciclo e os fenômenos específicos envolvidos.

Constata-se que, oscilando naturalmente ao longo do tempo, o clima é marcado pela regularidade e inevitabilidade da mudança. Variação é uma propriedade fundamental do sistema climático terrestre e, com base no conhecimento da paleociência, fica claro que as mudanças continuarão ocor- rendo no futuro, de forma cíclica e intrinsecamente conectada a fatores astronômicos.

Segundo Scafetta (2014), Pitágoras [570-495 a.C.] propôs que o Sol, a Lua e os planetas emitem seus próprios "sussurros" (ressonâncias orbitais) com base em suas revoluções orbitais, e que a vida na Terra reflete de alguma forma o teor dos "sons celestiais". Esse conceito filosófico antigo é conhecido como musica universalis (música universal ou "música das esferas"). Agindo em escalas de tempo diversificadas, os ciclos climáticos podem ser poética e analogamente interpretados como notas em uma música: orquestrada por ritmos astronômicos externos e compassos terrestres internos, a combinação se harmoniza e resulta na sinfonia que é o nosso clima na Terra. 
As variações cíclicas do clima terrestre abrem uma nova perspectiva sobre a recente mudança climática: é possível uma interpretação alternativa baseada nas evidências de que uma parte significativa dela é devida a oscilações naturais específicas, motivo pelo qual o aquecimento global antropogênico pode ser questionado. Nesse sentido, Scafetta (2016) aponta que os modelos climáticos convencionais não conseguem reconstruir adequadamente a variabilidade natural do clima. De fato, técnicas de análise avançadas revelam que a variabilidade natural do clima recente consiste na sobreposição de várias oscilações, muitas de origem astronômica, que vão desde a escala decenal até a escala milenar. Segundo o autor, as mesmas considerações levam à conclusão de que os modelos climáticos convencionais superestimam gravemente, em cerca de duas vezes, o aquecimento climático antropogênico.

\section{Agradecimentos}

Os autores agradecem à Profa. Michelle Simões Reboita (UNIFEI, Itajubá/MG) pela revisão crítica e cuidadosas sugestões feitas na primeira versão do manuscrito, que muito contribuíram para o aprimoramento da versão ora publicada.

\section{Referências}

Abreu J.A., Beer J., Ferriz-Mas A. 2010. Past and future solar activity from cosmogenic radionuclides. In: Cranmer S.R., Hoeksema J.T., Kohl J.L. (eds.). 2010. Astronomical Society of the Pacific Conference Series Vol. 428: SOHO-23: understanding a peculiar solar minimum. Proceedings of a workshop held 21-25 September 2009 in Northeast Harbor, Maine, USA. San Francisco: Astronomical Society of the Pacific. 428:287-295. [ISBN: 978-1-58381-736-0]. URL: <http:// adsabs.harvard.edu/full/2010ASPC..428..287A > . Acesso: 29.11.2015.

Abreu J.A., Beer J., Ferriz-Mas A., McCracken K.G., Steinhilber F. 2012. Is there a planetary influence on solar activity? Astronomy E Astrophysics. 548:A88. December 2012. [DOI: http://dx.doi.org/10.1051/0004-6361/201219997]

Agência Fapesp. 2004. Crateras reveladas. 10 mai. 2004. URL: $<$ http://agencia.fapesp.br/1767>. Acesso: 29.11.2015.

Agência Fapesp. 2010. Impacto acabou com dinossauros. 5 mar. 2010. URL: <http://www.agencia.fapesp.br/materia/11852/impacto-acabou-com-dinossauros.htm $>$. Acesso: 29.11.2015.

Alvarez L.W., Alvarez W., Asaro F., Michel H.V. 1980. Extraterrestrial Cause for the Cretaceous-Tertiary Extinction. Science. 208(4448):1095-1108. [DOI: http://dx.doi.org/10.1126/ science.208.4448.1095]

Arbab I.A. 2009. The Length of the Day: A Cosmological Perspective. Progress in Physics. 5(1):8-11. URL: <http:// www.ptep-online.com/index_files/2009/PP-16-02.PDF >.
Acesso: 29.11.2015

Assine M.L., Vesely F.F. 2008. Ambientes glaciais. In: Silva A.J.P., Aragão A.N.F., Magalhães A.J.C. (eds.). 2008. Ambientes de Sedimentação Siliciclástica do Brasil. São Paulo: Ed. Beca. p. 24-51. [ISBN: 8587256513; 343 p.]

Bartlein P.J. 2006. Time Scales of Climate Change. In: Elias S.A. (ed.). 2006. Encyclopedia of Quaternary Science. $1^{\mathrm{a}} \mathrm{ed}$. Amsterdam: Elsevier. p. 1873-1883. [ISBN: 978-0-44452747-9; 3576 p.] [DOI: http://dx.doi.org/10.1016/B044-452747-8/00010-7]

Beer J., Mender W., Stellmacher R. 2000. The role of the sun in climate forcing. Quaternary Science Reviews. 19(1-5):403-415. [DOI: http://dx.doi.org/10.1016/S0277-3791(99)00072-4]

Benkö F. 1985. Geological and cosmogonic cycles: as reflected by the new law of universal cyclicity. Budapest: Akademiai Kiado. [ISBN: $9630532980 ; 400$ p.]

Berger W.H., Patzold J., Wefe G. 2002. A Case for Climate Cycles: Orbit, Sun and Moon. In: Wefer G. et al. (eds.). 2002. Climate Development and History of the North Atlantic Realm. Berlin: Springer. p. 101-123. [ISBN: 978-3-64207744-9; 486 p.] [DOI: http://dx.doi.org/10.1007/978-3662-04965-5_8]

Bertrand C., van Ypersele J.P., Berger A. 1999. Volcanic and solar impacts on climate since 1700. Climate Dynamics. 15(5):355-367. [DOI: http://dx.doi.org/10.1007/ s003820050287]

Bindoff N.L. et al. 2007. Observations: Oceanic Climate Change and Sea Level. In: Solomon S. et al. (eds.). 2007. Climate Change 2007: The Physical Science Basis. Contribution of Working Group I to the Fourth Assessment Report of the Intergovernmental Panel on Climate Change. Cambridge: Cambridge Univ. Press. 996p. URL: < http:// www.ipcc.ch/pdf/assessment-report/ar4/wg1/ar4-wg1-chapter5.pdf>. Acesso: 29.11.2015.

Blizard J.B. 1987. Long-Range Prediction of Solar Activity. In: Rampino M.R., Sanders J.E. 1987. Newman W.S., Konigsson L.K. (eds.). 1987. Climate History, Periodicity, and Predictability. New York: van Nostrand Reinhold. p. 415-420. [ISBN: 0-442-27866-7; 544 p.]

Bond D.P.G., Grasby S.E. 2017. On the causes of mass extinctions. Palaeogeography, Palaeodimatology, Palaeoecology. 478: 3-29. [DOI: https://doi.org/10.1016/j.palaeo.2016.11.005]

Borovička J. et al. 2013. The trajectory, structure and origin of the Chelyabinsk asteroidal impactor. Nature. 503(7475):235-237. [DOI: http://dx.doi.org/10.1038/nature12671]

Borovička J., Spurný P., Brown P., Wiegert P., Kalenda P., Clark D., Lukáš S. 2013. The trajectory, structure and origin of the Chelyabinsk asteroidal impactor. Nature. 503(7475):235237. [DOI: http://dx.doi.org/10.1038/nature12671]

Brown P.G., Assink J. D., Astiz L., Blaauw R., Boslough M.B., Borovicka J., Brachet N., Brown D., Campbell-Brown M., Ceranna L., Cooke W., de Groot-Hedlin C., Drob D.P., Edwards W., Evers L.G., Garces M., Gill J., Hedlin M., Kingery A., Laske G., Le Pichon A., Mialle P., Moser D.E., Saffer, A., Silber E., Smets P., Spalding R.E., Spurny P., Tagliaferri E., Uren D., Weryk R.J., Whitaker R., Krzeminski Z. 2013. A 500-kiloton airburst over Chelyabinsk and an enhanced hazard from small impactors. Nature. 503(7475):238-241. [DOI: http://dx.doi.org/10.1038/nature12741]

Bryden H.L., Longworth H.R., Cunningham S.A. 2005. Slowing of the Atlantic meridional overturning circulation at $25^{\circ}$ N. Nature. 438(7068):655-657. [DOI: http://dx.doi. org/10.1038/nature04385] 
Cerveny R.S., Shaffer J.A. 2001. The Moon and El Niño. Geophysical Research Letters. 28(1):25-28. [DOI: http://dx.doi. org/10.1029/2000GL012117]

Charvátová I. 2000. Can origin of the 2400-year cycle of solar activity be caused by solar inertial motion? Annales Geophysicae. 18(4):399-405. [DOI: http://dx.doi.org/10.1007/ s00585-000-0399-x]

Christianto V., Pitkaneny M., Smarandache F. 2009. A Few Remarks on "The Length of Day: A Cosmological Perspective". Progress in Physics. 5(1):8-11. URL: < http://www. ptep-online.com/index_files/2009/PP-16-L2.PDF > . Acesso: 29.11.2015.

Chumakov N.M. 2002. One-way and quasi-periodic climate changes: Geologic evidence. Russian Journal of Earth Sciences. 4(4):277-299. URL: < http://elpub.wdcb.ru/journals/rjes/ v04/tje02088/tje02088.pdf? > . Acesso: 29.11.2015.

Chumakov N.M. 2005. Factors of Global Climatic Changes Inferred from Geological Data. Stratigraphy and Geological Correlation. 13(3):221-241.

Coghlan A. 2012. Earth's oldest impact crater found in Greenland. Newscientist. 29 jun. 2012. URL: < http://www.newscientist.com/article/dn21996-earths-oldest-impact-crater-found-in-greenland.html> . Acesso: 29.11.2015.

Compo G.P., Sardeshmukh P.D. 2009. Oceanic influences on recent continental warming. Climate Dynamics. 32(23):333-342. [DOI: http://dx.doi.org/10.1007/s00382-0080448-9]

Condie C.K. 1998. Episodic continental growth and supercontinents: a mantle avalanche connection? Earth and Planetary Science Letters. 163(1-4):97-108. [DOI: http://dx.doi. org/10.1016/S0012-821X(98)00178-2]

Condie K.C. 2011. The Supercontinent Cycle. In: Condie K.C. 2011. Earth as an Evolving Planetary System. $2^{\mathrm{a}}$ ed. Oxford: Academic Press. p. 317-355. [ISBN: 978-0-12385227-4; 578 p.]

Courtillot V., Gallet Y., Mouël J.L., Fluteau F., Genevey A. 2007. Are there connections between the Earth's magnetic field and climate? Earth and Planetary Science Letters. 253(3-4):328-339. [DOI: http://dx.doi.org/10.1016/j.epsl.2006.10.032]

Critchfield H.J. 1966. General climatology. $2^{\mathrm{a}}$ ed. Englewood Cliffs, N.J.: Prentice-Hall. [420 p.]

Crósta A.P. 1982. Estruturas de impacto no Brasil: uma síntese do conhecimento atual. In: Congr. Bras. Geol., 32, Salvador. Anais... Salvador: SBG. v. 4, p. 1372-1377.

Crósta A.P. 1986. Impact structures in Brazil. In: Pohl J. (ed.). 1986. Research in terrestrial impact structures. Braunschweig, Wiesbaden, Fried. Vieweg \& Sons. p. 30-38.

Crósta A.P. 2002. Domo de Araguainha (GO-MT): O maior astroblema da América do Sul. In: Schobbenhaus C., Campos D.A., Queiroz E.T., Winge M., Berbert-Born M. (eds.). 2002. Sítios Geológicos e Paleontológicos do Brasil. Vol. 1. Brasília: DNPM/CPRM/SIGEP. p. 531-540.

Crósta A.P. 2012. Estruturas de impacto e astroblemas brasileiros. In: Hasui Y., Carneiro C.D.R., Almeida F.F.M., Bartorelli A. (eds). 2012. Geologia do Brasil. São Paulo: Ed. Beca. p. 673-708. (Cap. 28). [ISBN 978-85-62768-10-1].

Davis B.A.S., Brewer S. 2011. A unified approach to orbital, solar, and lunar forcing based on the Earth's latitudinal insolation/temperature gradient. Quaternary Science Reviews. 30(15-16):1861-1874. [DOI: http://dx.doi.org/10.1016/j. quascirev.2011.04.016]

Davis M., Hut P., Muller R.A. 1984. Extinction of species by periodic comet showers. Nature. 308(5961):715-717. [DOI: http://dx.doi.org/10.1038/308715a0]
Dickey J.O., Marcus S.L., de Viron O. 2011: Air Temperature and Anthropogenic Forcing: Insights from the Solid Earth. Journal of Climate. 24(2):569-574. [DOI: http://dx.doi. org/10.1175/2010JCLI3500.1]

$\mathrm{DjSadhu}$. The helical model - our solar system is a vortex. Youtube, 24 ago. 2012. URL: < https://youtu.be/0jHsq36_NTU>. Acesso: 25.05.2017.

DjSadhu. The helical model - our Galaxy is a vortex. Youtube, 25 jan. 2013. URL: <https://youtu.be/C4V-ooITrws>. Acesso: 25.05.2017.

Dvorsky G. 2016. A inclinação estranha do nosso Sol pode significar que o Planeta 9 realmente existe. Gizmodo Brasil. 21 out. 2016. URL: < http://gizmodo.uol.com.br/inclinacao-sol-planeta-9/>. Acesso: 01.05.2017.

Engel A.E.G., Engel C.B. 1964. Continental accretion and the evolution of North America. In: Subramaniam A.P., Balakrishna S. (eds.). 1964. Advancing frontiers in geology and geophysics: Indian Geophysical Union. Hyderabad. p. 17-37. [511 p.]

Erlykin A.D., Harper D.A.T., Sloan T., Wolfendale A.W. 2017. Mass extinctions over the last 500 myr: an astronomical cause? Palaeontology. 60(2):159-167. [DOI: http://dx.doi. org/10.1111/pala.12283]

Erwin D.H. 1993. The Great Paleozoic Crisis: Life and Death in the Permian. New York: Columbia University Press. [ISBN: 0231074662; 327 p.]

Faustinoni J.M., Carneiro C.D.R. 2015. Movimentos da crosta e relações entre Tectônica e dinâmica atmosférica. Terrce Didatica, 11(3):173-181. < https://www.ige.unicamp.br/ terraedidatica/v11 3/00.html $>$.

Fiedler B. 2009. [Professor of Meteorology, National Weather Center, University of Oklahoma] Milankovitch Cycles, Orbit, and Cores. [Mensagem pessoal recebida em $12 \mathrm{dez}$. 2009]. URL (imagem com citação das fontes originais dos dados): $<$ http://en.wikipedia.org/wiki/File:MilankovitchCyclesO rbitandCores.png > . Acesso: 29.11.2015.

Fischer A.G. 1981. Climatic oscillations in the biosphere. In: Nitecki M.H. (ed.). 1981. Biotic crises in ecological and evolutionary time. New York: Academic Press. p. 103-131. [ISBN: 0125196407; 314 p.]

Fischer A.G. 1982. Long-Term Climatic Oscillations Recorded in Stratigraphy. In: National Research Council. 1982. Climate in Earth History: Studies in Geophysics. Washington, DC: The National Academies Press. p. 97-105. [ISBN: 0309107849; 212 p.]

Florides G.A., Christodoulides P. 2009. Global warming and carbon dioxide through sciences. Environment International. 35(2):390-401. [DOI: http://dx.doi.org/10.1016/j.envint.2008.07.007]

Frakes L.A., Francis J.E., Syktus J.I. 1992. Climate Modes of the Phanerozoic. Cambridge: Cambridge Univ. Press. [ISBN: 9780521021944; 274 p.]

French B.M. 1998. Traces of Catastrophe: A Handbook of Shock-Metamorphic Effects in Terrestrial Meteorite Impact Structures. LPI Contribution No. 954. Houston: Lunar and Planetary Institute. [120 p.]

Garde A.A., McDonald I., Dyck B., Keulen N. 2012. Searching for giant, ancient impact structures on Earth: The Mesoarchaean Maniitsoq structure, West Greenland. Earth and Planetary Science Letters. 337-338:197-210. [DOI: http:// dx.doi.org/10.1016/j.epsl.2012.04.026]

Gibney E. 2014. Did dark matter kill the dinosaurs? Nature News. 07 mar. 2014. URL: < http://www.nature.com/news/ did-dark-matter-kill-the-dinosaurs-1.14839> . Acesso: 30.04.2017. 
Gies D.R., Helsel J.W. 2005. Ice Age Epochs and the Sun's Path through the Galaxy. The Astrophysical Journal. 626(2):844848. [DOI: http://dx.doi.org/10.1086/430250]

Gillman M., Erenler H. 2008. The galactic cycle of extinction. International Journal of Astrobiology. 7(1):17-26. [DOI: http:// dx.doi.org/10.1017/S1473550408004047]

Giorgio. 2013a. Southern Oscillation Index. URL: <http:// en.wikipedia.org/wiki/File:Soi.svg > . Acesso: Acesso: 29.11.2015. [Dados originais - URL: < http://www.bom. gov.au/climate/current/soihtm1.shtml > ].

Giorgio. 2013b. Pacific Decadal Oscillation Index. URL: < http:// en.wikipedia.org/wiki/File:PDO.svg>. Acesso: 29.11.2015. [Dados originais - URL: < http://jisao.washington.edu/ pdo/PDO.latest $>$ ].

Giorgio. 2013c. Atlantic Multidecadal Oscillation. URL: < http:/ en.wikipedia.org/wiki/File:Atlantic_Multidecadal_Oscillation.svg > . Acesso: 29.11.2015. [Dados originais - URL: $<$ http://climexp.knmi.nl/data/iamo_ersst.dat $>$ ].

Gomes R.S., Soares J.S. 2012. Signatures of a Putative Planetary Mass Solar Companion on the Orbital Distribution of TNO's and Centaurs. American Astronomical Society, DDA meeting \#43, \#5.01.

Halliday A.N. 2000. Terrestrial accretion rates and the origin of the Moon. Earth and Planetary Science Letters. 176(1):17-30. [DOI: http://dx.doi.org/10.1016/S0012-821X(99)00317-9]

Hand E. 2016. Astronomers say a Neptune-sized planet lurks beyond Pluto. Science. 20 jan. 2016. URL: <http://www. sciencemag.org/news/2016/01/feature-astronomers-say-neptune-sized-planet-lurks-unseen-solar-system $>$. Acesso: 09.02.2016.

Harper C.K. 2007. Weather and Climate: Decade by Decade. New York: Facts On File, Inc. [ISBN: 0816055351; 272 p.]

Hasui Y. 2012. Evolução dos Continentes. In: Hasui Y., Carneiro C.D.R., Almeida F.F.M.de, Bartorelli A. (eds). 2012 Geologia do Brasil. São Paulo: Ed. Beca. p. 98-111 (Cap. 1). [ISBN: 9788562768101; 900 p.]

Hecht L. 1993-1994. The Coming (or Present) Ice Age. A long-term perspective on the current global warming fad. 21 ${ }^{\text {st }}$ Century, Winter: 23-35. URL: <http://21sci-tech.com/ Articles\%202005/ComingPresentIceAge.pdf > . Acesso 3.02.2016.

Holbourn A., Kuhnt W., Schulz M., Flores J.A., Andersen N. 2007. Orbitally-paced climate evolution during the middle Miocene "Monterey" carbon-isotope excursion. Earth and Planetary Science Letters. 261(3-4):534-550. [DOI: http:// dx.doi.org/10.1016/j.epsl.2007.07.026]

Jansa L.F., Aubry M.P., Gradstein F.M. 1990. Comets and extinctions: Cause and effect? Geological Society of America Special Papers. Global Catastrophes in Earth History: An Interdisciplinary Conference on Impacts, Volcanism, and Mass Mortality. 247:223-232. [DOI: http://dx.doi. org/10.1130/SPE247-p223]

Jose P.D. 1965. Sun's motion and sunspots. Astronomical Journal. 70(3):193-200. [DOI: http://dx.doi.org/10.1086/109714]

Keeling C.D., Whorf T.P. 1997. Possible forcing of global temperature by the oceanic tides. Proceedings of the National Academy of Sciences of the United States of America. 94(16):83218328. URL: <http://www.pnas.org/content/94/16/8321. abstract> . Acesso: 29.11.2015.

Keeling C.D., Whorf T.P. 2000. The 1,800-year oceanic tidal cycle: A possible cause of rapid climate change. Proceedings of the National Academy of Sciences of the United States of America. 97(8):3814-3819. URL: <http://www.pnas.org/content/97/8/3814.abstract >. Acesso: 29.11.2015.

Kern A.K., Harzhauser M., Piller W.E., Mandic O., Soliman
A. 2012. Strong evidence for the influence of solar cycles on a Late Miocene lake system revealed by biotic and abiotic proxies. Palaeogeography, Palaeoclimatology, Palaeoecology. 329-330:124-136. [DOI: http://dx.doi.org/10.1016/j. palaeo.2012.02.023]

Kerton A.K. 2009. Climate Change and the Earth's Magnetic Poles, a Possible Connection. Energy \& Environment. 20(1):7583. [DOI: http://dx.doi.org/10.1260/095830509787689286]

Kirkby J. 2007. Cosmic Rays and Climate. Surveys in Geophysics. 28(5-6):333-375. [DOI: http://dx.doi.org/10.1007/ s10712-008-9030-6]

Kopp G., Lean J. L. 2011. A new, lower value of total solar irradiance: Evidence and climate significance. Geophysical Research Letters. 38(1):L01706. [DOI: http://dx.doi. org/10.1029/2010GL045777]

Kostyk R.I. 2013. What are solar faculae? Kinematics and Physics of Celestial Bodies. 29(1):32-36. [DOI: http://dx.doi. org/10.3103/S0884591313010030]

Kutterolf S., Jegen M., Mitrovica J.X., Kwasnitschka T., Freundt A., Huybers P.J. 2013. A detection of Milankovitch frequencies in global volcanic activity. Geology. 41(2):227-230. [DOI: http://dx.doi.org/10.1130/G33419.1]

Kvasnytsya V. et al. 2013. New evidence of meteoritic origin of the Tunguska cosmic body. Planetary and Space Science. 84:131-140. [DOI: http://dx.doi.org/10.1016/j. pss.2013.05.003]

Landscheidt T. 1981. Swinging sun, 79ワyear cycle, and climatic change. Journal of Interdisciplinary Cycle Research. 12(1):3-19. [DOI: http://dx.doi.org/10.1080/09291018109359720]

Laurian A., Drijfhout S.S., Hazeleger W., van den Hurk B. 2010. Response of the Western European climate to a collapse of the thermohaline circulation. Climate Dynamics. 34(5):689-697. [DOI: http://dx.doi.org/10.1007/s00382008-0513-4]

Lovett R.A. 2012. New Planet Found in Our Solar System? National Geographic Daily News. 11 mai. 2012. URL: < http://news.nationalgeographic.com/news/2012/05/120511-new-planet-solar-system-kuiper-belt-space-science/>. Acesso: 29.11.2015.

Ma W., Tian J., Li Q., Wang P. 2011. Simulation of long eccentricity (400-kyr) cycle in ocean carbon reservoir during Miocene Climate Optimum: Weathering and nutrient response to orbital change. Geophysical Research Letters. 38(10):L10701. [DOI: http://dx.doi.org/10.1029/2011GL047680]

Machado F. 1967. Geological Evidence for a Pulsating Gravitation. Nature. 214(5095):1317-1318. [DOI: http://dx.doi. org/10.1038/2141317a0]

Mackey R. 2009. The Sun's Role in Regulating the Earth's Climate Dynamics. Energy E Environment. 20(1):25-73. [DOI: http://dx.doi.org/10.1260/095830509787689196]

Mantua N.J. et al. 1997. A Pacific Interdecadal Climate Oscillation with Impacts on Salmon Production. Bulletin of the American Meteorological Society. 78(6):1069-1079. [DOI: http://dx.doi.org/10.1175/1520-0477(1997)078\%3C1069: APICOW\%3E2.0.CO;2]

Mason B.G., Pyle D.M., Oppenheimer C. 2004. The size and frequency of the largest explosive eruptions on Earth. Bulletin of Volcanology. 66(8):735-748. [DOI: http://dx.doi. org/10.1007/s00445-004-0355-9]

Masuda K., Nagaya K., Miyahara H., Muraki Y., Nakamura T. 2009. Cosmogenic Radiocarbon and the Solar Activity. J. Phys. Soc. Japan, 78(Supl. A):1-6. [DOI: http://dx.doi. org/10.1143/JPSJS.78SA.1]

Matese J.J., Whitman P.G., Innanen K.A., Valtonen M.J. 1994. Modulating Terrestrial Impacts from Oort Cloud Comets 
by the Adiabatically Changing Galactic Tides. In: Papers Presented to New Developments Regarding the KT Event and Other Catastrophies in Earth History. LPI Contribution No. 825. Houston: Lunar and Planetary Institute. [138 p.]

Matese J.J., Whitmire D.P. 2011. Persistent evidence of a jovian mass solar companion in the Oort cloud. Icarus. 211(2):926938. [DOI: http://dx.doi.org/10.1016/j.icarus.2010.11.009]

Mazzarella A., Scafetta N. 2011. Evidences for a quasi 60-year North Atlantic Oscillation since 1700 and its meaning for global climate change. Theoretical and Applied Climatology. 107(3):599-609. [DOI: http://dx.doi.org/10.1007/s00704011-0499-4]

Mcgregor G.R., Nieuwolt S. 1998. Tropical climatology: an introduction to the climates of the low latitudes. $2^{\mathrm{a}}$ ed. New York: Wiley.[ISBN: 978-0-471-96611-1;339 p.]

Mcguffie K., Henderson-Sellers A. 2005. A climate modelling primer. $3^{\text {a }}$ ed. Chichester, West Sussex: John Wiley \& Sons. [ISBN: 047085751X; 280 p.]

McKinnell S.M., Crawford R.W.2007. The 18.6-year lunar nodal cycle and surface temperature variability in the northeast Pacific. Journal of Geophysical Research. 112(c2):C02002. [DOI: http://dx.doi.org/10.1029/2006JC003671]

Mclean J.D., Freitas C.R., Carter R.M. 2009. Influence of the Southern Oscillation on tropospheric temperature. Journal of Geophysical Research. 114(D14):1-8. [DOI: http://dx.doi. org/10.1029/2008JD011637]

Melott A.L., Bambach, R.K. 2010. Nemesis reconsidered. Monthly Notices of the Royal Astronomical Society: Letters. 407(1):L99-L102. [DOI: http://dx.doi.org/10.1111/j.17453933.2010.00913.x]

Mewaldt R.A. 1996. Cosmic Rays. In: Rigden J.S. 1996. MacMillan Encyclopedia of Physics. New York: Simon \& Schuster Macmillan. URL: < http://www.srl.caltech.edu/personnel/dick/cos_encyc.html>. Acesso: 29.11.2015. [ISBN: $0028645863 ; 1881$ p.]

Miall A.D. 2010. The Geology of Stratigraphic Sequences. $2^{\mathrm{a}}$ ed. New York: Springer. [ISBN: 9783642050268; 522 p.]

Molion L.C.B. 2006. Aquecimento Global, El Niños, Manchas Solares, Vulcões e Oscilação Decadal do Pacífico. Revista Climanálise. 3(1):1-5. URL: < http://climanalise.cptec. inpe.br/ rclimanl/revista/pdf/Artigo_Aquecimento_0805. pdf>. Acesso: 29.11.2015.

Molion L.C.B. 2015. [Professor de Meteorologia da Universidade Federal de Alagoas]. Minha visão sobre eventos El Niño. [Mensagem pessoal recebida em 01 ago. 2015]

Molion L.C.B. 2017. Gênese do El Niño. Revista Brasileira de Climatologia. 21:1-4. [Notas de Pesquisa].

Nance R.D., Murphy J.B. 2013. Origins of the supercontinent cycle. Geoscience Frontiers. 4(4):439-448. [DOI: http://dx.doi. org/10.1016/j.gsf.2012.12.007]

Nance R.D., Murphy J.B., Santosh M. 2014. The supercontinent cycle: A retrospective essay. Gondwana Research. 25(1):4-29. [DOI: http://dx.doi.org/10.1016/j. gr.2012.12.026]

NASA. 2002. The Great Dying. URL: < http://science1.nasa. gov/science-news/science-at-nasa/2002/28jan_extinction/>. Acesso: 29.11.2015.

NASA. 2003. The Solar 'Constant' - Faculae vs. Sunspots. NASA Scientific Visualization Studio. 02 jan. 2003. URL: $<$ https://svs.gsfc.nasa.gov/cgi-bin/details.cgi?aid=2644>. Acesso: 29.11.2015.

NASA. 2009. Fresh Craters on the Moon and Earth. NASA Earth Observatory. 13 ago. 2009. URL: <http://earthobservatory.nasa.gov/IOTD/view.php?id=39769>. Acesso: 29.11.2015.
NASA. 2010. NASA Study Finds Atlantic 'Conveyor Belt' Not Slowing. NASA News \& Features. 25 mar. 2010. URL: < http:// www.jpl.nasa.gov/news/news.php? release $=2010-101>$. Acesso: 29.11.2015.

NASA. 2011. NASA Study Goes to Earth's Core for Climate Insights. NASA Jet Propulsion Laboratory. 09 mar. 2011. URL: <http://www.jpl.nasa.gov/news/news. php? release $=2011-074>$. Acesso: 29.11.2015.

Newman M., Compo G.P., Alexander M.A. 2003. ENSO-Forced Variability of the Pacific Decadal Oscillation. Journal of Climate. 16(23):3853-3857. [DOI: http://dx.doi. org/10.1175/1520-0442(2003)016\%3C3853:EVOTPD\% 3E2.0.CO;2]

Oliveira M.J.de, Baptista G.M.M., Vecchia F.V., Carneiro C.D.R. 2015. História geológica e Ciência do Clima: métodos e origens do estudo dos ciclos climáticos na Terra. Terra. 12(1-2):03-26. URL: < http://www.ige.unicamp.br/ terrae/V12/T_V12_1.html>. Acesso 28.04.2016.

Oskar L. 2009. History of solar telescopes. Experimental Astronomy. 25(1-3):193-207. [DOI: http://dx.doi.org/10.1007/ s10686-009-9173-6]

Pälike H. et al. 2006. The Heartbeat of the Oligocene Climate System. Science. 314(5807):1894-1898. [DOI: http://dx.doi. org/10.1126/science.1133822]

Paulescu M., Paulescu E., Gravila P., Badescu V. 2013. Weather Modeling and Forecasting of PV Systems Operation. London: Springer-Verlag. [ISBN: 978-1-4471-4648-3; 358p.]

Petit J.R. et al. 1999. Climate and atmospheric history of the past 420,000 years from the Vostok ice core, Antarctica. Nature. 399(6735):429-436. [DOI: http://dx.doi. org/10.1038/20859]

Pierazzo E., Artemieva N. 2012. Local and Global Environmental Effects of Impacts on Earth. Elements. 8(1):55-60. [DOI: http://dx.doi.org/10.2113/gselements.8.1.55]

Pivetta M. 2013. A estufa de Araguainha. Revista Fapesp. 211:1621. URL: < http://revistapesquisa.fapesp.br/2013/09/12/a-estufa-de-araguainha/>. Acesso: 29.11.2015.

Price G.D., Twitchett R.J., Wheeley J.R., Buono G. 2013. Isotopic evidence for long term warmth in the Mesozoic. Nature. 3:1438. [DOI: http://dx.doi.org/10.1038/srep01438]

Prothero D. 2006. After the Dinosaurs: The Age of Mammals (Life of the Past). Bloomington: Indiana University Press. [ISBN: 0253347335; 384 p.]

Rampino M.R. 1998. The Galactic Theory of Mass Extinctions: an Update. Celestial Mechanics and Dynamical Astronomy. 69(1-2):49-58. [DOI: http://dx.doi. org/10.1023/A:1008365913573]

Rampino M.R., Caldeira K. 2015. Periodic impact cratering and extinction events over the last 260 million years. Monthly Notices of the Royal Astronomical Society. 454(4):34803484. [DOI: https://doi.org/10.1093/mnras/stv2088]

Rampino M.R., Haggerty B.M. 1996. The "Shiva Hypothesis": Impacts, Mass Extinctions, and the Galaxy. Earth, Moon and Planets. 72(1-3):441-460. [DOI: http://dx.doi.org/10.1007/ BF00117548]

Rampino M.R., Haggerty B.M., Pagano T.C. 1997. A unified theory of impact crises and mass extinctions: quantitative tests. Earth and Environmental Science Program, New York University, 10003, USA. Annals of the New York Academy of Sciences. 822:403-431. [DOI: http://dx.doi. org/10.1111/j.1749-6632.1997.tb48358.x]

Rampino M.R., Self S. 1993. Climate-Volcanism Feedback and the Toba Eruption of $~ 74,000$ Years Ago. Quaternary Research. 40(3):269-280. [DOI: http://dx.doi.org/10.1006/ qres.1993.1081] 
Randall L., Reece M. 2014. Dark Matter as a Trigger for Periodic Comet Impacts. Physical Review Letters. 112(16):161301. [DOI: https://doi.org/10.1103/PhysRevLett.112.161301]

Raup D.M., Sepkoski Jr. J.J. 1984. Periodicity of extinctions in the geologic past. Proceedings of the National Academy of Sciences of the United States of America. 81(3):801-805. URL: $<$ http://www.pnas.org/content/81/3/801.short>.

Reboita M.S., Pimenta A.P., Natividade U.A. 2015. Influência da inclinação do eixo de rotação da Terra na temperatura do ar global. Terre Didatica, 11(2):67-77. URL: <http:// www.ige.unicamp.br/terraedidatica/v11_2/00.html >. Acesso: 29.11.2015.

Reimer P.J. et al. 2004. IntCal04 Terrestrial Radiocarbon Age Calibration, 0-26 cal kyr BP. Radiocarbon. 46(3):1029-1058. URL: <https://journals.uair.arizona.edu/index.php/radiocarbon/article/view/4167> . Acesso: 29.11.2015. [Dados disponíveis na URL: < http://www.radiocarbon.org/ IntCal04.htm>]

Reimold W.U., Jourdan F. 2012. Impact! - Bolides, Craters, and Catastrophes. Elements. 8(1):19-24. [DOI: http://dx.doi. org/10.2113/gselements.8.1.19]

Ribeiro G.F. 2016. Brasileiro "previu" existência de $9^{\circ}$ planeta; busca existe desde o séc. 19. UOL Notícias. 22 fev. 2016. URL: $<$ http://noticias.uol.com.br/ciencia/ultimas-noticias/redacao/2016/01/22/brasileiro-previu-ja-em-2012-que-nono-planeta-poderia-existir.htm > . Acesso: 09.02.2016.

Robock A., Oman L., Stenchikov G.L., Toon O.B., Bardeen C., Turco R.P. 2007. Climatic consequences of regional nuclear conflicts. Atmospheric Chemistry and Physics. 7(8):20032012. [DOI: http://dx.doi.org/10.5194/acp-7-2003-2007]

Rodríguez-Tovar F.J. 2014. Orbital Climate Cycles in the Fossil Record: From Semidiurnal to Million-Year Biotic Responses. Annual Review of Earth and Planetary Sciences. 42:69-102. [DOI: http://dx.doi.org/10.1146/annurev-earth-120412-145922]

Rogers J.J.W., Santosh M. 2004. Continents and Supercontinents. Oxford: Oxford University Press, 2004. [ISBN: 0195165896; 304 p.]

Ryan P.D., Dewey J.F. 1997. Continental eclogites and the Wilson Cycle. Journal of the Geological Society. 154(3):437442. [DOI: http://dx.doi.org/10.1144/gsjgs.154.3.0437]

Sample I. 2013. Scientists reveal the full power of the Chelyabinsk meteor explosion. The Guardian. 07 nov. 2013. URL: < http:// www.theguardian.com/science/2013/nov/06/chelyabinsk-meteor-russia > . Acesso: 29.11.2015.

Scafetta N. 2010. Empirical evidence for a celestial origin of the climate oscillations and its implications. Journal of Atmospheric and Solar-Terrestrial Physics. 72(13):951-970. [DOI: http://dx.doi.org/10.1016/j.jastp.2010.04.015]

Scafetta N. 2012. Multi-scale harmonic model for solar and climate cyclical variation throughout the Holocene based on Jupiter-Saturn tidal frequencies plus the 11-year solar dynamo cycle. Journal of Atmospheric and Solar-Terrestrial Physics. 80:296-311 [DOI: http://dx.doi.org/10.1016/j.jastp.2012.02.016]

Scafetta N. 2014. The complex planetary synchronization structure of the solar system. Pattern Recognition in Physics. 2(1):1-19. [DOI: http://dx.doi.org/10.5194/prp-2-1-2014]

Scafetta N. 2016. Problems in Modeling and Forecasting Climate Change: CMIP5 General Circulation Models versus a Semi-Empirical Model Based on Natural Oscillations. International Journal of Heat and Technology. 34(Special Issue 2):S435-S442. [DOI: http://dx.doi.org/10.18280/ ijht.34Sp0235]

Scafetta N., Milani F., Bianchini A., Ortolani S. 2016. On the astronomical origin of the Hallstatt oscillation found in radiocarbon and climate records throughout the Holocene. Earth Science Reviews. 162:24-43. [DOI: https://doi. org/10.1016/j.earscirev.2016.09.004]

Schiermeier Q. 2005. Atlantic currents show signs of weakening. Nature News. 30 nov. 2005. URL: < http://www.nature. com/news/2005/051128/full/news051128-9.html>. Acesso: 29.11.2015.

Schiermeier Q. 2006. A Sea Change. Nature. 439(7074):256260. [DOI: http://dx.doi.org/10.1038/439256a]

Schlager W. 2005. Secular oscillations in the stratigraphic record - an acute debate. Facies. 51(1-4):12-16. [DOI: http:// dx.doi.org/10.1007/s10347-005-0066-5]

Schneider D.A., Kent D.V., Mello G.A. 1992. A detailed chronology of the Australasian impact event, the Brunhes-Matuyama geomagnetic polarity reversal, and global climate change. Earth and Planetary Science Letters. 111(2-4):395-405. [DOI: http://dx.doi.org/10.1016/0012-821X(92)90192-X]

Schöll M., Steinhilber F., Beer J., Haberreiter M., Schmutz M. 2007. Long-term reconstruction of the total solar irradiance based on neutron monitor and sunspot data. $A d-$ vances in Space Research. 40(7):996-999. [DOI: http://dx.doi. org/10.1016/j.asr.2007.02.092]

Schulte P. et al. 2010. The Chicxulub Asteroid Impact and Mass Extinction at the Cretaceous-Paleogene Boundary. Science. 327(5970):1214-1218. [DOI: http://dx.doi.org/10.1126/ science.1177265]

Shaviv N.J., Veizer J. 2003. Celestial driver of Phanerozoic climate? GSA Today. 13(7):4-10. URL: < http://www.geosociety.org/gsatoday/archive/13/7/pdf/11052-5173-13-7-4. pdf > . Acesso: 29.11.2015.

Shaviv N.J., Prokoph A., Veizer J. 2014. Is the Solar System's Galactic Motion Imprinted in the Phanerozoic Climate? Scientific Reports. 4:6150. [DOI: http://dx.doi.org/10.1038/ srep06150]

Siqueira A.H.B., Molion L.C.B. 2015. Análises Climáticas: o filtro Hodrick-Prescott aplicado aos índices atmosféricos da Oscilação Sul e da Oscilação do Atlântico Norte. Revista Brasileira de Meteorologia. 30(3):307-318. [DOI: http://dx.doi. org/10.1590/0102-778620130579]

Solanki S.K., Usoskin I.G., Kromer B., Schüssler M., Beer J. 2004. Unusual activity of the Sun during recent decades compared to the previous 11,000 years. Nature. 431(7012):1084-1087. [DOI: http://dx.doi.org/10.1038/ nature02995]

Steiner J. 1967. The sequence of geological events and the dynamics of the Milky Way galaxy. Journal of the Geological Society of Australia. 14(1):99-131. [DOI: http://dx.doi. org/10.1080/00167616708728648]

Stephenson F.R., Morrison L.V. 1995. Long-Term Fluctuations in the Earth's Rotation: 700 BC to AD 1990. Philosophical Transactions: Physical Sciences and Engineering. 351(1695):165202. [DOI: http://dx.doi.org/10.1098/rsta.1995.0028]

Stothers R.B. 1985. Terrestrial record of the Solar System's oscillation about the galactic plane. Nature. 317(6035):338341. [DOI: http://dx.doi.org/10.1038/317338a0]

Svensmark H. 2007. Cosmoclimatology: a new theory emerges. Astronomy \& Geophysics. 48(1):1.18-1.24. [DOI: http:// dx.doi.org/10.1111/j.1468-4004.2007.48118.x]

Terra. 2012. Astrônomo brasileiro dá novo rumo à busca pelo Planeta X. Notícias. 23 mai. 2012. URL: < http://noticias.terra.com. br/ciencia/astronomo-brasileiro-da-novo-rumo-a-busca-pelo-planeta-x,28a98116492da310VgnCLD200000bbcc eb0aRCRD.html> . Acesso: 29.11.2015.

Tiwari R.K., Rao K.N.N. 2003. Mega geocycles: echoes of 
astronomical events. Journal of the Geological Society of India. 62(2):181-190.

Tohver E. et al. 2012. Geochronological constraints on the age of a Permo-Triassic impact event: U-Pb and ${ }^{40} \mathrm{Ar} /{ }^{39} \mathrm{Ar}$ results for the $40 \mathrm{~km}$ Araguainha structure of central Brazil. Geochimica et Cosmochimica Acta. 86:214-227. [DOI: http:// dx.doi.org/10.1016/j.gca.2012.03.005]

Toon O.B., Robock A., Turco R.P. 2008. Environmental consequences of nuclear war. Physics Today. 61(12):37-42. [DOI: http://dx.doi.org/10.1063/1.3047679]

Toon O.B., Turco R.P., Covey C. 1997. Environmental perturbations caused by the impacts of asteroids and comets. Reviews of Geophysics. 35(1):41-78. [DOI: http://dx.doi. org/10.1029/96RG03038]

Treloar N.C. 2002. Luni-Solar Tidal Influences on Climate Variability. International Journal of Climatology. 22(12):15271542. [DOI: http://dx.doi.org/10.1002/joc.783]

Turco R.P., Toon O.B., Ackerman T.P., Pollack J.B., Sagan C. 1983. Nuclear Winter: Global Consequences of Multiple Nuclear Explosion. Science. 222(4630):1283-1292. [DOI: http://dx.doi.org/10.1126/science.222.4630.1283]

USGS. 2000. The Sun and Climate. U.S. Geological Survey. Fact Sheet 0095-00. URL: <http://pubs.usgs.gov/fs/fs-0095-00/ fs-0095-00.pdf > . Acesso: 29.11.2015.

UWA. 2013. Biggest extinction in history caused by climate-changing meteor. The University of Western Australia (UWA). 31 jul. 2013. URL: <http://www.news.uwa. edu.au/201307315921/international/biggest-extinction-history-caused-climate-changing-meteor $>$. Acesso: 29.11.2015.

Vail P.R., Mitchum R.W., Thompson S. 1977. Seismic stratigraphy and global changes in sea level 4, Global cycles of relative changes in sea level. In: Payton C.E. (ed.) 1977. Seismic Stratigraphy - Applications to Hydrocarbon Exploration (AAPG Memoir 26). Tulsa: American Association of Petroleum Geologists. p. 83-97. [ISBN: 0891813020; 516 p.]

van Andel T.H. 1994. New views on an old planet: a history of global change. $2^{\mathrm{a}}$ ed. Cambridge: Cambridge University Press. [ISBN: 9780521447553; 458 p.]

Versteegh G.J.M. 2005. Solar Forcing of Climate. 2: Evidence from the Past. Space Science Reviews. 120(3): 243-286. [DOI: http://dx.doi.org/10.1007/s11214-005-7047-4]

Veizer J., Godderis Y., Francois L.M. 2000. Evidence for decoupling of atmospheric $\mathrm{CO}_{2}$ and global climate during the Phanerozoic eon. Nature. 408(6813):698-701. [DOI: http://dx.doi.org/10.1038/35047044]

von Frese R.R.B. et al. 2009. GRACE gravity evidence for an impact basin in Wilkes Land, Antarctica. Geochemistry,
Geophysics, Geosystems. 10(2):Q02014. [DOI: http://dx.doi. org/10.1029/2008GC002149]

von Frese R.R.B., Kim H.R., Leftwich T.E., Kim J.W., Golynsky A.V. 2013. Satellite magnetic anomalies of the Antarctic Wilkes Land impact basin inferred from regional gravity and terrain data. Tectonophysics. 585:185-195. [DOI: http://dx.doi.org/10.1016/j.tecto.2012.09.009]

Whitmire D.P.,Jackson A.A. 1984. Are periodic mass extinctions driven by a distant solar companion? Nature. 308(5961):713715. [DOI: http://dx.doi.org/10.1038/308713a0]

Whitmire D.P., Matese J.J. 1985. Periodic comet showers and planet X. Nature. 313(5997):36-38. [DOI: http://dx.doi. org/10.1038/313036a0]

Williams M.A.J. et al. 2009. Environmental impact of the 73 ka Toba super-eruption in South Asia. Palaeogeography, Palaeodimatology, Palaeoecology. 284(3-4):295-314. [DOI: http:// dx.doi.org/10.1016/j.palaeo.2009.10.009]

Willis J.K. 2010. Can in situ floats and satellite altimeters detect long-term changes in Atlantic Ocean overturning? Geophysical Research Letters. 37(6):L06602. [DOI: http:// dx.doi.org/10.1029/2010GL042372]

Wilson I.R.G. 2013. Are global mean temperatures significantly affected by long-term lunar atmospheric tides? Energy \& Environment. 24(3-4):497-508. [DOI: http://dx.doi. org/10.1260/0958-305X.24.3-4.497]

Witze A. 2016. Evidence grows for giant planet on fringes of Solar System. Nature. 529(7586):266-267. [DOI: http:// dx.doi.org/10.1038/529266a]

Wood R.A., Vellinga M., Thorpe R. 2003. Global Warming and thermohaline circulation stability. Philosophical Transactions of the Royal Society A: Mathematical, Physical and Engineering Sciences. 361(1810):1961-1975. [DOI: http://dx.doi. org/10.1098/rsta.2003.1245]

Worm H.U. 1997. A link between geomagnetic reversals and events and glaciations. Earth and Planetary Science Letters. 147(1-4):55-67. [DOI: http://dx.doi.org/10.1016/S0012$-821 \mathrm{X}(97) 00008-3]$

Yasuda I.S., Osafune H.T. 2006. Possible explanation linking 18.6-year period nodal tidal cycle with bi-decadal variations of ocean and climate in the North Pacific. Geophysical Research Letters. 33(8):L08606 [DOI: http://dx.doi. org/10.1029/2005GL025237]

Zhang C. 2005. Madden-Julian Oscillation. Reviews of Geophysics. 43(2):RG2003. [DOI: http://dx.doi. org/10.1029/2004RG000158]

Zuffo A.C. 2015. O Sol, o motor das variabilidades climáticas. Revista DAE. 63(198):6-24. [DOI: http://dx.doi. org/10.4322/dae.2014.142]

Resumo: A periódica mudança climática na Terra pode ser explicada por um número reduzido de fatores terrestres e astronômicos. Nas escalas anual/diária, o clima obedece aos movimentos de translação e de rotação. Ciclos climáticos de períodos médios (décadas/ séculos/milênios) relacionam-se a mudanças na radiação solar, provocadas pela influência de grandes planetas do Sistema Solar. As oscilações oceânicas (ordem decadal) são possivelmente causadas por influências planetárias e lunares. Ciclos climáticos longos (dezenas a centenas de milhares de anos) são causados por variações nos parâmetros da órbita da Terra (excentricidade, obliquidade e precessão). Eventos de impacto de grandes corpos no planeta e extinções em massa de espécies advêm de superciclos (dezenas de milhões de anos) provocados pela oscilação vertical do Sistema Solar em relação ao plano galáctico. Tectonismo, vulcanismo e a evolução de supercontinentes exibem superciclos (centenas de milhões de anos) induzidos pelo deslocamento do Sistema Solar ao redor do centro da Via Láctea e pela variação de raios cósmicos. Fatores astronômicos permeiam praticamente todas as ordens dos ciclos climáticos e atuam direta ou indiretamente nos processos bio-geo-oceânico-atmosféricos. Conclui-se que o clima na Terra é caracterizado por ciclos controlados astronomicamente pela Lua, o Sol, os planetas, o Sistema Solar e, até mesmo, a Galáxia.

Palavras-Chave: Mudança climática, clima, Climatologia, Geologia, processos naturais, dióxido de carbono, aquecimento global antropogênico. 